\title{
BOILER MATERIALS FOR Ultrasupercritical Coal Power Plants
}

\author{
U.S. DOE NO.: DE-FG26-01NT41175 \\ OCDO NO.: D-00-20
}

Third Quarterly Report April 1 - June 30, 2004

Prepared by

R. Viswanathan

K. Coleman

J. Shingledecker

J. Sarver

G. Stanko

W. Mohn

M. Borden

S. Goodstine

I. Perrin

Submitted by

R. Viswanathan

K. Coleman

July 30, 2004

\section{Participating Organizations}

Alstom Power, Inc. 2000 Day Hill Road Windsor, CT 06095

McDermott Technology, Inc./ Babcock \& Wilcox Company 1562 Beeson St.

Alliance, $\mathrm{OH} 44601$
Riley Power Inc.

5 Neponset Street

Worcester, MA 01615

Electric Power Research Institute (EPRI)

3412 Hillview Avenue

Palo Alto, CA 94303
Foster Wheeler Development Corp. 12 Peach Tree Hill Road Livingston, NJ 07039

The Energy Industries of Ohio, Inc. Park Center One 6100 Oak Tree Boulevard Independence, OH 44131

Oak Ridge National Labs 1, Bethel Valley Road Oak Ridge, TN 37831 


\section{U.S. Department of Energy Disclaimer}

This report was prepared as an account of work sponsored by an agency of the United States Government. Neither the United States Government nor any agency thereof, nor any of their employees, makes any warranty, express or implied, or assumes any legal liability or responsibility for the accuracy, completeness, or usefulness of any information, apparatus, product, or process disclosed, or represents that its use would not infringe privately owned rights. Reference herein to any specific commercial product, process, or service by trade name, trademark, manufacturer, or otherwise does not necessarily constitute or imply its endorsement, recommendation, or favoring by the United States Government or any agency thereof. The views and opinions of authors expressed herein do not necessarily state or reflect those of the United States Government or any agency thereof.

\section{Project Consortium Legal Notice/Disclaimer}

This report was prepared by the Energy Industries of Ohio in consortium with the Electric Power Research Institute, Inc. (EPRI); Alstom Power, Inc; Riley Power Inc.; Babcock \& Wilcox/McDermott Technology, Inc.; and Foster Wheeler Development Corporation pursuant to a Grant partially funded by the U.S. Department of Energy (DOE) under Instrument Number DE-FG26-01NT41175 and the Ohio Coal Development Office/Ohio Air Quality Development Authority (OCDO/OAQDA) under Grant Agreement Number CDO/D-00-20. NO WARRANTY OR REPRESENTATION, EXPRESS OR IMPLIED, IS MADE WITH RESPECT TO THE ACCURACY, COMPLETENESS, AND/OR USEFULNESS OF INFORMATION CONTAINED IN THIS REPORT. FURTHER, NO WARRANTY OR REPRESENTATION, EXPRESS OR IMPLIED, IS MADE THAT THE USE OF ANY INFORMATION, APPARATUS, METHOD, OR PROCESS DISCLOSED IN THIS REPORT WILL NOT INFRINGE UPON PRIVATELY OWNED RIGHTS. FINALLY, NO LIABILITY IS ASSUMED WITH RESPECT TO THE USE OF, OR FOR DAMAGES RESULTING FROM THE USE OF, ANY INFORMATION, APPARATUS, METHOD OR PROCESS DISCLOSED IN THIS REPORT.

Reference herein to any specific commercial product, process, or service by trade name, trademark, manufacturer, or otherwise, does not necessarily constitute or imply its endorsement, recommendation, or favoring by the Department of Energy and/or the State of Ohio; nor do the views and opinions of authors expressed herein necessarily state or reflect those of said governmental entities. 


\section{Abstract}

The U.S. Department of Energy (DOE) and the Ohio Coal Development Office (OCDO) have recently initiated a project aimed at identifying, evaluating, and qualifying the materials needed for the construction of the critical components of coal-fired boilers capable of operating at much higher efficiencies than current generation of supercritical plants. This increased efficiency is expected to be achieved principally through the use of ultrasupercritical steam conditions (USC). The project goal initially was to assess/develop materials technology that will enable achieving turbine throttle steam conditions of $760^{\circ} \mathrm{C}\left(1400^{\circ} \mathrm{F}\right) / 35 \mathrm{MPa}(5000 \mathrm{psi})$, although this goal for the main steam temperature had to be revised down to $732^{\circ} \mathrm{C}\left(1350^{\circ} \mathrm{F}\right)$, based on a preliminary assessment of material capabilities. The project is intended to build further upon the alloy development and evaluation programs that have been carried out in Europe and Japan. Those programs have identified ferritic steels capable of meeting the strength requirements of USC plants up to approximately $620^{\circ} \mathrm{C}\left(1150^{\circ} \mathrm{F}\right)$ and nickel-based alloys suitable up to $700^{\circ} \mathrm{C}\left(1300^{\circ} \mathrm{F}\right)$. In this project, the maximum temperature capabilities of these and other available high-temperature alloys are being assessed to provide a basis for materials selection and application under a range of conditions prevailing in the boiler. This report provides a quarterly status report for the period of April to June 30, 2004. 


\section{Table of Contents}

Page

ABSTRACT .3

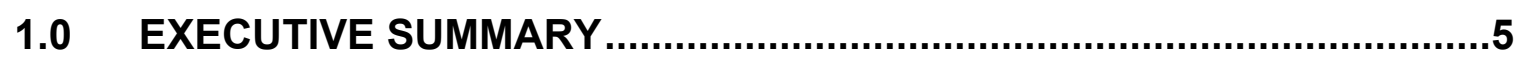

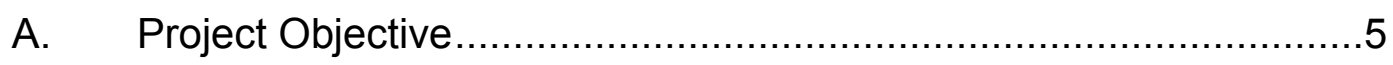

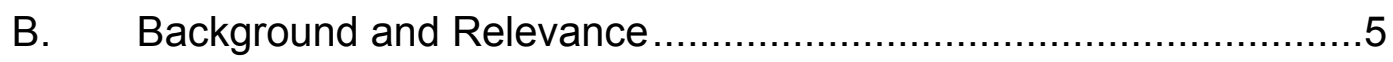

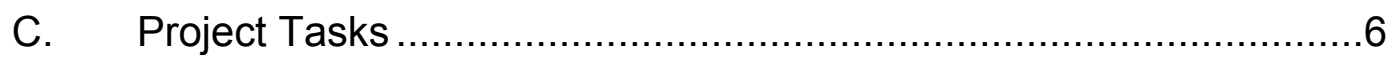

D. Major Accomplishments During the Quarter ................................6

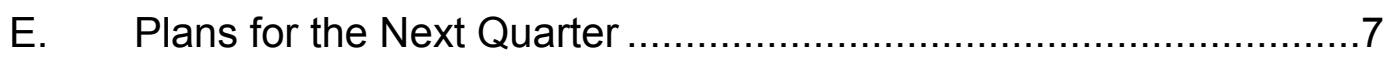

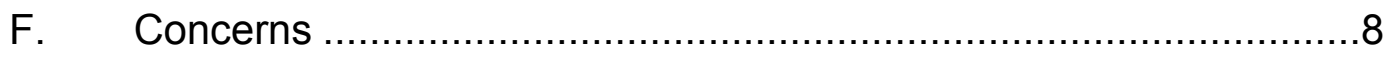

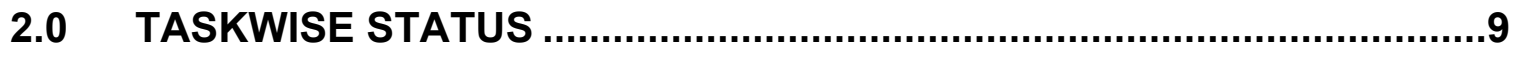

Task 1 Conceptual Design and Economic Analysis................................

Task 2 Mechanical Properties of Advanced Alloys ...............................11

Task 3 Steamside Oxidation.......................................................22

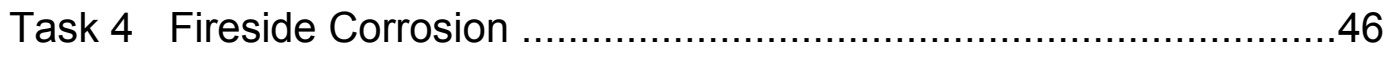

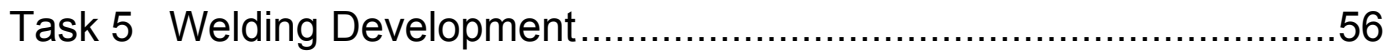

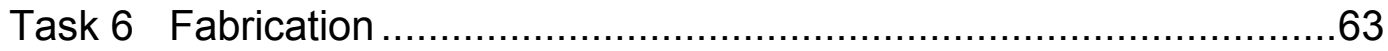

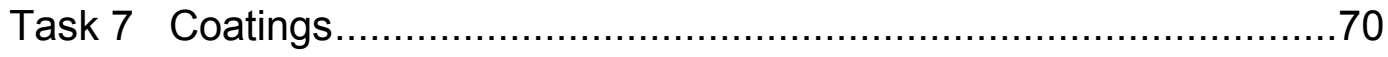

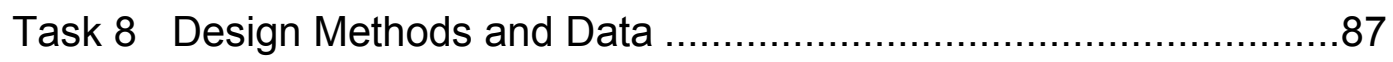

Task 9 Project Integration and Management .....................................93 


\section{Executive Summary}

\section{A. Project Objective}

The principal objective of this project is to develop materials technology for use in ultrasupercritical (USC) plant boilers capable of operating with $760^{\circ} \mathrm{C}\left(1400^{\circ} \mathrm{F}\right), 35 \mathrm{MPa}$ (5000 psi) steam.

\section{B. Background and Relevance}

In the 21st century, the world faces the critical challenge of providing abundant, cheap electricity to meet the needs of a growing global population while at the same time preserving environmental values. Most studies of this issue conclude that a robust portfolio of generation technologies and fuels should be developed to assure that the United States will have adequate electricity supplies in a variety of possible future scenarios.

The use of coal for electricity generation poses a unique set of challenges. On the one hand, coal is plentiful and available at low cost in much of the world, notably in the U.S., China, and India. Countries with large coal reserves will want to develop them to foster economic growth and energy security. On the other hand, traditional methods of coal combustion emit pollutants and $\mathrm{CO} 2$ at high levels relative to other generation options. Maintaining coal as a generation option in the 21st century will require methods for addressing these environmental issues.

This project has established a government/industry consortium to undertake a five-year effort to evaluate and develop of advanced materials that allow the use of advanced steam cycles in coal-based power plants. These advanced cycles, with steam temperatures up to $760^{\circ} \mathrm{C}$, will increase the efficiency of coal-fired boilers from an average of $35 \%$ efficiency (current domestic fleet) to $47 \%$ (HHV). This efficiency increase will enable coal-fired power plants to generate electricity at competitive rates (irrespective of fuel costs) while reducing $\mathrm{CO}_{2}$ and other fuel-related emissions by as much as $29 \%$.

Success in achieving these objectives will support a number of broader goals. First, from a national prospective, the program will identify advanced materials that will make it possible to maintain a cost-competitive, environmentally acceptable coal-based electric generation option. High sulfur coals will specifically benefit in this respect by having these advanced materials evaluated in high-sulfur coal firing conditions and from the significant reductions in waste generation inherent in the increased operational efficiency. Second, from a national prospective, the results of this program will enable domestic boiler manufacturers to successfully compete in world markets for building high-efficiency coal-fired power plants. 
The project is based on an R\&D plan developed by the Electric Power Research Institute (EPRI) that supplements the recommendations of several DOE workshops on the subject of advanced materials, and DOE's Vision 21. In view of the variety of skills and expertise required for the successful completion of the proposed work, a consortium that includes EPRI and the major domestic boiler manufacturers (Alstom Power, Babcock and Wilcox (a division of McDermott Technologies Inc.), Foster Wheeler, Riley Power Inc., and Oak Ridge National Labs) has been developed.

\section{Project Tasks}

The project objective is expected to be achieved through 9 tasks as listed below:

Task 1. Conceptual Design and Economic Analysis

Task 2. Mechanical Properties of Advanced Alloys

Task 3. Steamside Oxidation Resistance

Task 4. Fireside Corrosion Resistance

Task $5 . \quad$ Welding Development

Task 6. Fabricability

Task $7 . \quad$ Coatings

Task 8. Design Data and Rules

Task 9. Project Integration and Management

\section{Major Accomplishments During the Quarter}

- Parts I and II of the materials assessment report were released to the consortium for review.

- Several papers have been submitted and accepted for domestic and international conferences.

- Characterization test plans are complete for five fo the six alloys of most concern to the program. These include Super $304 \mathrm{H}, \mathrm{HR} 6 \mathrm{~W}$, alloy 230, CCA617, and Alloy 740.

- Total rupture testing time for some alloys has surpassed 9,000 hours (over one year).

- SEM examination, including EDX chemical analysis, was carried out on both the standard and modified Alloy 740, solution annealed and aged at 700 and $800^{\circ} \mathrm{C}$ for 16,100 , and 500 hours. No $\eta$ phase $\left(\mathrm{Ni}_{3} \mathrm{Ti}\right)$ was observed in any of the aged samples.

- Pressurized creep tests of Haynes 230 and HR6W bends were started.

- The initial design of the data exchange web site was completed and delivered to consortium members. 
- The first steam-side oxidation exposure at $800^{\circ} \mathrm{C}$ was complete. Samples were removed, weighed, descaled, and re-weighed. With the exception of the Abe alloy, the low alloyed materials experienced high oxidation and the austenitic and nickel based alloys exhibited the lowest weight gains. T23 almost entirely converted to oxide. An oxidation rate constant, $\mathrm{k}_{\mathrm{p}}$ was calculated for each alloy.

- The 1000-hr test for the first series of laboratory fireside corrosion tests at $850^{\circ} \mathrm{F}$ and $1200^{\circ} \mathrm{F}$ were completed. A second series of tests at $975^{\circ} \mathrm{F}$ and $1500^{\circ} \mathrm{F}$ has been started.

- High nickel alloys 214 and 602CA suffered appreciable attack. Abe alloy and HCM12A exhibited comparable results to austenitic alloys.

- Funding issues were resolved to allow for installation of air cooled corrosion probes at two plants. Material selection for these probes was completed.

- Welding trials were successfully completed on SAVE12 tube samples using Grade 92 filler metal. The samples are under evaluation.

- Welding trials were successfully completed on tube samples of HR6W using a custom HR6W filler metal. The samples are under evaluation.

- $\quad$ Tube samples were completed Super 304H and CCA 617 for testing by ORNL.

- U-bends were completed using SAVE 12 material at 15\%, 20\%, and 35\% strain levels.

- Microstructure and hardness were characterized for strained samples of 740, 230, HR6W, and SAVE 12.

- Haynes 230 tube has been successfully overlayed with $50 \mathrm{Cr} / 50 \mathrm{Ni}$ by Praxair using a laser. The same overlay has been completed by ASB using plasma transferred arc (PTA) process.

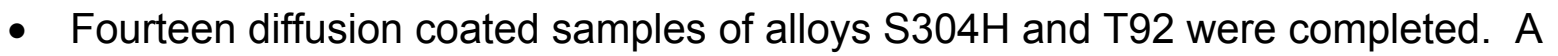
detailed report is attached to the Task 7 update. Required process temperatures and resulting thickness were determined.

- Presentations were made to ASME Section I and B31.1 on development of new methodology for design thickness for USC plants.

\section{E. Plans for the Next Quarter}

It is anticipated that the following work will be completed during the next quarter:

- X-ray samples of CCA 617 welded coupons and start cross weld rupture tests. 
- Begin stress relaxation tests of the new $9 \mathrm{Cr}$ Abe alloy.

- Begin thermal shock testing of materials.

- SEM/EDS analyses of the oxidation specimens removed the $800^{\circ} \mathrm{C}$ tests.

- Receive all materials for air cooled probes and install probes.

- Evaluation of welding Super $304 \mathrm{H}$ using the GMAW process and 347 filler material.

- Perform swaging trials on HR6W and SAVE 12.

- $\quad$ Prepare U-bend samples from Super 304H and CCA 617.

- Continue re-crystallization studies on 740 and 230 material.

\section{F. Concerns}

- Rupture testing of thick plate Alloy 740 will not start until proper overaging required for welding is determined.

- The heat of HR6W alloy received from Sumitomo demonstrated creep rupture lives less than previous reports. Communications with Sumitomo indicate that this was a weaker heat and a new heat of HR6W will be provided.

- Due to funding limitations, the start of the next oxidation exposure at $800^{\circ} \mathrm{C}$ will not occur until next funding year.

- The steam cooled loops operated below design temperature due to concerns about ozone.

- A second host site for a steam cooled probe has not been identified.

- Sumitomo indicated that they have no special filler metal for Super $304 \mathrm{H}$ using the GMAW process.

- CCA 617 welded with conventional Alloy 617 filler metal failed bend tests. Attempts to weld with matching filler metal resulted in poor weldability. 


\section{$2.0 \quad$ Taskwise Status}

\section{Task 1 \\ Conceptual Design and Economic Analysis (Task lead EPRI)}

The objective of Task 1 is to specify the temperature/pressure distribution for $760^{\circ} \mathrm{C} / 35$ $\mathrm{MPa}\left(1400^{\circ} \mathrm{F} / 5000 \mathrm{psi}\right)$ steam inlet conditions so that the data needs and the range of test parameters can be identified and the economics of material selection established.

\section{Task 1A: Alstom Approach (Alstom Power Co.)}

\section{Objectives}

The primary objectives of this subtask are:

- Develop a conceptual boiler design for a high efficiency ultra supercritical cycle designed for $1400^{\circ} \mathrm{F}$ steam temperature.

- Identify tubing and piping materials needed for high temperature surface construction.

- Estimate gas and steam temperature profiles so that appropriate mechanical, corrosion and manufacturing tests of materials could be designed and conducted to prove suitability of the selected alloys.

\section{Progress for the Task}

A final report has been completed and distributed.

\section{Task 1B: Babcock Approach}

\section{Objective}

The objectives of this subtask are the same as in Subtask 1A.

\section{Progress for the Quarter}

No work was performed on this task this quarter.

\section{Concerns:}

\section{Progress for the Quarter}

A final report has been completed and distributed. 


\section{Task 1C: Economic Analysis}

\section{Objective}

The objective of this task is to determine relative economics of the USC plant.

\section{Progress for the Task}

A final report has been completed and distributed.

\section{Concerns}

None 


\section{Task 2 \\ Mechanical Properties of Advanced Alloys (ORNL)}

The objective of Task 2 is to produce the mechanical properties database needed to design a boiler to operate at the steam conditions within the scope of the project.

\section{Task 2A: Assessment of the Alloy Performance Requirements}

\section{Objectives}

The primary objectives of this subtask are:

- Focus on performance needed for boiler service in the temperature range of $649^{\circ} \mathrm{C}$ $\left(1200^{\circ} \mathrm{F}\right)$ to $871^{\circ} \mathrm{C}\left(1600^{\circ} \mathrm{F}\right)$

- Produce reports that justify the materials selected for the pressure retention components of the USC boiler

\section{Progress for the Task}

Part I and II of the assessment report were released to the consortium for review. All comments and suggestions have been received and will be incorporated into the report before being transferred to EPRI for publication.

A paper abstract was submitted and accepted for the 2004 Pittsburg Coal Conference (September 13-17, 2004: Osaka, Japan). A paper and poster abstract were submitted and accepted for the 2004 ASM Materials Solution Conference (October 18-21, 2004: Columbus, $\mathrm{OH}$ ). Two abstracts were submitted and accepted for the EPRI Materials Conference (October 26-28, 2004: Hilton Head, SC).

\section{Task 2B: Detailed Test Plan}

\section{Progress for the Quarter}

The detailed mechanical properties test plan is intended to provide guidance on the scope of the mechanical testing for each material to support the resolution of issues related to the tasks undertaken in the project. Categories include mechanical characterization; data production for the development of code cases; effects of fabrication variables; weldment performance; fatigue and thermal-fatigue behavior; and the like. Progress and/or problems associated with the welding (Task 5) and fabrication (Task 6) tasks will determine testing specifics. Thus, to some measure the test plan continues to evolve. The testing plans for the thick-section materials, SAVE 12, CCA617, alloy 230, and Alloy 740 are still under development. In-depth discussions with Task 8 members at the March $31^{\text {st }}-$ April $1^{\text {st }}$ steering committee meeting helped to prioritize the plans for these materials. 
The six alloys, chemical compositions in Table 1 below, of most interest to the project are: SAVE12, Super 304H, HR6W, Haynes 230, CCA617, and Alloy 740. The characterization testing plans have been completed for five of the six tubing alloys (Super 304H, HR6W, alloy 230, CCA617, and Alloy 740). The creep-rupture database for Super $304 \mathrm{H}$ stainless steel and alloy 230 was judged to be adequate, since both materials are code alloys. A test plan for Alloy 740 tubing has been designed. Priority has been given to producing a database for the Alloy 740 tubing. These data will provide the main body creep/creep-rupture data needed to produce a code case on the material. To fabricate thick plate weldments of 740 , it may be necessary to overage the base material prior to welding. It is anticipated that this heat treatment will alter the creep strength of the alloy. Therefore, testing on the plate will not begin until a heattreatment is decided upon by the consortium.

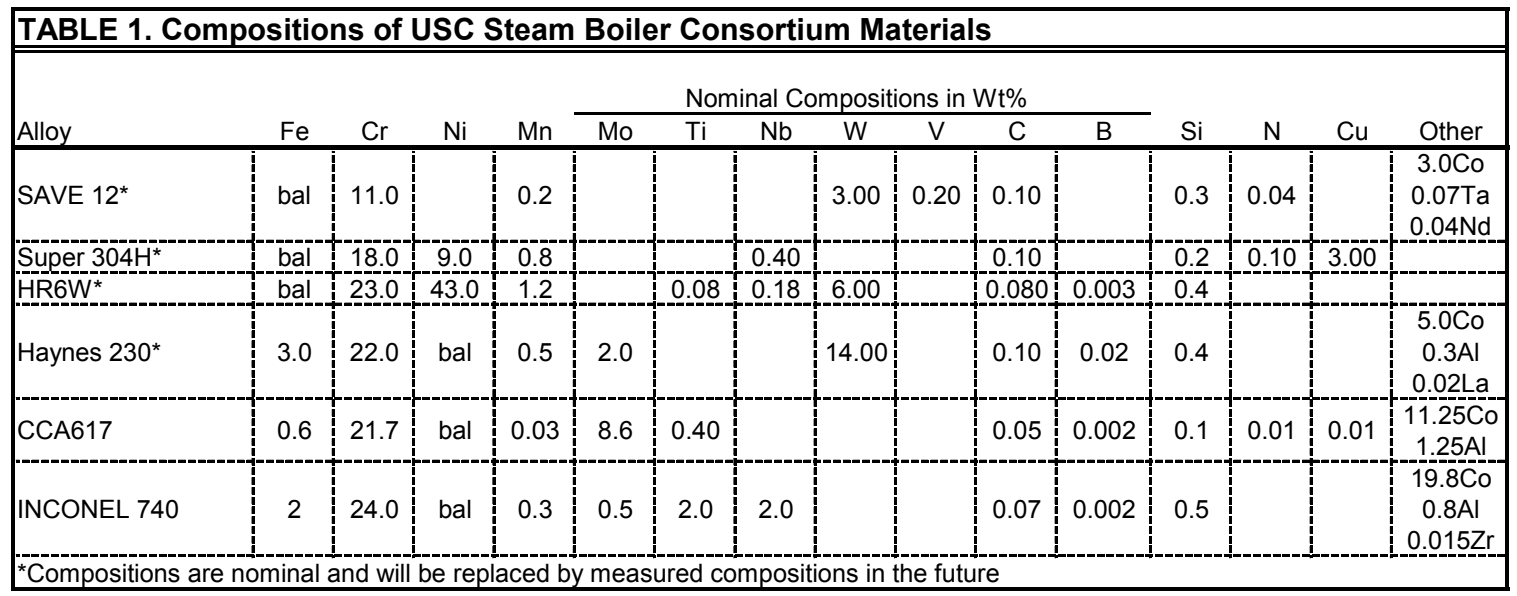

\section{Concerns}

None

\section{Task 2C: Long Term Creep Strength}

\section{Objectives}

The primary objectives of this subtask are:

- Identify the general characteristics of the creep behavior and damage accumulation in the candidate alloys

- Verify the creep-strength of code-approved alloys

- Assess the creep-strength non code-approved alloys; and provide creep/creeprupture data for a code case if deemed appropriate by consortium members 
- Provide accurate creep data (i.e. creep-curves) for boiler design on the candidate materials

\section{Progress for the Task}

The status for five tubing alloys currently in testing is provided in the tables below. In each table, comparison of the rupture lives may be made with the expected life based on prior data. The initial results indicate that the strength of the Super $304 \mathrm{H}$ and alloy 230 are meeting expectations, while the HR6W is below expectations. A set of tests on the HR6W has been struck from the test matrix in light of this behavior. The low creep strength of HR6W was discussed with a Sumitomo representative. Although Sumitomo will not furnish tabular data of a non-code approved alloy, he stated that Sumitomo was aware that the consortium heat of HR6W was weaker than other heats. A Sumitomo document, received via Babcock Power/Riley, showed the creep-rupture strength of four separate heats of HR6W with one heat, presumably the consortium heat, showing lower strengths compared to the other three heats. A new heat of HR6W with stronger creep strength is being produced for the European AD700 program. ORNL has requested some of this material to do some scoping creep tests. The CCA617 alloy is exceeding expectations in the lower temperature regime $\left(650^{\circ} \mathrm{C}\right.$ to $\left.700^{\circ} \mathrm{C}\right)$, based on performance equivalent to alloy 617. Larson-Miller-Parameter extrapolation shows the creep strength benefit may extend above $750^{\circ} \mathrm{C}$ for CCA617 vs. std. 617 . Additional shortterm tests have been added to the CCA617 test matrix. All of the planned Super $304 \mathrm{H}$ creep-rupture tests are in progress. Testing began this quarter on INCONEL 740 tubing. 100 and 1000 hours rupture lives appear close to predictions based off previous work at ORNL and data from Special Metals. However if large deviations are encountered, test conditions may be altered as needed. Overall, total testing time has surpassed 9,000 hours (over one year) for some USC candidate alloys.

\begin{tabular}{|c|c|c|c|c|c|c|}
\hline \multicolumn{6}{|c|}{ Creep-Rupture Testing of Super $304 \mathrm{H}$ (Case Code 2328) } \\
\hline Spec \# & Test \# & $\begin{array}{c}\text { Stress } \\
(\mathbf{M P a})\end{array}$ & $\begin{array}{c}\text { Temp. } \\
\left({ }^{\circ} \mathbf{C}\right)\end{array}$ & $\begin{array}{c}\text { Estimated } \\
\text { Life }\end{array}$ & Date Started & $\begin{array}{c}\text { Life } \\
\text { (hrs) }\end{array}$ \\
\hline SM-01 & 30298 & 240 & $600^{\circ} \mathrm{C}$ & $10000 \mathrm{Hrs}$ & $6 / 11 / 2003$ & \\
\hline SM-02 & 30299 & 280 & $600^{\circ} \mathrm{C}$ & $1000 \mathrm{Hrs}$ & $6 / 11 / 2003$ & \\
\hline SM-03 & 30383 & 340 & $600^{\circ} \mathrm{C}$ & $100 \mathrm{Hrs}$ & $12 / 1 / 2003$ & 864.6 \\
\hline SM-04 & 30293 & 120 & $650^{\circ} \mathrm{C}$ & $10000 \mathrm{Hrs}$ & $6 / 3 / 2003$ & \\
\hline SM-05 & 30292 & 210 & $650^{\circ} \mathrm{C}$ & $1000 \mathrm{Hrs}$ & $6 / 3 / 2003$ & 2240 \\
\hline SM-06 & 30372 & 260 & $650^{\circ} \mathrm{C}$ & $100 \mathrm{Hrs}$ & $10 / 21 / 2003$ & 412 \\
\hline SM-07 & 30377 & 110 & $700^{\circ} \mathrm{C}$ & $10000 \mathrm{Hrs}$ & $11 / 24 / 2003$ & \\
\hline SM-08 & 30294 & 160 & $700^{\circ} \mathrm{C}$ & $1000 \mathrm{Hrs}$ & $6 / 3 / 2003$ & 1011.5 \\
\hline SM-09 & 30384 & 210 & $700^{\circ} \mathrm{C}$ & $100 \mathrm{Hrs}$ & $12 / 2 / 2003$ & 106.2 \\
\hline
\end{tabular}




\begin{tabular}{|l|c|c|c|c|c|c|}
\hline Creep-Rupture Testing of HR-6W (Heat \#DZC1309) \\
\hline Spec \# & Test \# & $\begin{array}{c}\text { Stress } \\
(\mathbf{M P a})\end{array}$ & $\begin{array}{c}\text { Temp. } \\
\left({ }^{\circ} \mathbf{C}\right)\end{array}$ & $\begin{array}{c}\text { Estimated } \\
\text { Life }\end{array}$ & Date Started & $\begin{array}{c}\text { Life } \\
(\mathbf{h r s})\end{array}$ \\
\hline HR-6W-01 & 30282 & 200 & 650 & 1000 & $5 / 21 / 2003$ & 921.1 \\
\hline HR-6W-02 & 30315 & 175 & 650 & 6000 & $7 / 2 / 2003$ & 2194.2 \\
\hline HR-6W-03 & 30330 & 150 & 650 & 20000 & $7 / 31 / 2003$ & 5167.1 \\
\hline & & 200 & 675 & 500 & & \\
\hline & & 170 & 675 & 1000 & & \\
\hline HR-6W-08 & 30426 & 100 & 700 & 15000 & $3 / 15 / 2004$ & \\
\hline HR-6W-09 & 30317 & 150 & 700 & 1000 & $7 / 9 / 2003$ & 451.3 \\
\hline HR-6W-10 & 30325 & 120 & 700 & 10000 & $7 / 22 / 2003$ & 2056.7 \\
\hline HR-6W-11 & 30368 & 100 & 725 & 10000 & $10 / 14 / 2003$ & 2663.2 \\
\hline HR-6W-12 & 30283 & 150 & 725 & 500 & $5 / 21 / 2003$ & 187.5 \\
\hline HR-6W-13 & 30291 & 120 & 725 & 5000 & $6 / 2 / 2003$ & 723.8 \\
\hline & & 140 & 750 & 100 & & \\
\hline HR-6W-15 & 30405 & 120 & 750 & 500 & $2 / 2 / 2004$ & 202.5 \\
\hline HR-6W-16 & 30425 & 100 & 750 & 5000 & $3 / 15 / 2004$ & \\
\hline HR-6W-04 & 30424 & 85 & 750 & 20000 & $3 / 15 / 2004$ & \\
\hline HR-6W-05 & 30396 & 100 & 775 & 600 & $12 / 29 / 2003$ & 225 \\
\hline HR-6W-06 & 30401 & 85 & 775 & 5000 & $1 / 14 / 2004$ & 713.6 \\
\hline HR-6W-07 & 30395 & 100 & 800 & 150 & $12 / 29 / 2003$ & 80.24 \\
\hline HR-6W-14 & 30427 & 85 & 800 & 1000 & $3 / 15 / 2004$ & 251.8 \\
\hline
\end{tabular}

\begin{tabular}{|c|c|c|c|c|c|c|}
\hline \multicolumn{7}{|c|}{ Creep-Rupture Testing of Haynes 230} \\
\hline Spec \# & Test \# & $\begin{array}{c}\text { Stress } \\
\text { (MPa) }\end{array}$ & $\begin{array}{c}\text { Temp. } \\
\left({ }^{\circ} \mathrm{C}\right)\end{array}$ & Expected Life & Date Started & $\begin{array}{l}\text { Life } \\
\text { (hrs) }\end{array}$ \\
\hline H230-01 & 30302 & 350 & 650 & 200 & 6/16/2003 & 410.8 \\
\hline H230-02 & 30306 & 300 & 650 & 1000 & 6/18/2003 & 1071.4 \\
\hline H230-03 & & 200 & 650 & 10000 & & \\
\hline H230-04 & & 300 & 700 & 100 & & \\
\hline $\mathrm{H} 230-05$ & 30301 & 200 & 700 & 1500 & $6 / 12 / 2003$ & 1517.1 \\
\hline $\mathrm{H} 230-06$ & & 140 & 700 & 15000 & & \\
\hline H230-07 & & 200 & 750 & 100 & & \\
\hline $\mathrm{H} 230-08$ & 30399 & 140 & 750 & 2000 & $1 / 6 / 2004$ & 1501 \\
\hline $\mathrm{H} 230-09$ & 30402 & 100 & 750 & 15000 & $1 / 20 / 2004$ & \\
\hline $\mathrm{H} 230-10$ & 30373 & 140 & 800 & 100 & \multicolumn{2}{|c|}{ Test Discontinued } \\
\hline $\mathrm{H} 230-11$ & 30300 & 100 & 800 & 2000 & $6 / 11 / 2003$ & 2101.2 \\
\hline H230-12 & & 80 & 800 & 20000 & & \\
\hline $\mathrm{H} 230-13$ & 30375 & 140 & 800 & 100 & $11 / 3 / 2003$ & 169.2 \\
\hline
\end{tabular}




\begin{tabular}{|c|c|c|c|c|c|c|}
\hline \multicolumn{6}{|c|}{ Creep-Rupture Testing of CCA617 } \\
\hline Spec \# & Test \# & $\begin{array}{c}\text { Stress } \\
\text { (Mpa) }\end{array}$ & $\begin{array}{c}\text { Temp. } \\
(\circ \mathbf{C})\end{array}$ & $\begin{array}{c}\text { Estimated } \\
\text { Life }\end{array}$ & Date Started & $\begin{array}{c}\text { Life } \\
\text { (hrs) }\end{array}$ \\
\hline $\mathbf{6 1 7 - 0 1}$ & 30303 & $\mathbf{3 5 0}$ & $\mathbf{6 5 0}$ & 200 & $6 / 16 / 2003$ & \\
\hline $\mathbf{6 1 7 - 0 2}$ & 30305 & $\mathbf{3 0 0}$ & $\mathbf{6 5 0}$ & 1000 & $6 / 18 / 2003$ & \\
\hline $\mathbf{6 1 7 - 0 3}$ & 30357 & $\mathbf{2 0 0}$ & $\mathbf{6 5 0}$ & 10000 & $9 / 16 / 2003$ & \\
\hline $\mathbf{6 1 7 - 0 4}$ & 30337 & $\mathbf{3 0 0}$ & $\mathbf{7 0 0}$ & 100 & $8 / 19 / 2003$ & 2376.8 \\
\hline $\mathbf{6 1 7 - 0 5}$ & 30318 & $\mathbf{2 0 0}$ & $\mathbf{7 0 0}$ & 1500 & $7 / 9 / 2003$ & \\
\hline $\mathbf{6 1 7 - 0 6}$ & & $\mathbf{1 4 0}$ & $\mathbf{7 0 0}$ & 15000 & & \\
\hline $\mathbf{6 1 7 - 0 7}$ & 30363 & $\mathbf{2 0 0}$ & $\mathbf{7 5 0}$ & 100 & $9 / 30 / 2003$ & 1561.8 \\
\hline $\mathbf{6 1 7 - 0 8}$ & 30388 & $\mathbf{1 4 0}$ & $\mathbf{7 5 0}$ & 2000 & $12 / 8 / 2003$ & \\
\hline $\mathbf{6 1 7 - 0 9}$ & & $\mathbf{1 0 0}$ & $\mathbf{7 5 0}$ & 15000 & & \\
\hline $\mathbf{6 1 7 - 1 0}$ & 30331 & $\mathbf{1 4 0}$ & $\mathbf{8 0 0}$ & 100 & $8 / 6 / 2003$ & 329.9 \\
\hline $\mathbf{6 1 7 - 1 1}$ & 30343 & $\mathbf{1 0 0}$ & $\mathbf{8 0 0}$ & 2000 & $9 / 3 / 2003$ & 1831 \\
\hline $\mathbf{6 1 7 - 1 2}$ & & $\mathbf{8 0}$ & $\mathbf{8 0 0}$ & 20000 & & \\
\hline $\mathbf{6 1 7 - 1 3}$ & 30352 & $\mathbf{4 0 0}$ & $\mathbf{6 5 0}$ & 200 & $9 / 10 / 2003$ & 1279.7 \\
\hline $\mathbf{6 1 7 - 1 4}$ & 30387 & $\mathbf{4 0 0}$ & $\mathbf{7 0 0}$ & 100 & $12 / 3 / 2003$ & 301.6 \\
\hline $\mathbf{6 1 7 - 1 5}$ & & $\mathbf{3 0 0}$ & $\mathbf{7 5 0}$ & 100 & & \\
\hline
\end{tabular}

\begin{tabular}{|c|c|c|c|c|c|c|c|c|}
\hline Creep-Rupture Testing of INCONEL $\mathbf{7 4 0}$ (Heat \# CLH4663) - Aged 16hrs, 800C, Ar \\
\hline Spec \# & $\begin{array}{c}\text { Product } \\
\text { Form }\end{array}$ & $\begin{array}{c}\text { SA } \\
\text { Temp(C) }\end{array}$ & Test \# & $\begin{array}{c}\text { Stress } \\
\text { (MPa) }\end{array}$ & $\begin{array}{c}\text { Temp. } \\
(\mathbf{\circ} \mathbf{C})\end{array}$ & Expected Life & Date Started & $\begin{array}{c}\text { Life } \\
\text { (hrs) }\end{array}$ \\
\hline $\mathbf{7 4 0 - 0 1}$ & Tube & 1120 & 30443 & $\mathbf{4 8 0}$ & $\mathbf{7 0 0}$ & 100 & $4 / 13 / 2004$ & 308 \\
\hline $\mathbf{7 4 0 - 0 2}$ & Tube & 1120 & 30448 & $\mathbf{3 7 0}$ & $\mathbf{7 5 0}$ & 100 & $5 / 4 / 2004$ & 142.8 \\
\hline $\mathbf{7 4 0 - 0 3}$ & Tube & 1120 & 30455 & $\mathbf{2 5 0}$ & $\mathbf{8 0 0}$ & 100 & $5 / 17 / 2004$ & 167.5 \\
\hline $\mathbf{7 4 0 - 0 4}$ & Tube & 1120 & 30461 & $\mathbf{1 5 0}$ & $\mathbf{8 5 0}$ & 100 & $5 / 26 / 2004$ & 157.1 \\
\hline $\mathbf{R 7 4 0 - 0 1}$ & Tube & 1190 & 0 & $\mathbf{5 8 0}$ & $\mathbf{6 5 0}$ & 100 & $1 / 0 / 1900$ & 0 \\
\hline $\mathbf{R 7 4 0 - 0 2}$ & Tube & 1190 & 30437 & $\mathbf{5 2 0}$ & $\mathbf{6 5 0}$ & 1000 & $3 / 29 / 2004$ & 1599.6 \\
\hline $\mathbf{R 7 4 0 - 0 3}$ & Tube & 1190 & 0 & $\mathbf{4 6 5}$ & $\mathbf{6 5 0}$ & 10000 & $1 / 0 / 1900$ & 0 \\
\hline $\mathbf{R 7 4 0 - 0 4}$ & Tube & 1190 & 0 & $\mathbf{4 8 0}$ & $\mathbf{7 0 0}$ & 100 & $1 / 0 / 1900$ & 0 \\
\hline $\mathbf{R 7 4 0 - 0 5}$ & Tube & 1190 & 0 & $\mathbf{4 2 0}$ & $\mathbf{7 0 0}$ & 1000 & $1 / 0 / 1900$ & 0 \\
\hline $\mathbf{R 7 4 0 - 0 6}$ & Tube & 1190 & 0 & $\mathbf{3 4 0}$ & $\mathbf{7 0 0}$ & 10000 & $1 / 0 / 1900$ & 0 \\
\hline $\mathbf{R 7 4 0 - 0 7}$ & Tube & 1190 & 30464 & $\mathbf{3 7 0}$ & $\mathbf{7 5 0}$ & 100 & $6 / 7 / 2004$ & 289.3 \\
\hline $\mathbf{R 7 4 0 - 0 8}$ & Tube & 1190 & 30467 & $\mathbf{3 0 0}$ & $\mathbf{7 5 0}$ & 1000 & $6 / 11 / 2004$ & \\
\hline $\mathbf{R 7 4 0 - 0 9}$ & Tube & 1190 & 0 & $\mathbf{2 2 0}$ & $\mathbf{7 5 0}$ & 10000 & $1 / 0 / 1900$ & 0 \\
\hline $\mathbf{R 7 4 0 - 1 0}$ & Tube & 1190 & 30449 & $\mathbf{2 5 0}$ & $\mathbf{8 0 0}$ & 100 & $5 / 4 / 2004$ & 279.2 \\
\hline $\mathbf{R 7 4 0 - 1 1}$ & Tube & 1190 & 30439 & $\mathbf{1 8 0}$ & $\mathbf{8 0 0}$ & 1000 & $3 / 30 / 2004$ & 1491.1 \\
\hline $\mathbf{R 7 4 0 - 1 2}$ & Tube & 1190 & 0 & $\mathbf{1 3 0}$ & $\mathbf{8 0 0}$ & 10000 & $1 / 0 / 1900$ & 0 \\
\hline $\mathbf{R 7 4 0 - 1 3}$ & Tube & 1190 & 30463 & $\mathbf{1 5 0}$ & $\mathbf{8 5 0}$ & 100 & $6 / 1 / 2004$ & 275.6 \\
\hline $\mathbf{R 7 4 0 - 1 4}$ & Tube & 1190 & 30457 & $\mathbf{1 0 0}$ & $\mathbf{8 5 0}$ & 1000 & $5 / 19 / 2004$ & \\
\hline $\mathbf{R 7 4 0 - 1 5}$ & Tube & 1190 & 0 & $\mathbf{7 0}$ & $\mathbf{8 5 0}$ & 10000 & $1 / 0 / 1900$ & 0 \\
\hline
\end{tabular}

Task 2D: Microstructural Analysis

\section{Objective}

The primary objectives of this subtask are: 
- Identify the microstructural changes that lead to significant changes in the strengthening, weakening, and internal damage characteristics of each material.

- Explore how these changes relate to the exposure conditions of the testing.

\section{Progress for the Task}

The University of Cincinnati (UC) has been tasked with the metallurgical characterization of the USC materials (excluding the SAVE12). The characterization work at the UC includes: microhardness, optical microscopy, scanning electron microscopy (SEM) with elemental analysis by energy dispersive spectroscopy (EDS), and transmission electron microscopy (TEM). Short-term aging is being done on the USC materials at the UC in addition to longer-term aging at ORNL. Creep-tested specimens will also be analyzed. The goal of the aging is to understand the microstructural evolution of the USC materials at temperatures encountered during service in a boiler. The creep-tested specimens will be used to understand differences in microstructural evolution compared to aging without stress and how dislocations interact with precipitates and other microstructural elements.

During this quarter, analyses were performed on standard and modified Alloy 740 aged (up to 500 hours) at $700^{\circ} \mathrm{C}$ and $800^{\circ} \mathrm{C}$. SEM examination, including EDX chemical analysis, was carried out on both the standard and modified INCONEL 740, solution annealed and aged at 700 and $800^{\circ} \mathrm{C}$ for 16,100 , and 500 hours. Both the unmodified and modified samples showed precipitates of square-shaped Ti-rich $\mathrm{MC}$ and $\mathrm{Cr}$-rich $\mathrm{M}_{23} \mathrm{C}_{6}$ type carbides along the grain boundaries and within the grains. No $\eta$ phase $\left(\mathrm{Ni}_{3} \mathrm{Ti}\right)$ was observed in any of the aged samples. This is probably because the temperature is not high enough and/or the ageing time not long enough to allow the metastable $\gamma$ to transform to $\eta$. This was in sharp contrast to the Alloy 740 sample that had been creep-tested under the conditions of $816^{\circ} \mathrm{C}, 320$ hours, which showed extensive precipitation of $\eta$ in a Widmanstatten morphology.

The ion milling provided good thin areas in the TEM samples. A comprehensive characterization, including $B$ /DF imaging and electron diffraction, was performed on samples of the standard and modified Alloy 740 materials that had been solution annealed and aged $\left(700^{\circ} \mathrm{C}, 100\right.$ and $500 \mathrm{~h} ; 800^{\circ} \mathrm{C}$, for 500 hours). A high volume fraction of both primary cuboidal and secondary spheroidal $\gamma^{\prime}$ precipitates were observed in these samples. A small amount of $\mathrm{Cr}$ - rich $\mathrm{M}_{23} \mathrm{C}_{6}$ type carbides was also detected. The existence of $\mathrm{M}_{6} \mathrm{C}$ could not be confirmed because the crystal structures of $\mathrm{M}_{6} \mathrm{C}$ and $\mathrm{M}_{23} \mathrm{C}_{6}$ are very similar and the Mo content of both these two samples is very small (only $0.5 \%$ ). More studies are required to confirm the existence of $M_{6} C$. Again no $\eta$ phase observed.

During the quarter, aged specimens of Super $304 \mathrm{H}$ and HR6W were sent to the University of Cincinnati. Additionally, a number of creep tested specimens of Super $304 \mathrm{H}$ and CCA617 specimens were supplied for characterization. Work on the creep tested specimens will begin next quarter. 


\section{Task 2E: Assessment of Creep-Fatigue Properties}

\section{Objectives}

The primary objectives of this subtask are:

- Develop a database that will lead to practical, yet conservative methods.

- Address the issue of creep-fatigue in the boiler materials.

\section{Progress for the Task}

A creep-fatigue machine has been operated successfully. Data acquisition equipment has been received for the machine. Three other machines are in various states of readiness. An air-line, for cooling of an MTS extensometer, was installed this quarter. Check-out tests on the continuous fatigue machine with the new extensometer should begin next quarter.

\section{Task 2F: Modeling of Weld Joints}

\section{Objectives}

The primary objectives of this subtask are:

- Produce the experimental data needed to model dissimilar metal and thick-section weld joints.

\section{Progress for the Task}

Creep-rupture testing continues on Haynes $\circledast 230$ tubing and plate weldments. The tests include: cross-weldments on plate and tube, parallel welded plate, and weld-metalonly tests. Their progress is indicated in the tables below. Initial results show that the plate weldments have better creep strength than the tube weldments. Thick plates (2" thick) of welded (SAW and SMAW) CCA617 were received at ORNL. A thin section of each plate was removed for archival purposes. These sections were polished and macro-etched. Visually, the SAW plate weldment appears good, but the SMAW weldment shows small pits/cracks/inclusions in the interface region between the weldment and the base material. Hardness profiles will be taken of the weldments. To prepare the welds for $\mathrm{x}$-ray, the backing plates were removed and the weld crowns were smoothed. The plates were then $x$-rayed for flaws/defects. Results from the first round of $x$-rays were inconclusive. It was not possible to $x$-ray the plate at a higher power because the machine was already at its maximum rating. However, better surface preparation may make it possible to detect flaws. The surfaces have been smoothed and all ridges have been removed. These plates will be x-rayed again next quarter. After this is complete, specimens will be taken from the plates for testing. Butt-welded tubes of HR6W with 617 and 82 filler welds were received at ORNL. Cross-weld specimens were prepared for testing in creep and tensile. A limited number of creep tests have started on the HR6W with the 617 and the 82 filler. The results are included in the table below. 


\begin{tabular}{|c|c|c|c|c|c|c|}
\hline \multicolumn{7}{|c|}{ Creep-Rupture Testing: Haynes 230 (Tube 5) Cross-Weldments } \\
\hline Spec \# & Test \# & $\begin{array}{c}\text { Stress } \\
\text { (MPa) }\end{array}$ & $\begin{array}{c}\text { Temp. } \\
\left({ }^{\circ} \mathrm{C}\right)\end{array}$ & $\begin{array}{c}\text { Base Metal } \\
\text { Expected Life }\end{array}$ & Date Started & $\begin{array}{l}\text { Life } \\
\text { (hrs) }\end{array}$ \\
\hline H230-W01 & 30311 & 350 & 650 & 200 & $6 / 26 / 2003$ & 84.9 \\
\hline H230-W02 & 30290 & 300 & 650 & 1000 & $6 / 3 / 2003$ & 825.4 \\
\hline H230-W03 & 30313 & 300 & 700 & 100 & $7 / 1 / 2003$ & 22.7 \\
\hline H230-W04 & 30319 & 200 & 700 & 1500 & $7 / 10 / 2003$ & 207.1 \\
\hline H230-W05 & 30320 & 200 & 750 & 100 & \begin{tabular}{|l|}
$7 / 14 / 2003$ \\
\end{tabular} & 30.7 \\
\hline H230-W06 & 30327 & 140 & 750 & 2000 & $7 / 23 / 2003$ & 170.6 \\
\hline H230-W07 & 30328 & 200 & 650 & 10000 & $7 / 24 / 2003$ & 1550.6 \\
\hline H230-W08 & 30332 & 140 & 700 & 15000 & $8 / 6 / 2003$ & 1472 \\
\hline \multicolumn{7}{|c|}{ Creep-Rupture Testing: Haynes 230 (Tube 2) Cross-Weldments } \\
\hline H230-W09 & 30361 & 100 & 800 & 2000 & $9 / 23 / 2003$ & 231.6 \\
\hline H230-W10 & 30365 & 80 & 800 & 20000 & $10 / 1 / 2003$ & 419.2 \\
\hline H230-W11 & 30369 & 60 & 800 & & $10 / 14 / 2003$ & \\
\hline H230-W12 & 30370 & 100 & 750 & 15000 & $10 / 14 / 2003$ & 1117.8 \\
\hline
\end{tabular}

\begin{tabular}{|c|c|c|c|c|c|c|}
\hline \multicolumn{7}{|c|}{ Creep-Rupture Testing: Haynes 230 Weld Metal (Plate 3) } \\
\hline Spec \# & Test \# & $\begin{array}{c}\text { Stress } \\
(\mathrm{MPa})\end{array}$ & $\begin{array}{c}\text { Temp. } \\
(\circ \mathrm{C})\end{array}$ & $\begin{array}{c}\text { Estimated Life } \\
(\mathrm{hrs})\end{array}$ & Date Started & $\begin{array}{c}\text { Life } \\
(\mathrm{hrs})\end{array}$ \\
\hline W3-01 & 30403 & $\mathbf{2 0 0}$ & $\mathbf{6 5 0}$ & 1500 & $1 / 22 / 2004$ & \\
\hline W3-02 & & $\mathbf{1 4 0}$ & $\mathbf{7 0 0}$ & 1500 & & \\
\hline W3-03 & & $\mathbf{1 0 0}$ & $\mathbf{7 5 0}$ & 1500 & & \\
\hline W3-04* & & $\mathbf{1 0 0}$ & $\mathbf{7 5 0}$ & 1500 & & \\
\hline W3-05 & & $\mathbf{8 0}$ & $\mathbf{8 0 0}$ & 1500 & & \\
\hline
\end{tabular}

\begin{tabular}{|c|c|c|c|c|c|c|}
\hline \multicolumn{6}{|c|}{ Creep-Ruture Testing:Haynes 230 Cross Weld (Plate 2) } \\
\hline Spec \# & Test \# & $\begin{array}{c}\text { Stress } \\
(\mathbf{M P a})\end{array}$ & $\begin{array}{c}\text { Temp. } \\
(\circ \mathrm{C})\end{array}$ & $\begin{array}{c}\text { Estimated Life } \\
\text { (hrs) }\end{array}$ & Date Started & $\begin{array}{c}\text { Life } \\
(\mathrm{hrs})\end{array}$ \\
\hline CW-01 & 30418 & $\mathbf{2 0 0}$ & $\mathbf{6 5 0}$ & 1500 & $3 / 2 / 2004$ & \\
\hline CW-02 & & $\mathbf{1 4 0}$ & $\mathbf{7 0 0}$ & 1500 & & \\
\hline CW-03 & & $\mathbf{1 0 0}$ & $\mathbf{7 5 0}$ & 1500 & & \\
\hline CW-04 & & $\mathbf{8 0}$ & $\mathbf{8 0 0}$ & 1500 & & \\
\hline
\end{tabular}

\begin{tabular}{|c|c|c|c|c|c|c|}
\hline \multicolumn{6}{|c|}{ Creep-Rupture Testing:Haynes 230 Parallel Weld (Plate 2) } \\
\hline Spec \# & Test \# & $\begin{array}{c}\text { Stress } \\
(\mathrm{MPa})\end{array}$ & $\begin{array}{c}\text { Temp. } \\
(\circ \mathrm{C})\end{array}$ & $\begin{array}{c}\text { Estimated Life } \\
(\mathrm{hrs})\end{array}$ & Date Started & $\begin{array}{c}\text { Life } \\
(\mathrm{hrs})\end{array}$ \\
\hline PW-01 & 30419 & $\mathbf{2 0 0}$ & $\mathbf{6 5 0}$ & 2000 & $3 / 2 / 2004$ & \\
\hline PW-02 & & $\mathbf{1 4 0}$ & $\mathbf{7 0 0}$ & 2000 & & \\
\hline PW-03 & & 100 & $\mathbf{7 5 0}$ & 2000 & & \\
\hline PW-04 & & $\mathbf{8 0}$ & $\mathbf{8 0 0}$ & 2000 & & \\
\hline
\end{tabular}

\begin{tabular}{|c|c|c|c|c|c|c|}
\hline \multicolumn{6}{|c|}{ Creep-Rupture Testing of HR6W Tubing w/617 Welds } \\
\hline Spec \# & Test \# & $\begin{array}{c}\text { Stress } \\
(\mathrm{MPa})\end{array}$ & $\begin{array}{c}\text { Temp. } \\
(\circ \mathrm{C})\end{array}$ & $\begin{array}{c}\text { Estimated } \\
\text { Life }\end{array}$ & Date Started & $\begin{array}{c}\text { Life } \\
\text { (hrs) }\end{array}$ \\
\hline 617W-01 & 30459 & $\mathbf{1 7 5}$ & $\mathbf{6 5 0}$ & & $5 / 24 / 2004$ & \\
\hline $617 \mathrm{~W}-02$ & 30460 & $\mathbf{1 2 0}$ & $\mathbf{7 0 0}$ & & $5 / 24 / 2004$ & \\
\hline $617 \mathrm{~W}-03$ & & $\mathbf{8 5}$ & $\mathbf{7 5 0}$ & & & \\
\hline
\end{tabular}




\begin{tabular}{|c|c|c|c|c|c|c|}
\hline \multicolumn{6}{|c|}{ Creep-Rupture Testing of HR6W Tubing w/82 Welds } \\
\hline Spec \# & Test \# & $\begin{array}{c}\text { Stress } \\
(\mathrm{MPa})\end{array}$ & $\begin{array}{c}\text { Temp. } \\
(\circ \mathrm{C})\end{array}$ & $\begin{array}{c}\text { Estimated } \\
\text { Life }\end{array}$ & Date Started & $\begin{array}{c}\text { Life } \\
\text { (hrs) }\end{array}$ \\
\hline $\mathbf{8 2 W - 0 1}$ & 30465 & $\mathbf{1 7 5}$ & $\mathbf{6 5 0}$ & & $6 / 9 / 2004$ & \\
\hline $\mathbf{8 2 W}-02$ & & $\mathbf{1 2 0}$ & $\mathbf{7 0 0}$ & & & \\
\hline $\mathbf{8 2 W - 0 3}$ & & $\mathbf{8 5}$ & $\mathbf{7 5 0}$ & & & \\
\hline
\end{tabular}

\section{Task 2G: Study of Accelerated Test Methods}

\section{Objectives}

The primary objective of this task is:

- Provide a method to rapidly characterize changes in the strength of candidate materials.

\section{Progress}

The purported high creep strength $9 \mathrm{Cr}$ ferritic Abe Alloy (nano-nitride) was of interest to the consortium. Two thick plates (1" thick) were received from Abe last quarter. Stressrelaxation specimens were machined from the plate and testing will begin next quarter. During the quarter, stress-relaxation testing at $650^{\circ} \mathrm{C}$ was started and completed on a sample of HCM12A. HCM12A represents one of the stronger 9 to 12 Chrome ferritic steels and will provide a baseline from which to compare the nano-nitride alloy.

\section{Task 2H: Model Validation}

\section{Objectives}

The primary objective of this task is:

- Produce a database that can be used to confirm or validate design rules that are developed in Task 8.

\section{Progress}

Pressurized creep testing of tube U-bends, to evaluate coldwork effects, was started this quarter on two Haynes 230 bends and one HR6W bend. The test temperature was set at $775^{\circ} \mathrm{C}$. It was agreed, through discussions with Task 8 , that this temperature would be aggressive enough to produce recrystallization during the tests while keeping the pressures within safety limits. The internal pressure was set to produce rupture in 24,000 hours; based off the current ASME Section I formula for tubes. The tubes were measured using a CMM (Coordinate Measuring Machine) before testing. The tubes were removed after 1,000 hours, measured by the CMM, and put back into the test station for an additional 2,000 hours. The specimens will be measured after a total of 3,000 hours, and the final removal will be at 6,000 hours. 
Task 8 indicated a need for creep-rate data at lower stresses than those planned for the creep-rupture tests. A step-up-step-down creep test was started on the CCA617 at $60 \mathrm{MPa}$. A steady-state condition was reached during the quarter and the stress was lowered, to 50MPa, to determine the creep-rate and to evaluate the stress change characteristics of the material. Further changes in stresses will be incorporated next quarter.

The induction coil on the thermal shock testing apparatus was tested out. Thermal cycles on a dummy specimen have been completed and the data acquisition equipment is working properly. Difficulties were encountered in attaching the thermocouples so they could survive multiple thermal cycles. This problem has been fixed and new thermocouples have been installed on a CCA617 thermal shock specimen. Testing should begin next quarter.

\section{Task 2l: Data Transfer Web Site}

\section{Objectives}

The primary objective of this task is:

- Develop and maintain a secure website for transferring mechanical properties data from Task 2 to the consortium.

\section{Progress}

The initial design of the website is complete. A secure password has been applied to the site. A letter was sent to the consortium members with the URL, user id, and password. After numerous discussions with the website designer, it was agreed that the best way to upload data in a quick and easy manner was to purchase additional web design software. Software has been ordered. When it is received, updated data and additional files will be applied to the site. Chemistry tables for each alloy have been started.

\section{Concerns}

A better way was needed to upload data and update the website in a timely manner. To alleviate this problem, web design software was ordered so the web designer could be bypassed for simple tasks such as updating tables and adding links to new data files.

\section{Plans for Next Quarter}

Comments on the assessment reports will be incorporated into the final report for parts I and II. Creep-rupture tests will continue with emphasis placed on the INCONEL 740 tubing. Creep-tested specimens of CCA617 and Super $304 \mathrm{H}$ will be characterized by electron microscopy. Check-out testing will be performed on a continuous fatigue machine with a new extensometer. Stress-relaxation testing on the Abe alloy will begin. Specimens will be taken from the CCA617 welded plate after x-ray analysis. The Haynes 230 and HR6W tube U-bends will be removed for measurement after a total 
exposure time of 3,000 hours. Additional stress changes in the low-stress CCA617 test will be performed. Thermal shock testing should begin. 


\section{Task 3 \\ Steamside Oxidation \\ $(\mathrm{B} \& \mathrm{~W})$}

\section{Task 3A: Autoclave Testing}

\section{Background}

Steamside oxidation tests will be performed on commercially available and developmental materials at temperatures between $650^{\circ} \mathrm{C}$ and $900^{\circ} \mathrm{C}\left(1202^{\circ} \mathrm{F}-1652^{\circ} \mathrm{F}\right)$.

\section{Experimental}

The first exposure period at $800^{\circ} \mathrm{C}(1,006$ hours) was completed during this quarter. One third of the specimens were removed from the test rack and weighed. Half of the removed specimens were decaled and re-weighed; the other half of the specimens were submitted for SEM/EDS evaluation. The results from the analyses conducted todate were evaluated and are presented below under the following headings: Weight Change, Descaled Weight Loss, Exfoliation, and Oxidation Kinetics.

\section{Weight Change}

The average measured weight changes for the materials under test after the first exposure period at $800^{\circ} \mathrm{C}$ are presented in Table 1 . As with the weight change results reported for tests at $650^{\circ} \mathrm{C}$, these data somewhat underestimate the actual weight gain experienced by the specimens since some oxide spallation occurs on the specimens.

It can be observed from Table 1 that the $2 \% \mathrm{Cr}$ T23 experienced severe oxidation. The $9 \% \mathrm{Cr}$ alloys $\mathrm{P} 92$ and SAVE12 displayed higher weight gains at $800^{\circ} \mathrm{C}$ than at $650^{\circ} \mathrm{C}$; however, the form of the oxidation on these materials is of greater concern than the weight gain. As shown in Figure 1, P92 and SAVE12 experienced severe localized oxidation, particularly at edges. This behavior is consistent with their observed behavior at $650^{\circ} \mathrm{C}$, where "islands" of thick oxide were observed on the surface of the specimens. The weight gains experienced by the austenitic materials and by the ferritic Abe alloy and VM12 were relatively low and consistent. The austenitic alloys exhibiting the lowest weight gains were 347HFG (which actually lost weight, presumably due to oxide spallation) and Alloy 214. 
TABLE 1

$800^{\circ} \mathrm{C}$ Measured Weight Change Results

\begin{tabular}{|l|l|l|}
\hline Material & $\% \mathrm{Cr}$ & Measured Weight Change After 1006 hours $(\mathrm{mg} / \mathrm{cm} 2)$ \\
\hline T23 & 2.09 & 316.927 \\
\hline P92 & 8.93 & 11.650 \\
\hline Abe & 9.16 & 0.854 \\
\hline SAVE12 & 9.25 & 17.808 \\
\hline VM12 & 11.37 & 0.543 \\
\hline 214 & 16.34 & 0.146 \\
\hline 347HFG & 18.61 & -0.194 \\
\hline $304 H$ & 18.83 & 1.315 \\
\hline S304H & 19.1 & 0.765 \\
\hline CCA617 & 21.73 & 0.773 \\
\hline SAVE25 & 21.85 & 0.400 \\
\hline 230 & 22.42 & 0.574 \\
\hline HR6W & 23.44 & 0.568 \\
\hline 740 & 24.31 & 0.822 \\
\hline Mod 740 & 24.86 & 0.935 \\
\hline HR120 & 25.94 & 0.628 \\
\hline 310HCbN & 25.98 & 0.693 \\
\hline
\end{tabular}




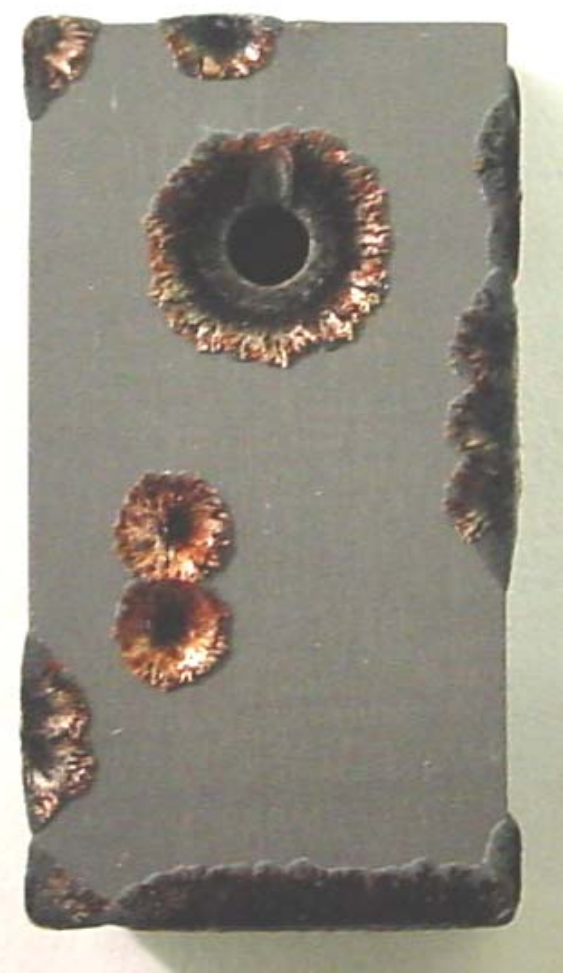

Figure 1. Severe Localized Oxidation on SAVE12 after 1006 hours at $800^{\circ} \mathrm{C}$

\section{Descaled Weight Loss}

Following the exposure, one specimen from each material was descaled using alkaline permanganate, hot diammonium citrate and, when necessary, hot inhibited hydrochloric acid. The descaled weights are reported in Table 2.

The T23 specimen broke during descaling and it was observed that almost the entire specimen had been converted to oxide, as shown in Figure 2 (note that the original specimen dimensions are clearly visible). The original specimen weight was entered in Table 2 as the descaled weight loss for T23. Due to the severe localized oxidation on P92 and SAVE12, all of the oxide in the heavily oxidized locations could not be removed; thus, the descaled weight loss reported in Table 2 for these specimens is less than their actual weight loss had all of the oxide been removed. The $12 \% \mathrm{Cr}$ ferritic alloy VM12 exhibited a descaled weight loss that was slightly less than several of the austenitic alloys. The $9 \% \mathrm{Cr}$ Abe alloy exhibited a descaled weight loss about three times greater than that exhibited by VM12, but equivalent to the descaled weight loss of $304 \mathrm{H}$. Of the austenitic materials, Alloy 214 exhibited essentially no descaled weight loss. This suggests that Alloy 214 formed very little oxide during the 1006 hour exposure in $800^{\circ} \mathrm{C}$ steam.

A comparison of the descaled weight losses after 1,000 hours of exposure for materials tested at both $650^{\circ} \mathrm{C}$ and $800^{\circ} \mathrm{C}$ are displayed in Figures 3-5. 
TABLE 2

\section{$800^{\circ} \mathrm{C}$ Descaled Weight Loss Results}

\begin{tabular}{|l|l|l|}
\hline Material & $\% \mathrm{Cr}$ & Descaled Weight Loss After 1006 hours $\left(\mathrm{mg} / \mathrm{cm}^{2}\right)$ \\
\hline T23 & 2.09 & 938.523 \\
\hline P92 & 8.93 & 20.687 \\
\hline Abe & 9.16 & 3.426 \\
\hline SAVE12 & 9.25 & 8.278 \\
\hline VM12 & 11.37 & 1.277 \\
\hline 214 & 16.34 & -0.002 \\
\hline 347 HFG & 18.61 & 0.974 \\
\hline $304 \mathrm{H}$ & 18.83 & 3.768 \\
\hline S304H & 19.1 & 1.950 \\
\hline CCA617 & 21.73 & 1.099 \\
\hline SAVE25 & 21.85 & 1.436 \\
\hline 230 & 22.42 & 1.294 \\
\hline HR6W & 23.44 & 1.458 \\
\hline 740 & 24.31 & 1.168 \\
\hline Mod 740 & 24.86 & 1.428 \\
\hline HR120 & 25.94 & 1.363 \\
\hline $310 H C b N$ & 25.98 & 1.685 \\
\hline
\end{tabular}




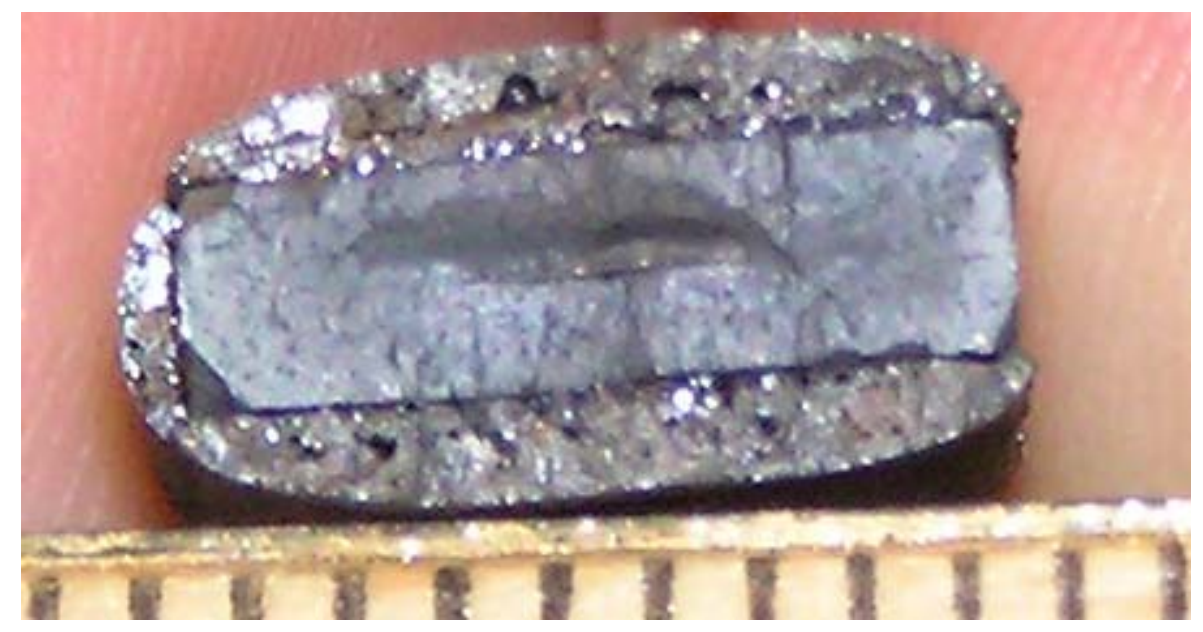

Figure 2. Complete Oxidation of T23 after 1006 hours at $800^{\circ} \mathrm{C}$

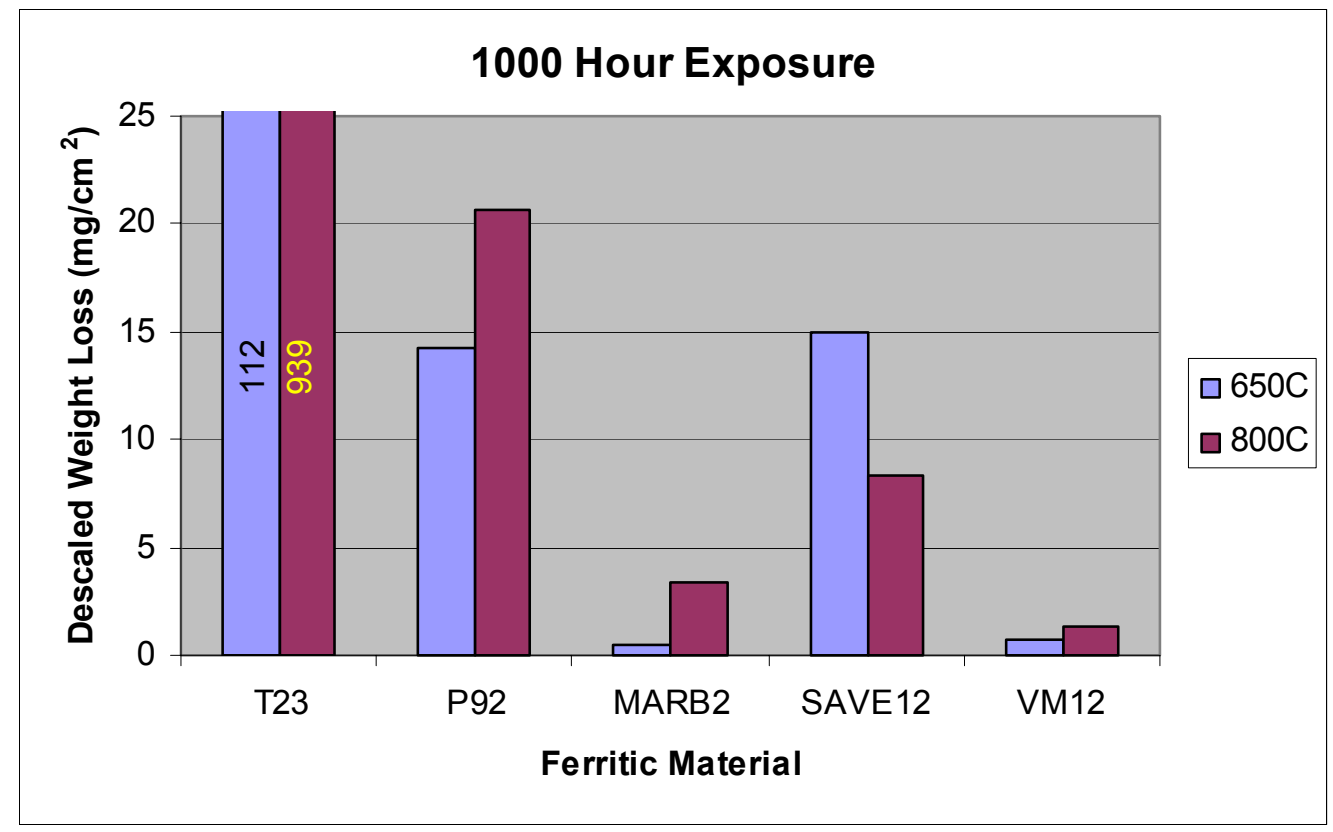

Figure 3. Comparison of Descaled Weight Loss for Ferritic Materials after 1000 Hours at $650^{\circ} \mathrm{C}$ and $800^{\circ} \mathrm{C}$ 


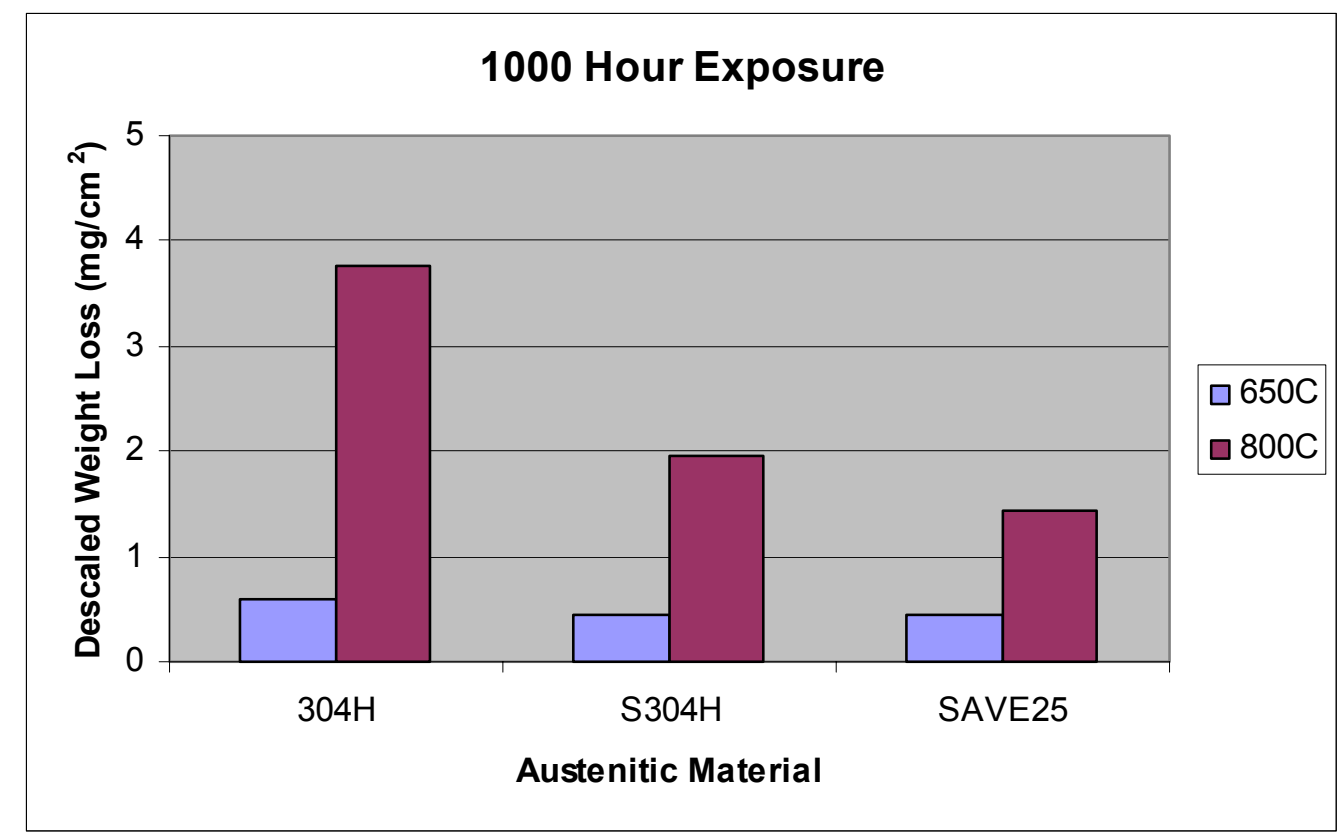

Figure 4. Comparison of Descaled Weight Loss for Austenitic Materials after 1000 Hours at $650^{\circ} \mathrm{C}$ and $800^{\circ} \mathrm{C}$

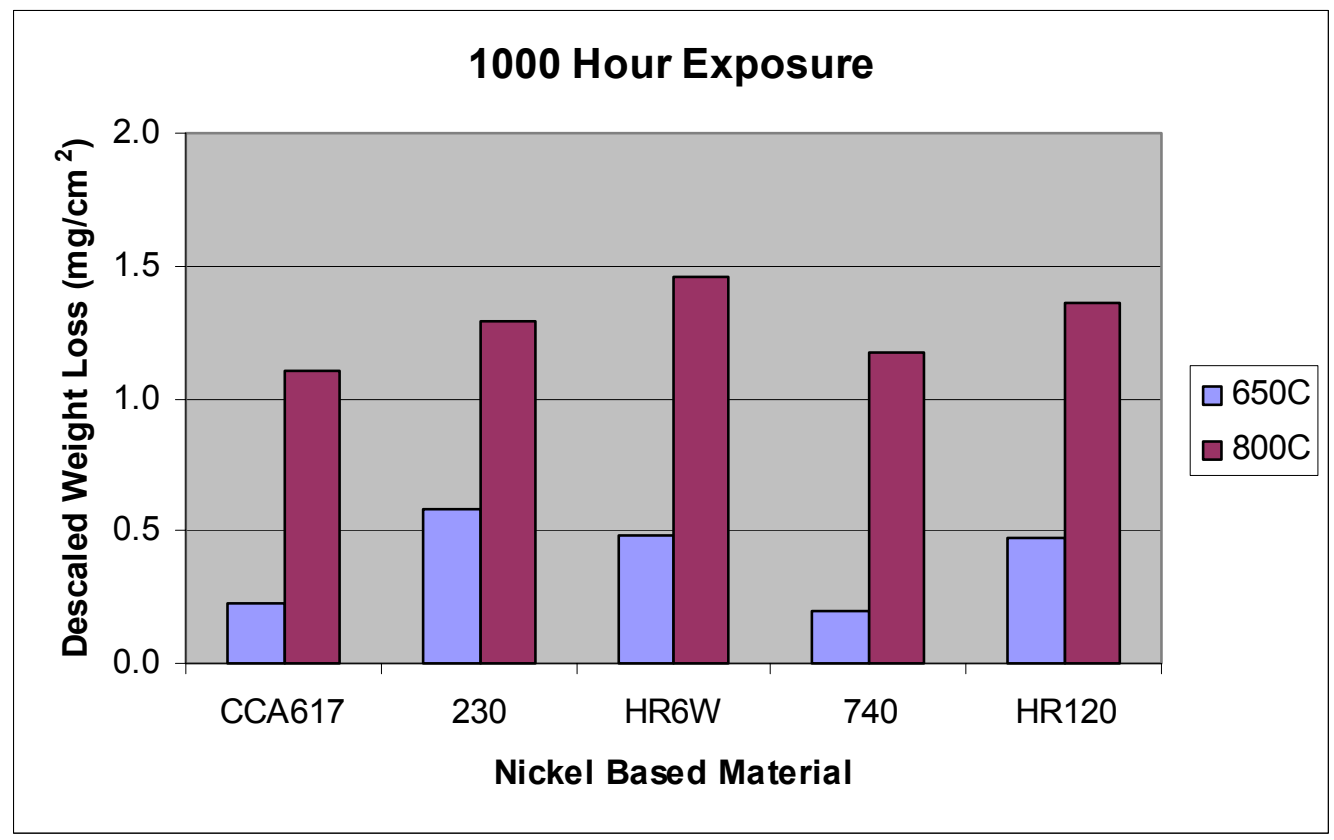

Figure 5. Comparison of Descaled Weight Loss for Nickel Based Materials after 1000 Hours at $650^{\circ} \mathrm{C}$ and $800^{\circ} \mathrm{C}$ 


\section{Exfoliation}

The weight of exfoliated oxide from each material was calculated by subtracting the measured weight change from the weight change calculated from the descaled weight loss. From the $650^{\circ} \mathrm{C}$ tests, it was suggested that the possible error in this calculation is approximately $\pm 1 \mathrm{mg} / \mathrm{cm}^{2}$ due to variability in weighing and descaling. The only specimens that exhibited calculated exfoliated metal oxides in excess of $1 \mathrm{mg} / \mathrm{cm}^{2}$ was the Abe alloy $\left(1.6 \mathrm{mg} / \mathrm{cm}^{2}\right), 347 \mathrm{HFG}\left(1.9 \mathrm{mg} / \mathrm{cm}^{2}\right)$ and $304 \mathrm{H}\left(1.2 \mathrm{mg} / \mathrm{cm}^{2}\right)$.

\section{Oxidation Kinetics}

- Calculation of $\mathrm{k}_{\mathrm{p}}$

The oxidation rate constant, $k_{p}$, was calculated using the weight change calculated from descaled weight loss and assuming parabolic kinetics. These values are displayed in Table 3. $k_{p}$ values from the first 1,000 hour exposure at $650^{\circ} \mathrm{C}$ are also included in Table 3 for materials that are common to both tests. These results indicate that the increase in temperature from $650^{\circ} \mathrm{C}$ to $800^{\circ} \mathrm{C}$ increased the $\mathrm{k}_{\mathrm{p}}$ by about an order of magnitude. The $\mathrm{k}_{\mathrm{p}}$ values calculated by ORNL at $700^{\circ} \mathrm{C}$ are also included in Table 3 .

The $800^{\circ} \mathrm{C}$ kp values in Table 3 for P92 and SAVE12 are influenced by the fact that not all of the severe localized oxidation could be removed from these specimens. Thus, the $\mathrm{kp}$ value for SAVE12 at $800^{\circ} \mathrm{C}$ is reported as being less than the $\mathrm{kp}$ value at $650^{\circ} \mathrm{C}$. It is interesting to note that the advanced ferritic Abe alloy and VM12 exhibit kp values that are essentially the same as those exhibited by many of the austenitic alloys after 1000 hours at $800^{\circ} \mathrm{C}$. Since Alloy 214 exhibited no weight loss after descaling, the kp value for this material is essentially nil.

TABLE 3

Comparison of Calculated Oxidation Rate Constants - Parabolic Kinetics

\begin{tabular}{|l|l|l|l|l|}
\hline Material & $\% \mathrm{Cr}$ & $\begin{array}{l}\mathrm{k}_{\mathrm{p}} \text { at } 800^{\circ} \mathrm{C}-1,000 \mathrm{hrs} \\
\left(\mathrm{g}^{2} \mathrm{~cm}^{-4} \mathrm{~s}^{-1}\right)\end{array}$ & $\begin{array}{l}\mathrm{k}_{\mathrm{p}} \text { at } 650^{\circ} \mathrm{C}-1,000 \mathrm{hrs} \\
\left(\mathrm{g}^{2} \mathrm{~cm}^{-4} \mathrm{~s}^{-1}\right)\end{array}$ & $\begin{array}{l}\text { ORNL } \mathrm{k}_{\mathrm{p}} \text { at } 700^{\circ} \mathrm{C} \\
\left(\mathrm{g}^{2} \mathrm{~cm}^{-4} \mathrm{~s}^{-1}\right)\end{array}$ \\
\hline T23 & 2.09 & $3.55 \mathrm{E}-08$ & $5.59 \mathrm{E}-10$ & ----- \\
\hline P92 & 8.93 & $1.72 \mathrm{E}-11$ & $9.04 \mathrm{E}-12$ & $7.50 \mathrm{E}-11$ \\
\hline Abe & 9.16 & $4.73 \mathrm{E}-13$ & $1.08 \mathrm{E}-14$ & ----- \\
\hline SAVE12 & 9.25 & $2.76 \mathrm{E}-12$ & $1.00 \mathrm{E}-11$ & ----- \\
\hline VM12 & 11.37 & $6.57 \mathrm{E}-14$ & $2.14 \mathrm{E}-14$ & ----- \\
\hline 214 & 16.34 & $1.60 \mathrm{E}-19$ & ----- & ----- \\
\hline $347 \mathrm{HFG}$ & 18.61 & $4.89 \mathrm{E}-14$ & ---- & ---- \\
\hline $304 \mathrm{H}$ & 18.83 & $7.32 \mathrm{E}-13$ & $1.97 \mathrm{E}-14$ & ----- \\
\hline S304H & 19.1 & $1.96 \mathrm{E}-13$ & $1.13 \mathrm{E}-14$ & ----- \\
\hline
\end{tabular}




\begin{tabular}{|l|l|l|l|l|} 
CCA617 & 21.73 & $6.22 \mathrm{E}-14$ & $3.03 \mathrm{E}-15$ & ---- \\
\hline SAVE25 & 21.85 & $1.06 \mathrm{E}-13$ & $1.12 \mathrm{E}-14$ & $2.20 \mathrm{E}-15$ \\
\hline 230 & 22.42 & $8.62 \mathrm{E}-14$ & $1.96 \mathrm{E}-14$ & ---- \\
\hline HR6W & 23.44 & $1.10 \mathrm{E}-13$ & $1.33 \mathrm{E}-14$ & ---- \\
\hline 740 & 24.31 & $7.03 \mathrm{E}-14$ & $2.31 \mathrm{E}-15$ & $2.70 \mathrm{E}-15$ \\
\hline Mod 740 & 24.86 & $1.05 \mathrm{E}-13$ & ---- & ---- \\
\hline HR120 & 25.94 & $9.57 \mathrm{E}-14$ & $1.28 \mathrm{E}-14$ & $2.60 \mathrm{E}-15$ \\
\hline $310 \mathrm{HCbN}$ & 25.98 & $1.46 \mathrm{E}-13$ & ---- & ---- \\
\hline
\end{tabular}

- Calculation of Activation Energy

For those materials common to the $650^{\circ} \mathrm{C}$ and $800^{\circ} \mathrm{C}$ tests, activation energies were calculated from the $k_{p}$ values listed in Table 3 and the actual temperatures that the materials were subjected to during their first 1,000 hour exposures. The activation energy, $Q$, was calculated from the Arrhenius equation:

$\mathrm{k}_{\mathrm{p}}=\mathrm{A} \mathrm{e}^{-\mathrm{Q} / \mathrm{RT}}$

where: $\quad k_{p}$ is the oxidation rate constant
$A$ is the Arrhenius constant
$Q$ is the activation energy
$\mathrm{R}$ is the gas constant $\left(0.008314 \mathrm{~kJ} / \mathrm{mole}^{\circ} \mathrm{K}\right)$
$\mathrm{T}$ is the temperature $\left({ }^{\circ} \mathrm{K}\right)$

This equation can also be expressed as:

$\log k_{p}=\log A-\left(Q /\left(2.3^{*} R^{*} T\right)\right)$

Plots of log $k_{p}$ vs. 1000/T yielded a line with a slope of $-Q /\left(2.3^{*} R^{*} 1000\right)$, from which $Q$ was calculated. The calculated activation energies are listed in Table 4. Again, realize that the activation energies calculated for P92 and SAVE12 are influenced by the severe localized oxidation experienced by these materials 
TABLE 4

Activation Energies

\begin{tabular}{|l|l|}
\hline Material & $\begin{array}{l}\text { Q - 1000 Hrs } \\
(\mathrm{kJ} / \text { mole })\end{array}$ \\
\hline T23 & 213 \\
\hline P92 & 35 \\
\hline Abe & 221 \\
\hline SAVE12 & -71 \\
\hline VM12 & 66 \\
\hline 304H & 202 \\
\hline Super 304H & 162 \\
\hline CCA617 & 158 \\
\hline SAVE25 & 127 \\
\hline Alloy 230 & 80 \\
\hline HR6W & 117 \\
\hline Alloy 740 & 186 \\
\hline HR120 & 106 \\
\hline
\end{tabular}

The values listed in Table 4 are of the same general magnitude as described by Wright and Pint in CORROSION 2002 Paper 020377. Activation energies for the materials will be calculated with greater confidence as tests are conducted at longer times and additional temperatures.

\section{Concerns}

Due to inadequate funding, the start of the next exposure at $800^{\circ} \mathrm{C}$ will not be started until next GFY.

\section{Activities Next Quarter}

SEM/EDS analyses on the specimens removed after the first $800^{\circ} \mathrm{C}$ exposure will be completed.

\section{Task 3B Coating Tests}

\section{Background}

Coated specimens for steamside oxidation testing will be prepared in conjunction with Task 7 and evaluated after testing. 


\section{Experimental}

The first exposure period at $800^{\circ} \mathrm{C}(1,006$ hours $)$ was completed during this quarter. One third of the coated specimens (6 of 18) were removed from the test rack and weighed. Half of the removed specimens were descaled and re-weighed; the other half of the specimens were submitted for SEM/EDS evaluation. The results from the analyses conducted to-date were evaluated and are presented below.

The weight change and descaled weight loss experienced by the coated Super $304 \mathrm{H}$ specimens supplied by Alstom are presented in Table 5 .

TABLE 5

$800^{\circ} \mathrm{C}$ Weight Change and Descaled Weight Loss Results from Coated Materials

\begin{tabular}{|l|l|l|}
\hline Material & $\begin{array}{l}\text { Measured Weight Change after 1006 } \\
\text { Hours }\left(\mathrm{mg} / \mathrm{cm}^{2}\right)\end{array}$ & $\begin{array}{l}\text { Descaled Weight Loss after 1000 Hours } \\
(\mathrm{mg} / \mathrm{cm} 2)\end{array}$ \\
\hline $\mathrm{CrS304H}$ & -0.675 & 3.281 \\
\hline $\mathrm{AlCrS304H}$ & 1.812 & 72.026 \\
\hline $\mathrm{SiCrS304H}$ & 0.556 & 2.267 \\
\hline
\end{tabular}

The results in Table 5 suggest that the $\mathrm{SiCrS} 304 \mathrm{H}$ specimens exhibited the best performance after 1,000 hours in $800^{\circ} \mathrm{C}$ steam. Even the SiCrS304H material did not perform as well as the austenitic materials in this test, consistent with the results at $650^{\circ} \mathrm{C}$.

\section{Concerns}

None

\section{Activities Next Quarter}

SEM/EDS analyses on the coated specimens removed after 1000 hours at $800^{\circ} \mathrm{C}$ will be completed.

\section{Task 3C Assessment of Temperature}

\section{Background}

Based on the steamside oxidation test results, the practical temperature limits for the materials tested will be determined. 


\section{Experimental}

Initial activation energy calculations are presented in Task 3A.

\section{Concerns}

None

\section{Activities Next Quarter}

None

\section{Task 3D Review of Available Information \& Reporting}

\section{Background}

Available steamside oxidation literature pertaining to materials and environmental conditions of interest will be reviewed. Project status updates will be prepared and status meetings will be attended as required.

\section{Experimental}

Monthly status reports were prepared for April and May, 2004, and Quarterly Reports were prepared for the January - March, 2004 and April - June, 2004 time periods.

A technical paper for the $8^{\text {th }}$ UltraSteel Workshop in Tsukuba, Japan was prepared, approved and issued. This paper will be presented in July, 2004.

\section{Concerns}

None.

\section{Activities Next Quarter}

Monthly status reports will be written for July and August, 2004.

A technical paper will be presented in July, 2004 at the $8^{\text {th }}$ Ultra-Steel Workshop in Japan. 


\section{Task 3E Conduct Experimental Exposures}

\section{Background}

The steam oxidation behavior of model Fe-Cr alloys will be evaluated.

\section{Experimental}

$\mathrm{B} \& \mathrm{~W}$ is remaining cognizant of the ORNL tests on these model alloys.

\section{Concerns}

None

\section{Activities Next Quarter}

None

\section{Task 3F Characterization}

\section{Background}

Samples of the model Fe-Cr alloys fabricated in Task 3E will be characterized before and after steamside oxidation testing using metallographic and electron optic techniques.

\section{Experimental}

None.

\section{Concerns}

None

\section{Activities Next Quarter}

None 


\section{Task 3G Data Analysis and Coordination}

\section{Background}

The steamside oxidation results will be evaluated to determine the effects of material properties and environmental factors on oxidation behavior.

\section{Experimental}

No progress will be possible until the steamside oxidation tests have been completed (GFY2006).

\section{Concerns}

None

\section{Activities Next Quarter}

None

\section{Milestone Chart}

Dates are listed in GFY

\begin{tabular}{|c|c|c|c|c|c|c|c|c|}
\hline \multirow[b]{2}{*}{ ID } & \multirow[b]{2}{*}{ Task Name } & 2002 & 2003 & \multicolumn{2}{|l|}{2004} & \multicolumn{2}{|r|}{2006} & \\
\hline & & \begin{tabular}{|l|l|l|l|l}
$\mathrm{Q}$ & $\mathrm{Q} 2$ & $\mathrm{Q} 3$ & $\mathrm{Q} 4$ \\
\end{tabular} & \begin{tabular}{|l|l|l|l|}
$\mathrm{Q} 1$ & $\mathrm{Q} 2$ & $\mathrm{Q3}$ & $\mathrm{Q} 4$ \\
\end{tabular} & \begin{tabular}{|l|l|l|}
$\mathrm{Q} 1$ & $\mathrm{Q} 2$ & $\mathrm{Q} 3$ \\
\end{tabular} & Q4 & \begin{tabular}{l|l|l|l|l}
$\mathrm{Q}$ & $\mathrm{Q} 2$ & $\mathrm{Q3}$ & $\mathrm{Q4}$ & \\
\end{tabular} & \begin{tabular}{|l|l|l|l|}
$\mathrm{Q} 1$ & $\mathrm{Q} 2$ & $\mathrm{Q} 3$ & $\mathrm{Q} 4$ \\
\end{tabular} & Q1 \\
\hline 1 & 3A Autoclave Testing & 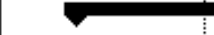 & & & & & & \\
\hline 2 & Design, Build \& Test Facility & topoce & yloke: & & & & & \\
\hline 3 & Procure $\&$ Characterize Materials & to: & 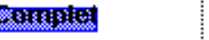 & & & & & \\
\hline 4 & Design \& Build Test Sections & & to: canplete & & & & & \\
\hline 5 & Perform $4000 \mathrm{hr}$ Test $@ 650$ \& Evaluate & & 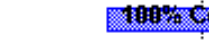 & 3imsstox & & & & \\
\hline 6 & Perform $4000 \mathrm{hr}$ Test $@ 800$ \& Evaluate & & & t5 & mpl & fote & & \\
\hline 7 & Perform $4000 \mathrm{hr}$ Test $@ 900 \&$ Evaluate & & & & & & & \\
\hline 8 & 3B Coating Tests & & & & & & & \\
\hline 9 & Prepare Coupons & & Ains, & & & & & \\
\hline 10 & Post-test Evaluation & & & $40 \%$ & Com & plete, , 圈 & A & \\
\hline 11 & 3C Assessment of Temperature & & & & & & & \\
\hline 12 & Compile and Analyze Test Data & & & 用整\% & Con & ppleten, &, $1 \ldots \ldots \ldots$ & \\
\hline 13 & Determine Material Temp Limits & & & & & & & \\
\hline 14 & 3D Literature Review \& Reporting & & & & & & & \\
\hline 15 & Literature Review & 1toon & & & & & & \\
\hline 16 & Monthly Updates & $|1||||||||| \mid$ & 1111111111 & $\| 1111111$ & 111 & $\| 1111111111$ & \|\|\|\|\|\|\|\| & \\
\hline 77 & Quarterly Updates & l 11 & 1 I & I & & I I & I & \\
\hline 98 & Meetings & 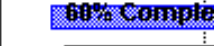 & & & & & & \\
\hline 99 & 3E Model Fe-Cr Alloys & & & & & & & \\
\hline 100 & Cognizance of ORNL Activities & 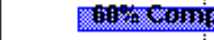 & stotes: & & & & & \\
\hline
\end{tabular}




\section{Task 3 \\ Steamside Oxidation (ORNL)}

The run at $700^{\circ} \mathrm{C}$ in $1.7 \mathrm{MPa}$ (250 psig) steam has been completed, and a run planned for $4,000 \mathrm{~h}$ at $800^{\circ} \mathrm{C}$ in $1.7 \mathrm{MPa}$ steam has reached $2,500 \mathrm{~h}$. Data for $700^{\circ} \mathrm{C}$, and for up to $2,000 \mathrm{~h}$ at $800^{\circ} \mathrm{C}$ are reported. The alloys tested at 700 and $800^{\circ} \mathrm{C}$ are shown in Table 1.

TABLE 1

Listing of Alloys Tested

\begin{tabular}{lccc|cc}
\hline Alloy & \multicolumn{3}{c|}{$\mathbf{7 0 0}^{\circ} \mathbf{C}$} & \multicolumn{2}{c}{$\mathbf{8 0 0}^{\circ} \mathbf{C}$} \\
\cline { 2 - 6 } & 17 bar & B\&W & Niles & 17 bar & B\&W \\
\hline T91 & Y & & & & \\
T92 (NF616) & Y & Y & & & \\
T122 (HCM12A) & Y & & & & \\
FCVN (12Cr) & Y & & & Y & \\
NF709 & Y & & Y & Y & \\
SAVE25 & Y & Y & Y & Y & Y \\
310HCbN (HR3C) & Y & Y & Y & Y & Y \\
Haynes HR120 & Y & & Y & Y & \\
Inconel 740 & Y & Y & Y & Y & \\
Super304 & & & & Y & Y \\
HR6W & & & & Y & Y \\
CCA617 & & & & Y & Y \\
Haynes 230 & & & & Y & Y \\
Haynes 214 & & & & Y & Y \\
\hline
\end{tabular}

\section{Mass-Based Oxidation Kinetics at $700^{\circ} \mathrm{C}, 1.7 \mathrm{MPa}(250 \mathrm{psig})$}

The procedure used was to start with four specimens of each alloy; mass change data were measured at $500 \mathrm{~h}$ intervals, and one specimen of each alloy was removed at $1,000 \mathrm{~h}$ intervals for metallographic examination. Mass change data for the low- $\mathrm{Cr}$ alloys are summarized in Fig. 1 . While the progression with time was consistent for each alloy, both T91 and T92 exhibited much larger mass gains than did T122 and FCVN $(12 \% \mathrm{Cr})$ from the first $500 \mathrm{~h}$ exposure onward. The difference between the mass gain rates for T91 and T92, and those for T122 and FCVN, suggested that the nominally $12 \% \mathrm{Cr}$ alloys were forming a different, more protective scales. 
As shown later, T122 and FCVN initially formed protective scales, which accounted for the initially low mass gains and, with time, local breakdown of these scales occurred to form similar, iron oxide-based scales as those on T91 and T92. The random/discontinuous nature of this behavior is reflected in the mass changes of the individual specimens of T122 and FCVN, shown in Fig. 1. It would be logical to assume that the oxidation behavior of T91 and T92 followed the same sequence of events as T122--on that basis, it would appear that these two alloys transitioned to breakaway oxidation behavior in the first $500 \mathrm{~h}$ of exposure at $700^{\circ} \mathrm{C}$. Shorter exposures might be appropriate to confirm this.

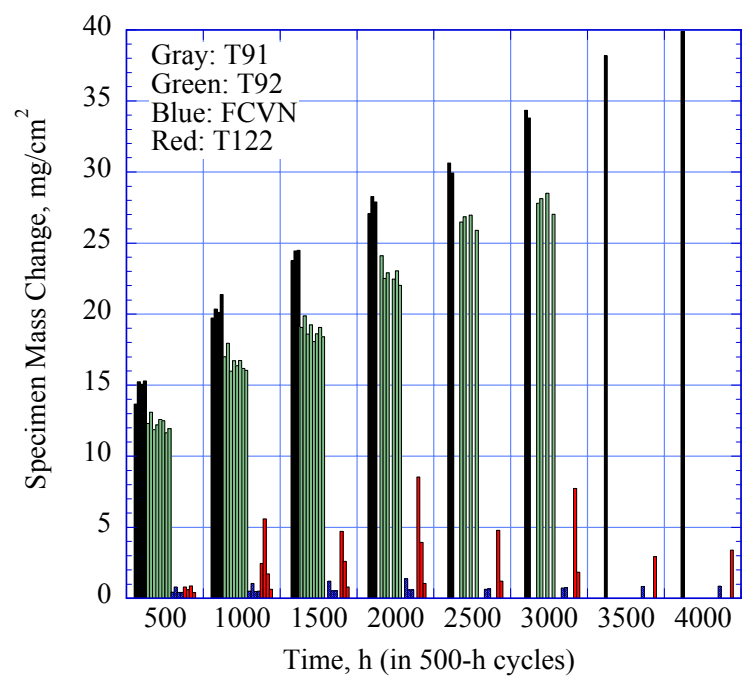

Figure 1. Mass gain data for multiple specimens of the low-Cr alloys exposed in steam at $1.7 \mathrm{MPa}$ and $700^{\circ} \mathrm{C}$

The comparison shown in Fig. 2 with data from similar tests elsewhere (COST522 Round Robin tests in $1 \mathrm{MPa}$ steam), indicates that the current data for $\mathrm{T92}$ at $700^{\circ} \mathrm{C}$ are consistent with previous observations. Note also the variability in results from seven different laboratories at $650^{\circ} \mathrm{C}$ (including $\mathrm{B} \& \mathrm{~W}$ data for the same alloy heat as the ORNL data). 


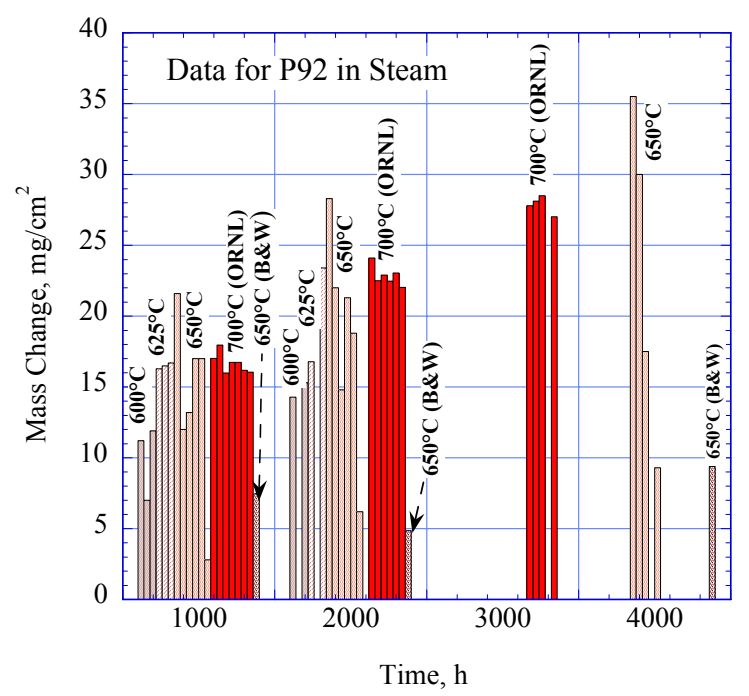

FIGURE 2. Mass gain data for Alloy P/T92 exposed in steam by different laboratories; includes data at $650^{\circ} \mathrm{C}$ from $\mathrm{B} \& W$, and at $700^{\circ} \mathrm{C}(1.7 \mathrm{MPa})$ from ORNL

Figure 3 is a summary of the mass gain data for the high-Cr alloys. The mass gains for each alloy increased monotonically with time, with some reduction in mass gain with decreasing $\mathrm{Cr}$ content, except for $310 \mathrm{HCbN}$, which had the highest $\mathrm{Cr}$ content (but also the highest mass gain). Since little, if any, scale spallation was observed for these high$\mathrm{Cr}$ alloys, the mass gain kinetics probably are a good indication of the rate of metal consumption; the time dependence was found to be parabolic, indicating diffusioncontrolled oxidation.

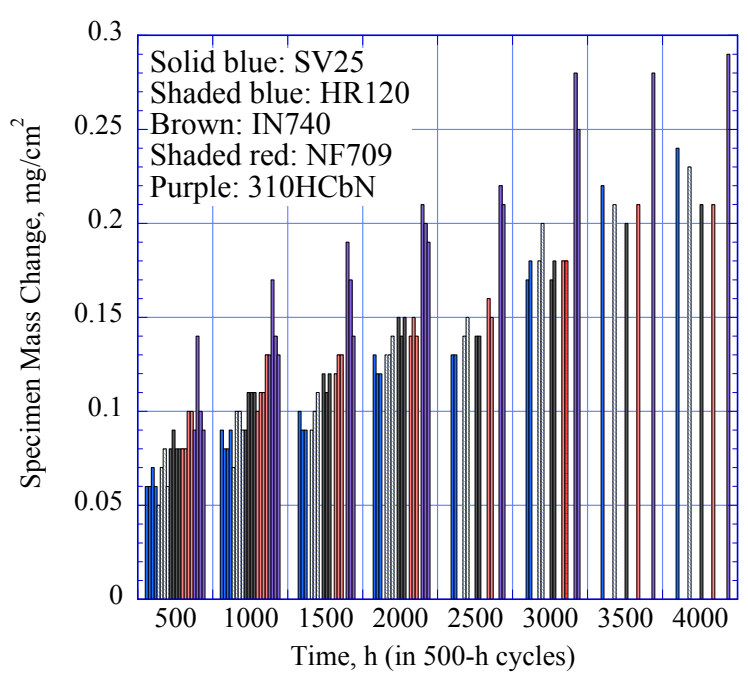

FIGURE 3. Mass gain data for multiple specimens of the high-Cr alloys exposed in steam at $1.7 \mathrm{MPa}$ and $700^{\circ} \mathrm{C}$ 
Table 2 lists the parabolic rate constants derived for each alloy. The benefit in terms of reduced oxidation rate for the $12 \% \mathrm{Cr}$ compared to the $9 \% \mathrm{Cr}$ alloys is clearly seen; FCVN exhibited the slowest oxidation rate of this group (before breakaway oxidation occurred). The rate constants for the austenitic alloys were all very similar, with $310 \mathrm{HCbN}$ showing the fastest rate. Comparison with the rate constant measured for PMCr, a CrFe- $\mathrm{Y}_{2} \mathrm{O}_{3}$ alloy that reliably forms a protective $\mathrm{Cr}_{2} \mathrm{O}_{3}$ scale, suggests that all the austenitic alloys (except, perhaps $310 \mathrm{HCbN}$ ) exhibited protective oxidation behavior that was based on rate control by the growth of and evaporation of $\mathrm{Cr}$ from a $\mathrm{Cr}_{2} \mathrm{O}_{3}$ based scale.

TABLE 2

Summary of Mass Change-Based Oxidation Kinetics

\begin{tabular}{llll}
\hline Alloy & $\mathrm{k}_{\mathrm{p}}, \mathrm{g}^{2} \mathrm{~cm}^{-4} \mathrm{~s}^{-1}$ & $\mathrm{R}^{2}$ & Comments \\
\hline T91 & $1.0 \times 10^{-10}$ & 0.994 & $0-4 \mathrm{kh}$ \\
T92 & $6.9 \times 10^{-11}$ & 0.985 & $0-3 \mathrm{kh}$ \\
T122 & $1.6-13.7 \times 10^{-13}$ & $0.837-0.975$ & before breakaway $(<2.5 \mathrm{kh})$ \\
FCVN & $4.7-26.0 \times 10^{-14}$ & $0.975-0.990$ & before breakaway \\
310HCbN & $5.9 \times 10^{-15}$ & 0.943 & $0-4 \mathrm{kh}$ \\
SAVE 25 & $3.4 \times 10^{-15}$ & 0.896 & $0-4 \mathrm{kh}$ \\
IN740 & $2.6 \times 10^{-15}$ & 0.953 & $0-4 \mathrm{kh}$ \\
NF709 & $2.6 \times 10^{-15}$ & 0.950 & $0-4 \mathrm{kh}$ \\
HR120 & $2.5 \times 10^{-15}$ & 0.922 & accelerated after 3kh? \\
PMCr & $3.1-3.8 \times 10^{-15}$ & $0.957-0.964$ & reliable $\mathrm{Cr}_{2} \mathrm{O}_{3}$-former \\
\hline
\end{tabular}

\section{Scale Morphologies Formed at $700^{\circ} \mathrm{C}$ in $1.7 \mathrm{MPa}$ Steam}

Figures 4a-d illustrate the thick, Fe-rich scales remaining on alloy T91 after 1,000, $2,000,3,000$, and 4,000h, respectively. However, the appearance of the scale morphology was not the expected uniform outer layer of magnetite (and possibly haematite), with an inner layer of Fe-Cr oxide. Instead, the 'outer' layer appeared to consist of at least two layers, apparently of the same oxide. The 'inner' layer was more obviously multilayered, and again all layers appeared to consist of the same oxide. There was evidence of cracks that penetrated through the thickness of the 'outer' layer (Fig. 4b), and that ran along or near the interface between the 'outer' and 'inner' layers (Fig. 4d). After 3,000h, it appeared that all of the 'outer' layer of scale had been lost prior to mounting and sectioning. 

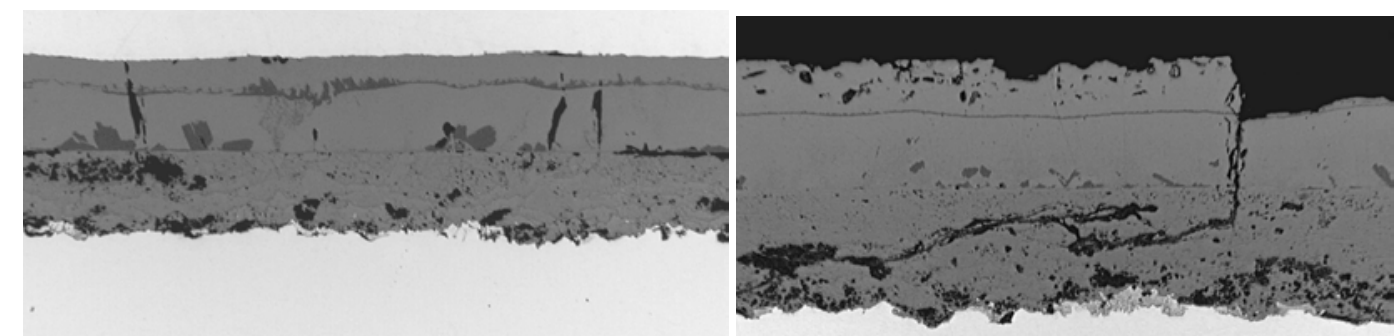

)
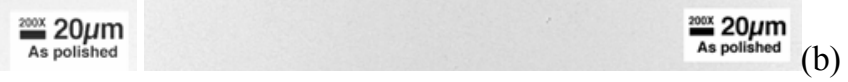

(c)
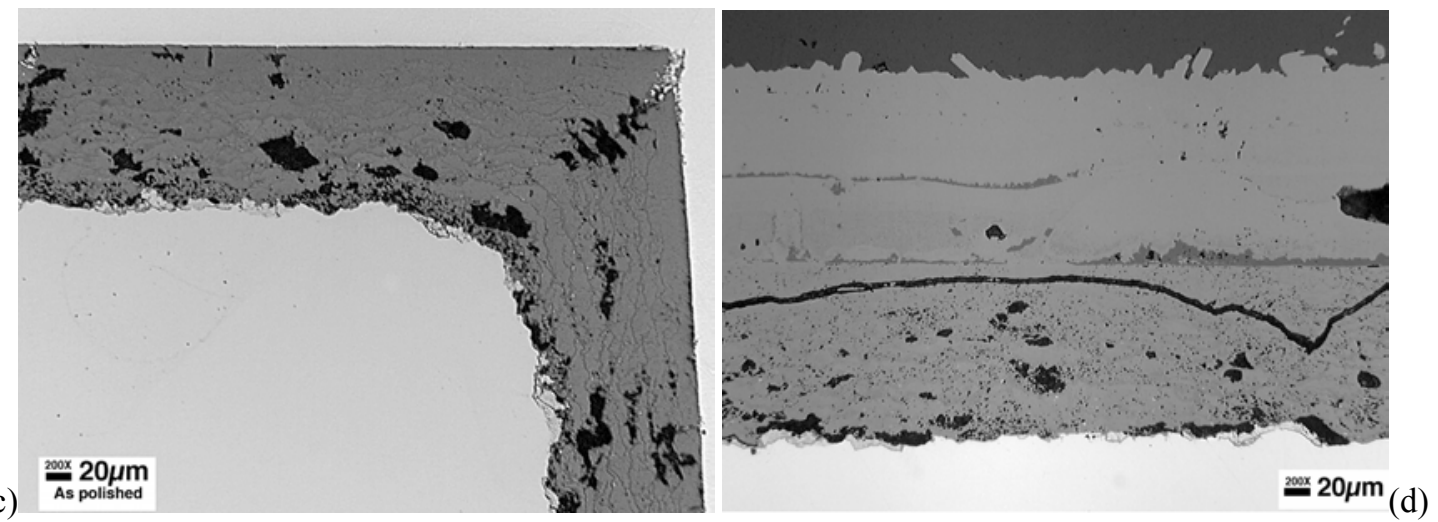

FIGURE 4. Cross sections of T91 after (a) 1,000h, showing multiple layers; (b) 2,000h, with scale cracking; (c) 3,000h, showing extensive loss of outer scale layer and cracking at corner; and (d) 4,000h, showing multiple layers and cracking.

The scale formed on Alloy T92 more closely resembled the expected morphologies, Fig. 5a-h, and was two-layered with an apparently single-phase outer layer, and an inner layer of $\mathrm{Fe}-\mathrm{Cr}$ oxide that exhibited multiple (though not uniform) layers that were $\mathrm{Cr}$-rich. The scale appeared to have remained attached to the alloy for all specimens examined (to $3,000 \mathrm{~h}$ ), although extensive cracking was present in the outer layer after 3,000h, with major cracks running along the interface between the major scale layers (Fig. 5h). Porosity and occasional through cracks were present in the scale after 1,500 and $2,000 \mathrm{~h}$ (Figs. 5c,e). Penetrations of $\mathrm{Cr}$-rich oxide, often encircling alloy grains immediately below the metal-oxide interface, indicated that the alloy $\mathrm{Cr}$ content was just insufficient to form a continuous, protective basal oxide layer. Incorporation of these incomplete $\mathrm{Cr}$-rich oxide layers into the encroaching overall inner oxide layer presumably resulted in the observed layered structure. Significant areas of the surface of alloy T-122 were covered by a thin, protective oxide, even after 4,000h, Fig. 6a,c,e. In other areas, a thick, two-layered scale was present, either as discrete nodules (Fig. $6 \mathrm{a}, \mathrm{c}, \mathrm{e}$ ) or as a continuous scale (Fig. 6c). The nodules appeared to be randomly distributed over the alloy surface, and not obviously associated with any alloy features. As in T92, where oxide penetration occurred along alloy grain boundaries near the 
metal-oxide interface, these penetrations were Cr-rich. In some cases, the outer oxide layer had spalled from the nodules (Fig. 6d). The presence of both protective and nonprotective forms of oxide indicates that the $\mathrm{Cr}$ content in the alloy is borderline for the formation of a continuous, protective external scale.
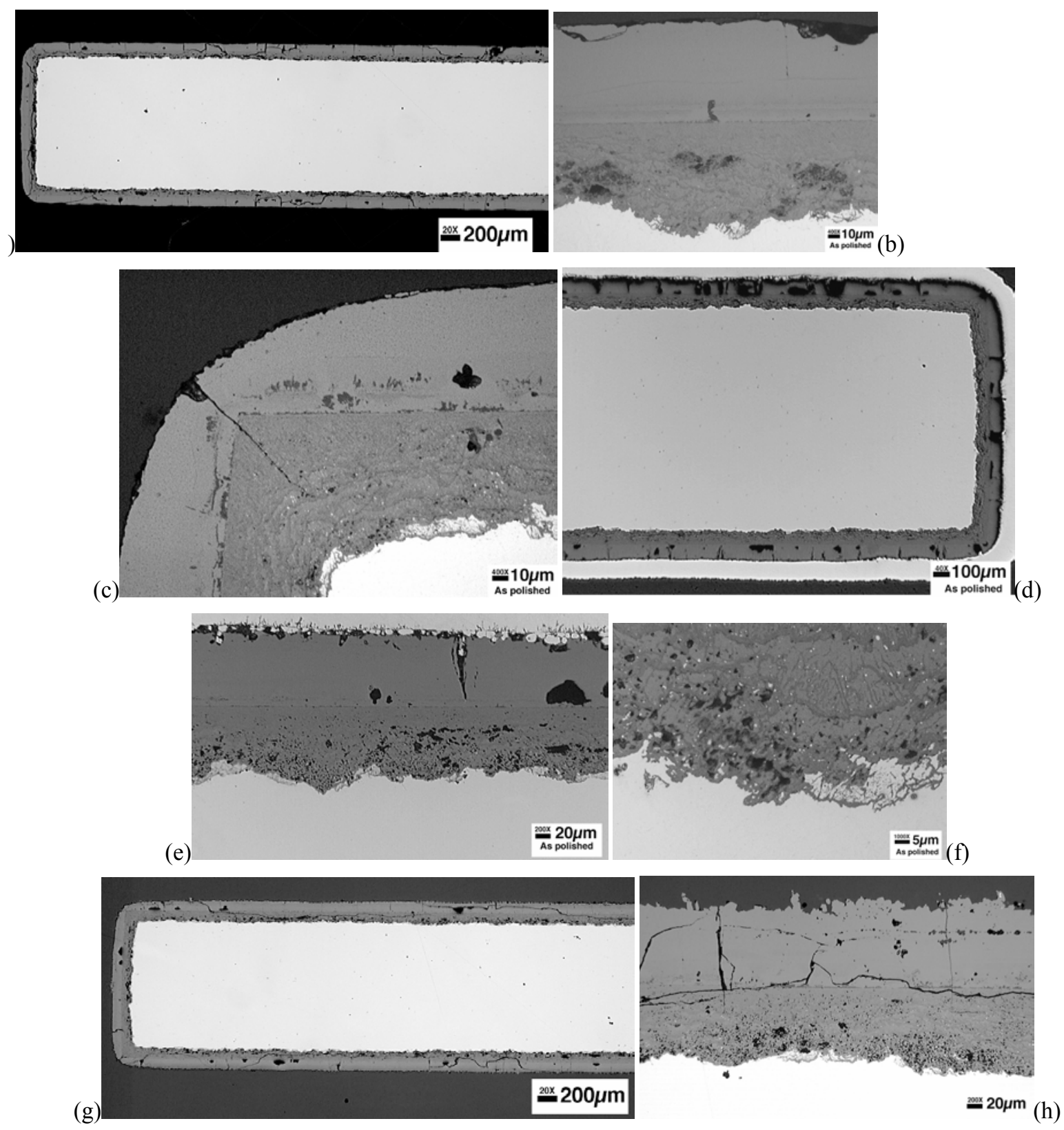

FIGURE 5. Cross sections of T92 after (a) 1,000h; (b) and (c) 1500h; (d)-(f) 2,000h; (g) and (h) $3,000 \mathrm{~h}$ at $700^{\circ} \mathrm{C}, 250 \mathrm{psi}$. 

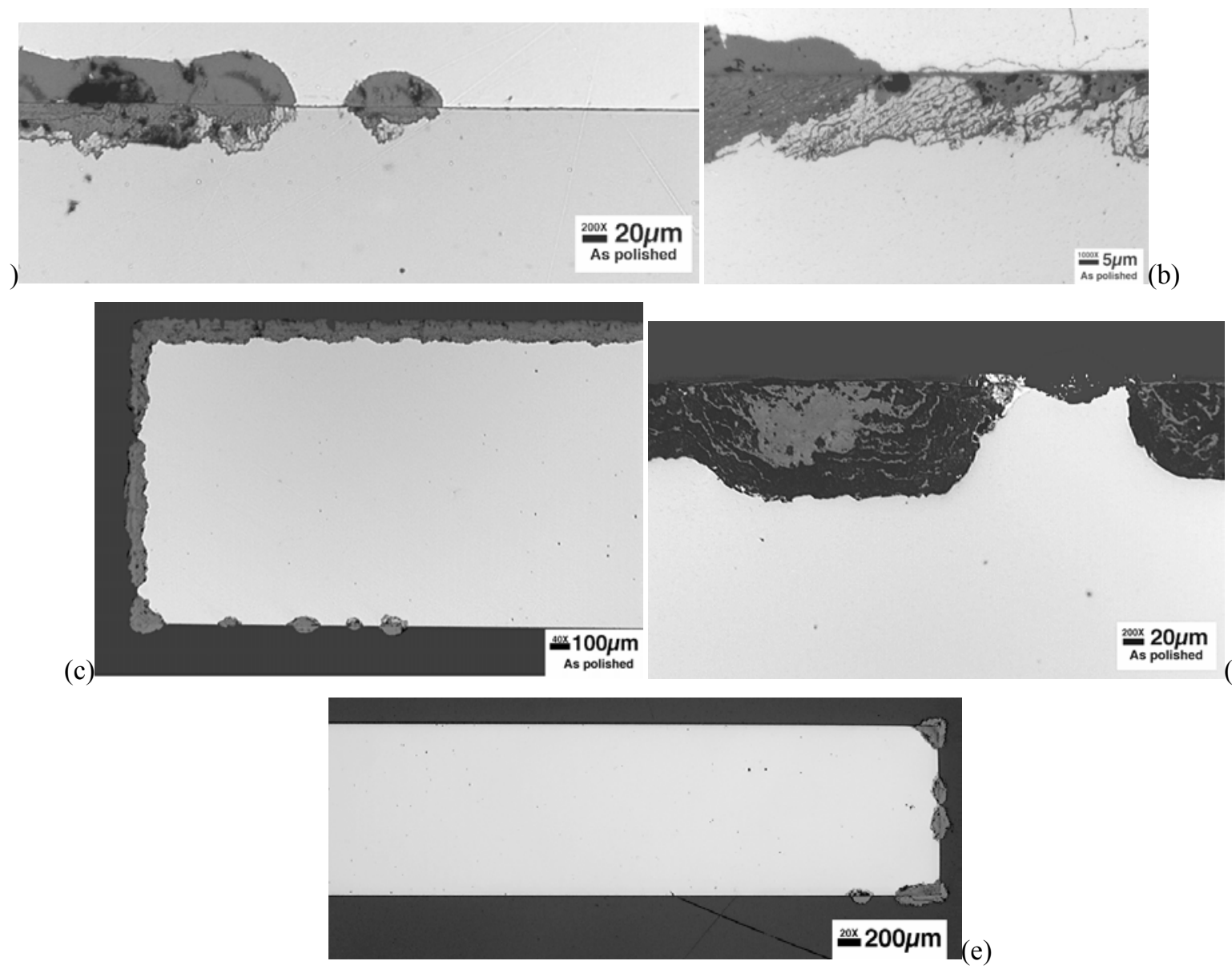

(d)

FIGURE 6. Cross sections of T122 after (a) and (b) 1,500h, showing nodule formation and spreading; (c) 2,000h, with 'breakaway oxidation of one side; (d) $3,000 \mathrm{~h}$, showing loss of external layer from nodules; and (e) $4,000 \mathrm{~h}$, with nodule formation only at one end.

The $12 \mathrm{Cr}$ alloy FCVN showed a significant improvement over T122 at $700^{\circ} \mathrm{C}$, Fig. 7 a-f. Like T122, this alloy apparently formed a thin, protective scale initially (as indicated by the early kinetics, Table 2) but, with time, nodules of Fe-rich scale developed. Even after $4,000 \mathrm{~h}$, the majority of the alloy surface was covered by a thin, protective scale (Fig. 7b), with an occasional nodule (Fig. 7e). Compared to T122, there were fewer (and smaller) such nodules on FCVN at all times.

The scales formed on the high-Cr alloys after 1,000-4,000h were too thin to resolve sufficiently to make meaningful observations with optical microscopy. However, features such as nodule formation and internal penetration were readily resolved; these are recorded in Table 3, which summarizes the metallographic measurements. 

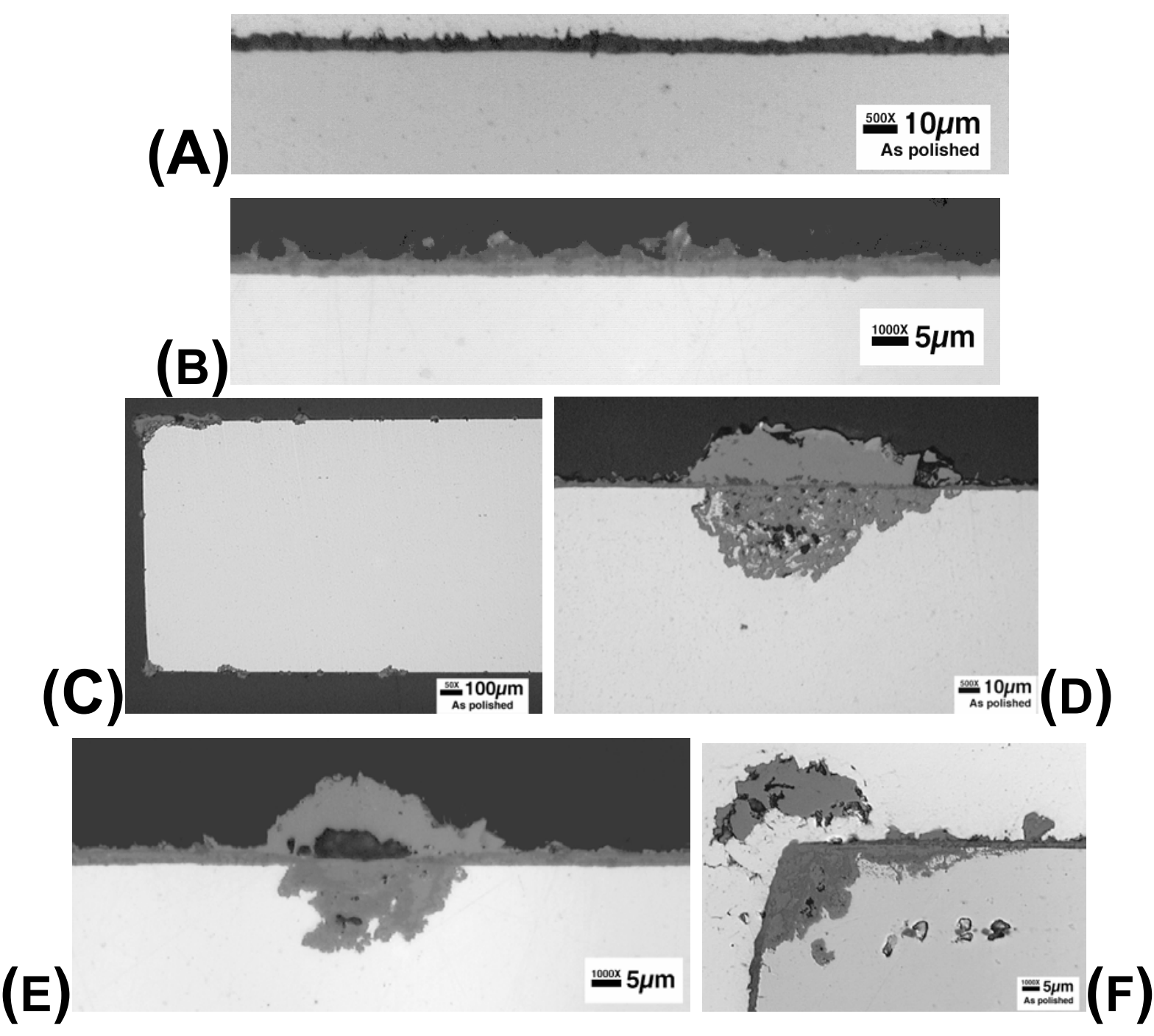

FIGURE 7. Cross sections of FCVN (12\%Cr, Alstom) after (a) 1,000h; (b) 4,000h; (c) and (d) $2,000 \mathrm{~h}$; (e) $4,000 \mathrm{~h}$; and (f) $3,000 \mathrm{~h}$ in steam at 17 bar and $700^{\circ} \mathrm{C}$.

\section{Metal Thickness Loss-Based Oxidation Kinetics at $700^{\circ} \mathrm{C}$, in 17 bar Steam.}

Figure 8 defines the post-test measurements made on metallographically-prepared cross sections. The maximum metal loss due to surface recession, and the maximum depth of penetration of oxidation-related features were recorded, and used to compute the maximum metal loss (= maximum uniform loss + maximum depth of penetration). The resulting measurements produced four data sets for each alloy that had been oxidized to 4,000h. These data were plotted on linear and parabolic axes, and the best fits to the data were computed. Examples of parabolic fits to the data for T91 and NF709 are illustrated in Fig. 9. From these rate data, the maximum metal thickness 
loss due to oxidation for one year was computed to provide a basis for comparison; these results are shown in Table 3 . Note that the bests fits to the data sets for HR120 and IN740 were linear; extrapolations based on both linear and parabolic fits for IN740 are shown. Also note that the large value for internal penetration for T122 refers to the situation before the oxidation behavior was dominated by the formation of thick iron oxide-based scales; in locations where a few 'breakaway' nodules were formed while most of the scale was thin and protective, the nodules were classified by the measurement procedure used as 'internal penetration.' Overall, the oxidation rates of the 9 to $12 \% \mathrm{Cr}$ alloys appeared to be unacceptably fast at this temperature, while those of the high-Cr alloys would be considered acceptable.

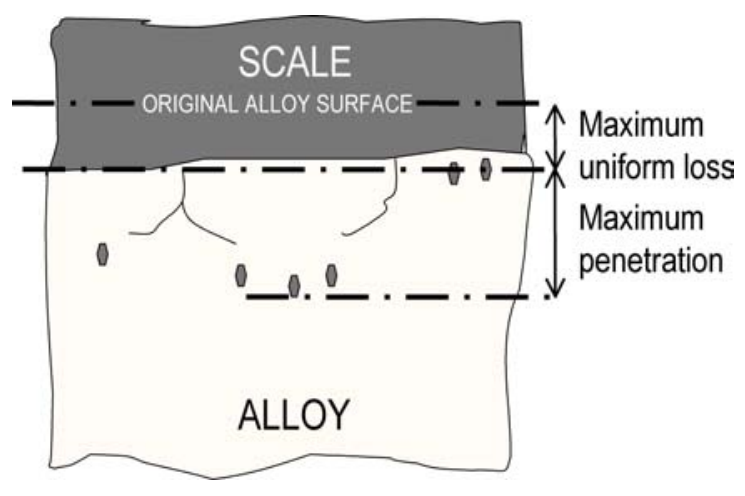

FIGURE 8. Schematic diagram showing metallographic measurements made on cross sections of oxidized specimens.

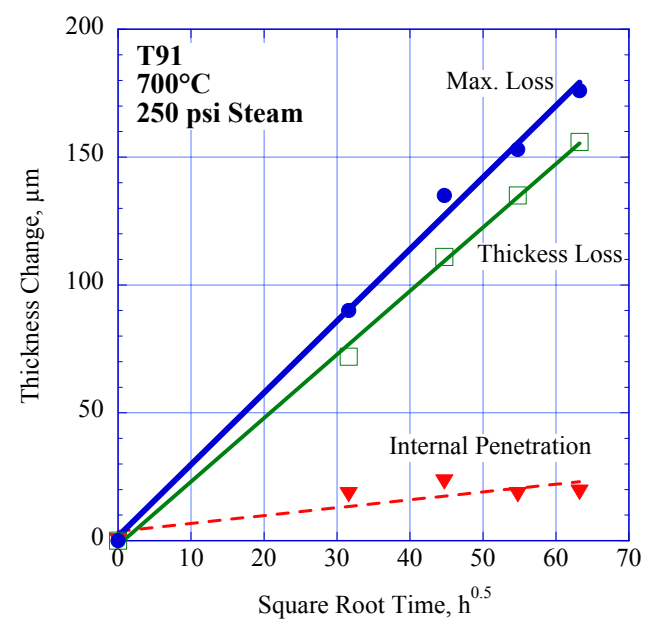

(a)

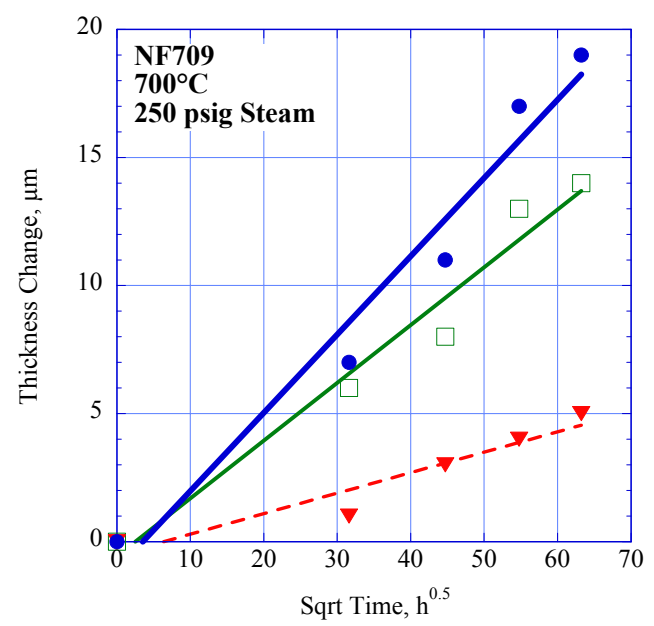

(B)

FIGURE 9. Examples of the metal thickness-based kinetics for (a) T91, and

(b) NF709 
TABLE 3.

Summary of Metal Thickness Change-Based Oxidation Kinetics (Total metal loss = max. uniform loss + max. penetration)

\begin{tabular}{lccccl}
\hline \multicolumn{1}{c}{ Alloy } & \multicolumn{5}{c}{ Metal Loss (mils in 1 yr) } \\
\\
& Rate law & Total & Uniform & Penetration & Comments \\
\hline T91 & parabolic & 10.3 & 9.2 & 1.1 & \\
T92 & parabolic & 6.2 & 5.0 & 1.2 & \\
T122 & parabolic & 9.4 & 1.9 & 7.4 & \\
$310 H C b N$ & parabolic & 0.8 & 0.2 & 0.6 & \\
HR120 & linear & 3.1 & 2.3 & 0.5 (parab) & overall best fit is linear \\
SAVE 25 & parabolic & 1.2 & 0.7 & 0.5 & \\
NF709 & parabolic & 1.1 & 0.8 & 0.3 & \\
IN740 & parabolic & 3.4 & 1.8 & 0.8 & Data are equally well represented by \\
& & & & & parabolic and linear fits \\
\hline
\end{tabular}

Figure 10 compares the total mass gain with the measured scale thicknesses for the T91 and T92. With one exception, there was good correlation of scale thickness to measured mass gain for T92, suggesting that the scale had remained adherent; the slope of the fit indicated a nominal scaledensity of $4.0 \mathrm{gcm}^{-3}$, suggesting that the scale contained approximately $23 \%$ porosity. Figure 10 also includes the fit to similar data for T92 oxidized in steam at $700^{\circ} \mathrm{C}$ and 1 bar (from the European COST program); those results suggest a scale density of $4.0 \mathrm{gcm}^{-3}$, and a porosity level of $30 \%$. Of the four data points for T91 shown in Fig. 10, only two are in reasonable agreement with the correlation for T92. The other two data points exhibited a higher mass gain that would correspond to the thickness of the remaining scale, indicating significant scale spallation during the test.

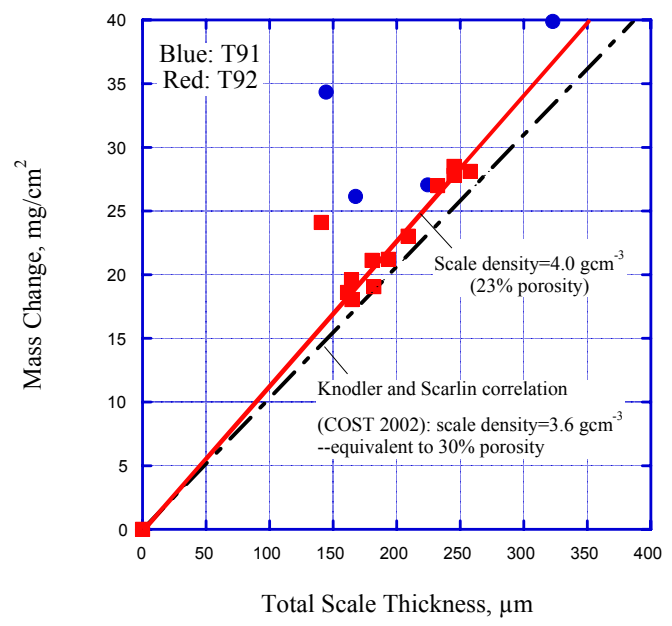

Figure 10. Plot to indicate scale spallation tendencies of T91 and T92 


\section{Mass-Based Oxidation Kinetics at $800^{\circ} \mathrm{C}$ in $17 \mathrm{MPa}$ Steam.}

The mass gains measured to 2,000h for specimens exposed in steam at 17 bar and $800^{\circ} \mathrm{C}$ are shown in Fig. 11. Comparison with the data for $700^{\circ} \mathrm{C}$ shown in Fig. 3 indicates a significant increase in mass gain for all alloys at the higher temperature.

The main candidates for service at $760^{\circ} \mathrm{C}$ exhibited the highest mass gains of the high$\mathrm{Cr}$ alloys at $800^{\circ} \mathrm{C}$, with those for IN740 being slightly lower than those for CCA617 (Figs $11 \mathrm{a}$ and b). Some reversal in alloy ranking compared to $700^{\circ} \mathrm{C}$ also is evident: compare, for instance, SAVE25 with $310 \mathrm{HCbN}$. There was little obvious scale spallation from most alloys, whereas the mass change behavior of Super 304 was dominated by scale loss, as shown in Fig. 11c. The $12 \% \mathrm{Cr}$ alloy, FCVN, exhibited rapid oxidation at $800^{\circ} \mathrm{C}$ (Fig. 11c), as expected. Metallographic measurements for the 1,000 and 2,000h specimens are currently being made.

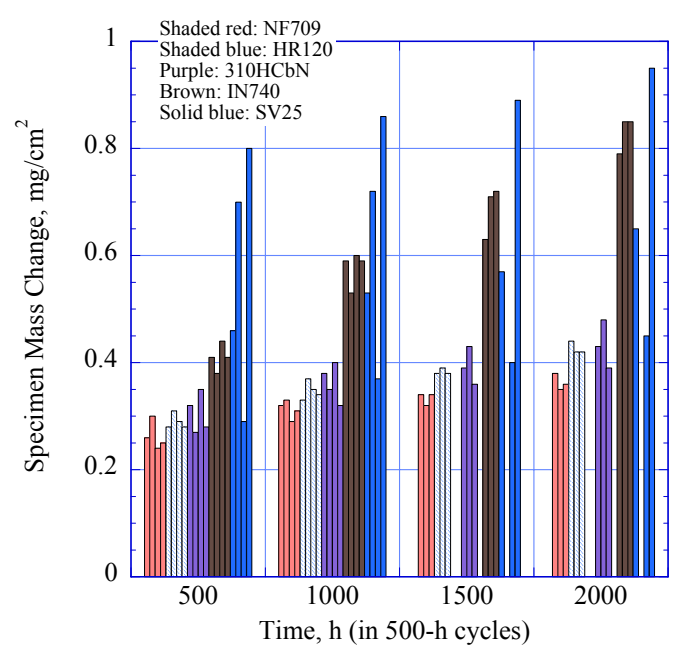

(a)

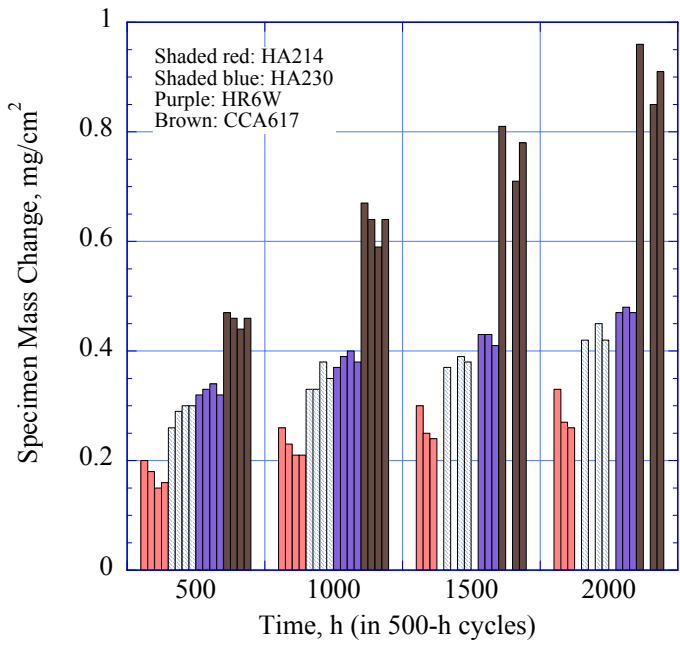

(b)

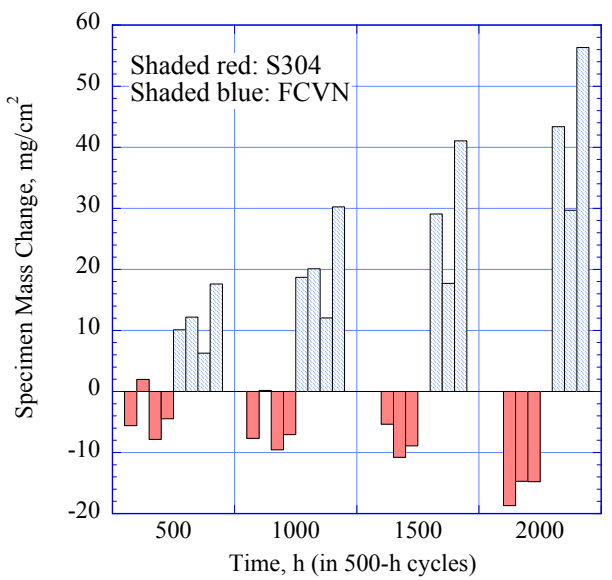

(c)

FIGURE 11. Mass gain data for multiple specimens of alloys exposed in steam at 17 bar and $800^{\circ} \mathrm{C}$ 


\section{Task 4 \\ Fireside Corrosion \\ (Foster Wheeler)}

The objective of the task is to evaluate the relative resistance of various advanced alloys for waterwall and reheater/superheater construction to fireside corrosion over the full temperature range expected for the USC plant. The corrosive environment promoted by three different coals, representative of an eastern coal, a midwestern coal, and a western coal, will be evaluated.

\section{Task 4A: Laboratory Testing}

\section{Objectives}

The objective of this sub-task is to perform laboratory corrosion tests on the candidate alloys. This will be accomplished by exposing metal coupons to various deposits and flue gases representative of three coals (e.g., eastern, Midwestern, and western) at the range of temperatures expected for the USC plant.

\section{Experimental Progress}

The 1000-hour exposure for the first series of laboratory testing was completed. The test temperatures were $850^{\circ} \mathrm{F}$ for waterwall conditions and $1200^{\circ} \mathrm{F}$ for superheater/reheater conditions. (Note: The deposit and flue gas compositions, representing eastern, midwestern, and western fuels, used in the tests were reported in the January - March Quarterly report.) The second series of testing, which is being performed at $975^{\circ} \mathrm{F}$ for waterwall conditions and $1500^{\circ} \mathrm{F}$ for superheater/reheater conditions, also commenced. At the end of the quarter, 600 hours of testing in this series was completed.

The post test analysis of the $850^{\circ} \mathrm{F}$ waterwall and $1200^{\circ} \mathrm{F}$ superheater/reheater specimens was started. The preliminary results of the Total Metal Wastage (wall loss plus subsurface penetration) of the superheater/reheater specimens in 1000 hours are shown in Figure 1. Preliminary comments are:

- As expected for each material, the specimens tested under the midwestern deposit/flue gas conditions exhibited the highest wastage, whereas those tested under the western deposit/flue gas conditions suffered the least wastage.

- For the wrought alloys, the wastage decreased as the chromium level increased.

- For wrought alloys containing 22 to $27 \mathrm{Cr}$, the wastage was essentially similar provided that the nickel level was less than 50-percent. 


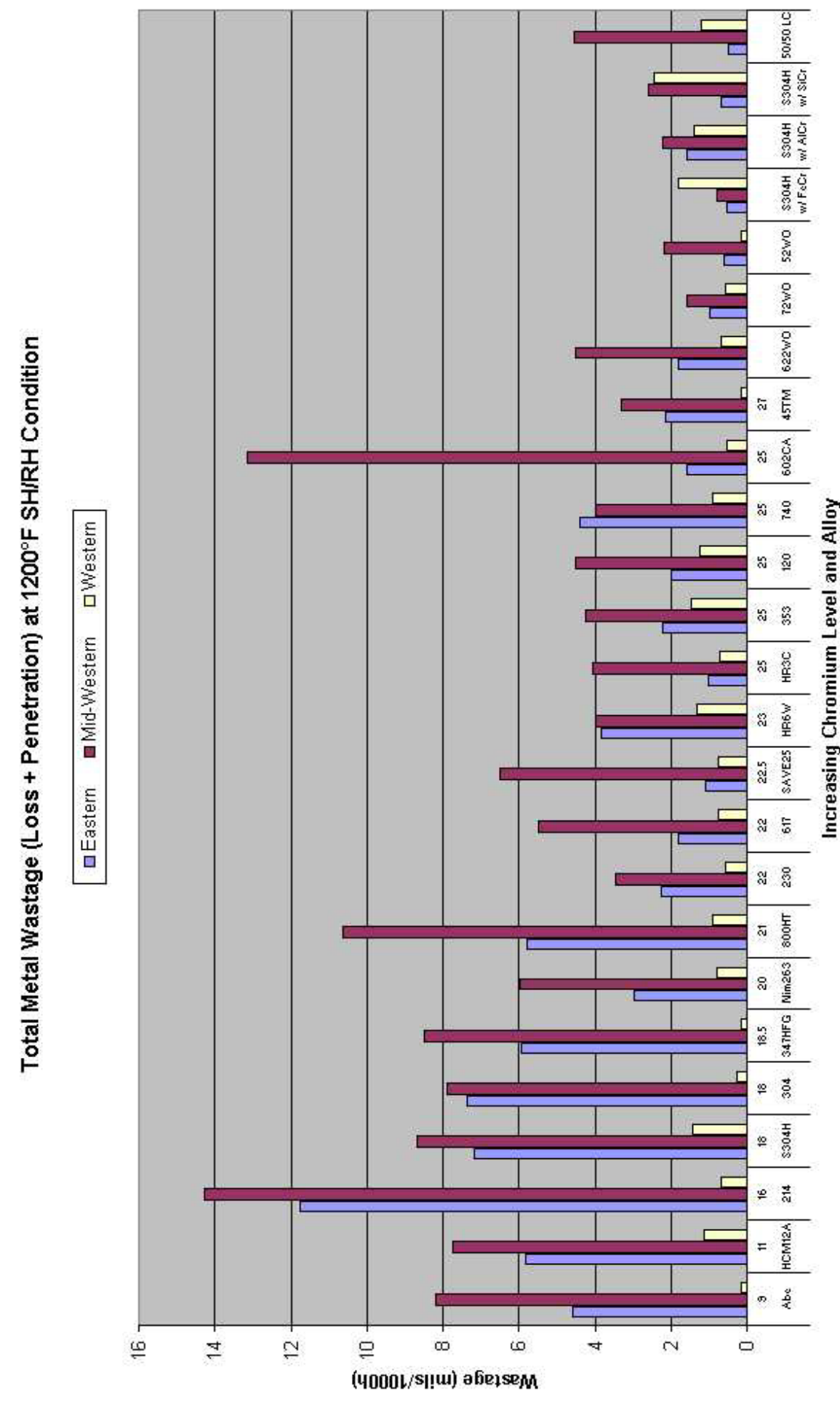

Figure 1: The preliminary results of the Total Metal Wastage (wall loss plus subsurface penetration) of the $1200^{\circ} \mathrm{F}$ superheater/reheater specimens in 1000 hours are shown 
- High nickel alloys 214 (76Ni) and 602CA (63Ni) suffered appreciable attack, particularly under the midwestern conditions.

- The two ferritic alloys, Abe and HCM12A, exhibited comparable results to the $18 \mathrm{Cr}$ austenitic alloys.

- Of the weld overlays, 52 (typically $28 \mathrm{Cr}$ ) and 72 (typically $42 \mathrm{Cr}$ ) performed better than 622 (typically $21 \mathrm{Cr}$ ). Further, the 52 and 72 were better than the wrought alloys, while the 622 did not offer any significant improvement over wrought alloys in the 22 $-27 \mathrm{Cr}$ range.

- With regard to the diffusion coatings, they exhibited less wastage than the wrought alloys and were comparable to the weld overlays. There appeared to be a slight loss of coating thickness in all three coatings tested under the midwestern conditions, whereas the specimens tested under the eastern and western conditions experienced primarily subsurface penetration.

The post test analysis of the waterwall specimens is still ongoing.

Insofar as the second series of laboratory testing, control specimens of 740,230 , and HR3C material in the superheater/reheater furnaces testing midwestern and western fuels were evaluated after 500 hours. Photomicrographs of the specimens are shown in Figures 2 (midwestern conditions) and 3 (western conditions). Similar to the $1200^{\circ} \mathrm{F}$ tests, the midwestern conditions promoted more corrosion than the western conditions. Of the three alloys, HR3C exhibited the least wastage and 230 the most wastage under the midwestern conditions, while all three alloys exhibited essentially similar results (mild pitting) under western conditions.

\section{Concerns}

No concerns at this time.

\section{Plans for Next Quarter}

- Finish 1000 -hour cycle at $950^{\circ} \mathrm{F}$ for waterwall samples and $1500^{\circ} \mathrm{F}$ for reheater/superheater samples.

- Finish analyzing specimens from first 1000-hour cycle and start analyzing specimens from the second 1000-hour cycle.

- Start third 1000 -hour test cycle $\left(1100^{\circ} \mathrm{F}\right.$ for waterwall and temperature for sh/rh to be determined) 


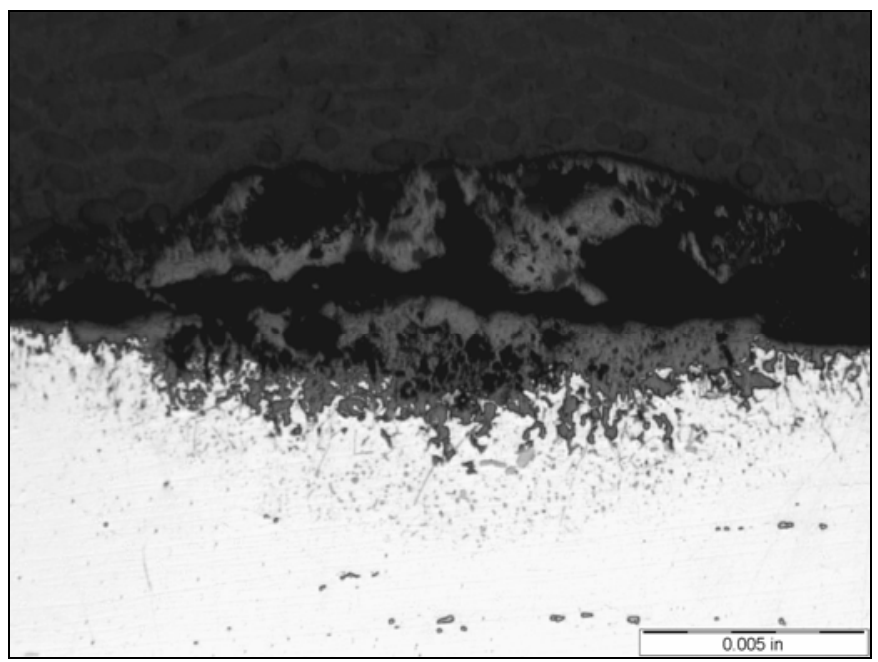

740

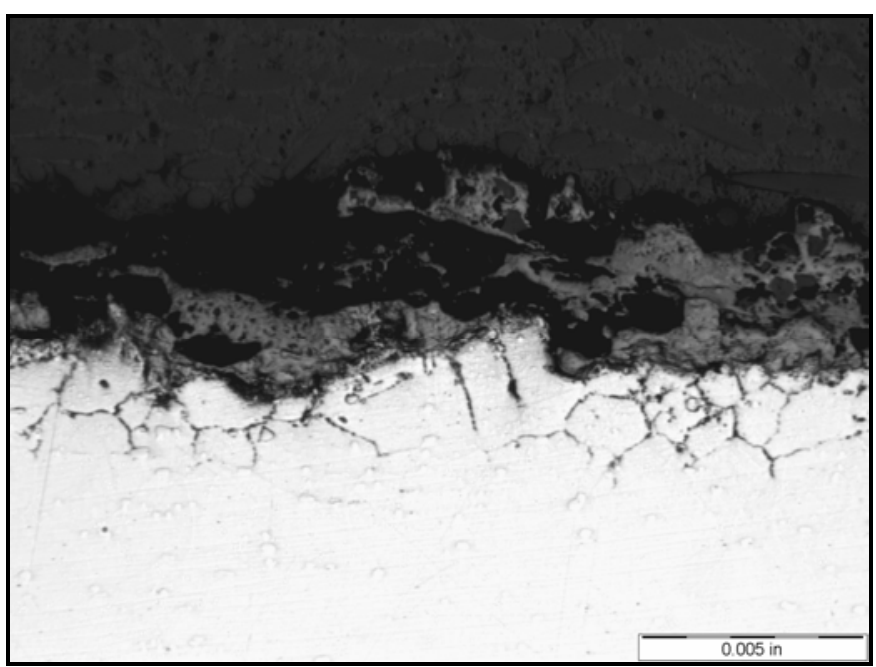

230

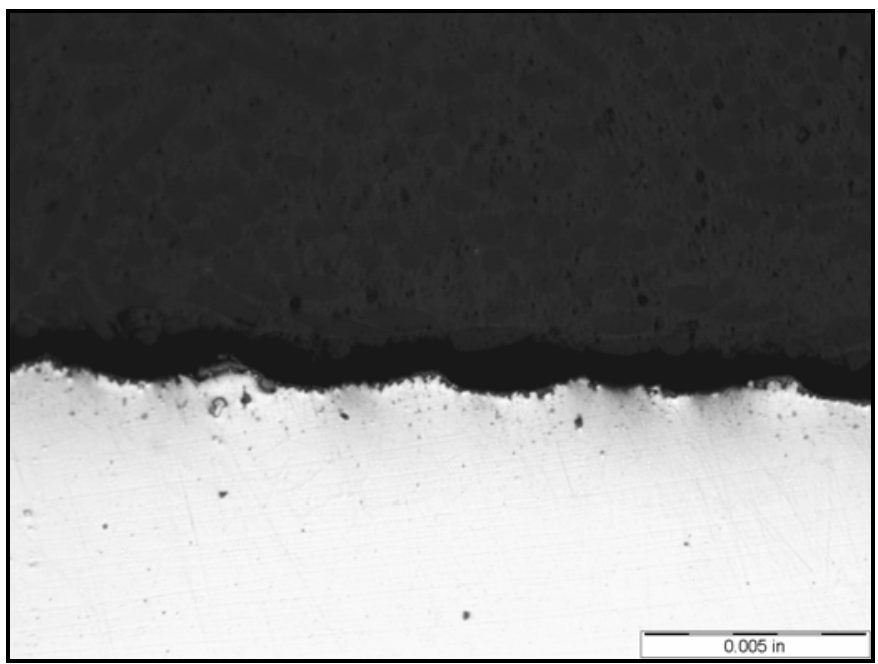

HR3C

Figure 2: The appearance of the three control samples after being exposed to 500 hours under the midwestern conditions is shown 


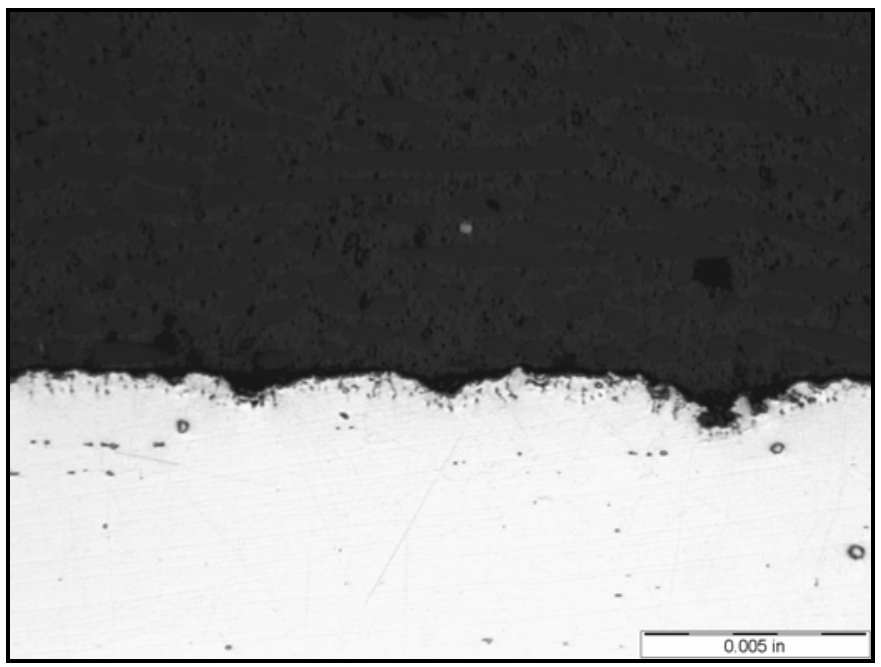

740

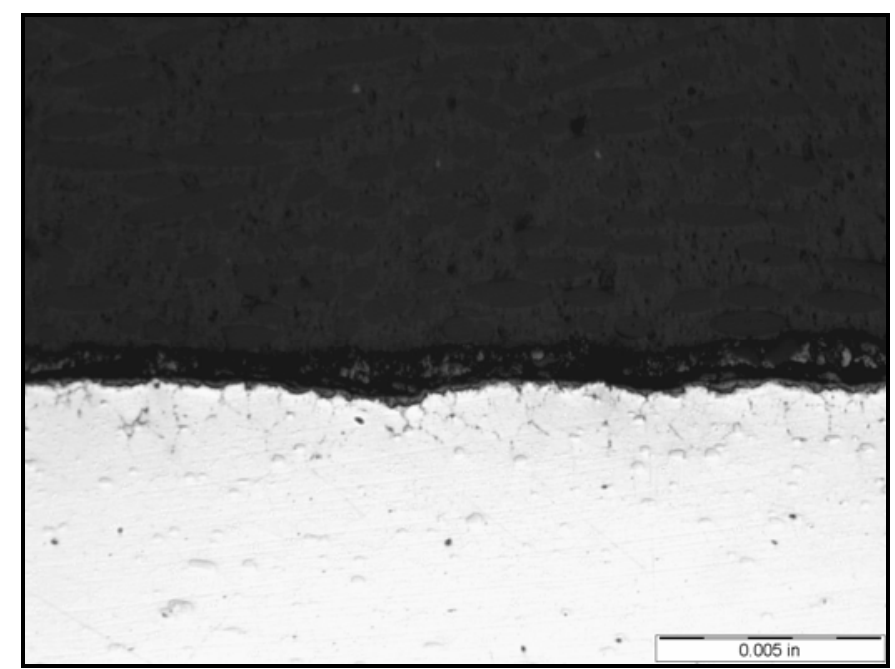

230

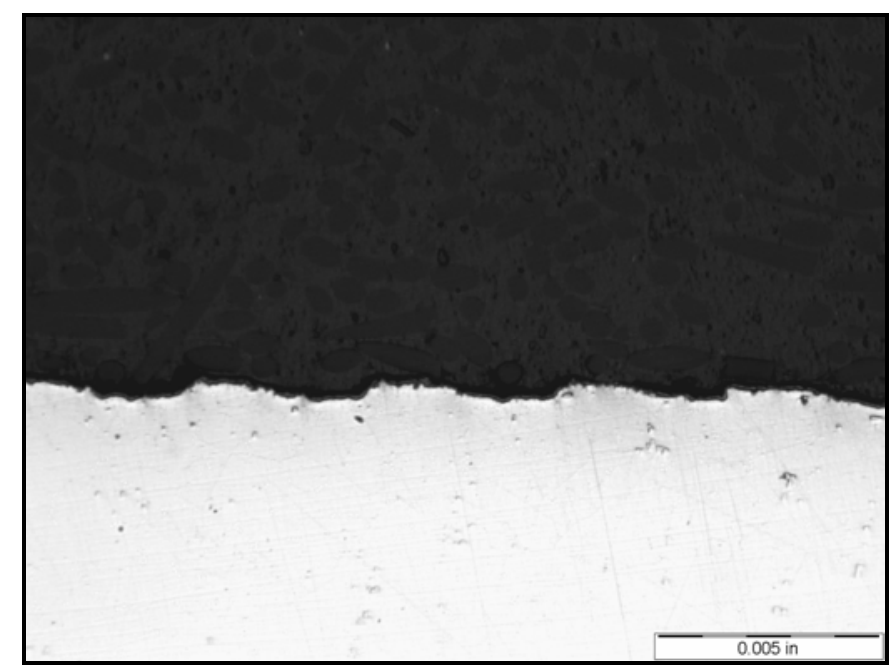

HR3C

Figure 3: The appearance of the three control samples after being exposed to 500 hours under the western conditions is shown 


\section{Task 4B Corrosion Probe Testing in Utility Boilers}

\section{Objective}

The objective of this sub-task is to install corrosion probes comprised of various alloys/coatings/weld overlays at three coal-fired power plants and control them in the temperature range expected for reheater/superheater components in the USC plant. The plants should burn coals representative of the three types specified earlier.

\section{Experimental Progress}

- Funding issues pertaining to this task were resolved by moving forward funds allocated to future work. Funding is currently available to fabricate and install corrosion probes at two coal-fired plants during 2004. The two plants that were selected for the initial installations were Cinergy Gibson Generating Station (Indiana) and Xcel Energy Pawnee Station (Colorado). Gibson is firing a high-sulfur Farmersburg coal, while Pawnee is firing a low-sulfur Eagle Butte coal.

- Mechanical design of the probe retraction mechanism was completed. An illustration of the retraction mechanism is shown in Figure 4. Procurement of equipment required in order to construct the retraction mechanisms is under way. Assembly of retraction mechanism components will begin shortly.

- Data acquisition and control software for use at two host utilities was purchased. Implementation of the instrumentation and controls systems of the probe retraction mechanism has started.

- A list of tube materials for probe samples, shown in Table 1, was prepared and circulated among the steering committee members to finalize the probe material selection. Comments were received and incorporated to refine material selection. Most of the probe materials have been procured. Discussions with B\&W and Alstom took place regarding the weld overlay and coated samples. Work continues to finalize the corrosion probe assembly arrangement to accommodate the final material samples.

\section{Concerns}

No concerns at this time.

\section{Plans for Next Quarter}

- Purchase remaining components for probe retraction mechanisms.

- Fabricate probe retraction mechanisms.

- Continue work on the instrumentation and controls systems. 
- Finalize corrosion probe material list, including the weld overlay and coated samples.

- Complete probe design, incorporating final materials list.

- Construct the probes, with supports and instrumentation

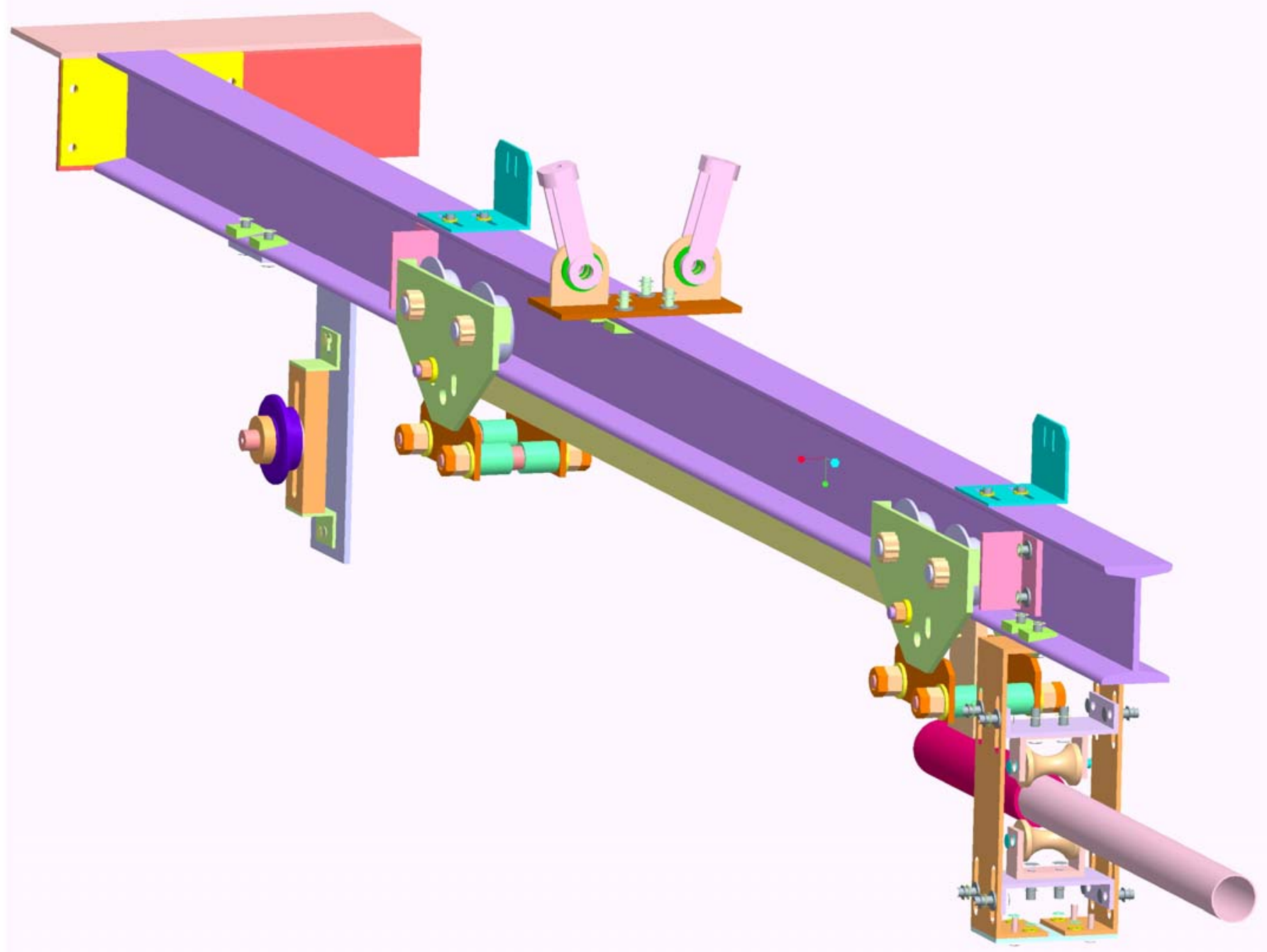

Figure 4. Illustration of corrosion probe retraction mechanism 
Table 1

Probe Material List

\begin{tabular}{|l|l|l|l|l|l|l|l|l|l|l|l|}
\hline Material & $\mathrm{Cr}$ & $\mathrm{Ni}$ & $\mathrm{Co}$ & $\mathrm{Fe}$ & $\mathrm{Mo}$ & $\mathrm{W}$ & $\mathrm{Nb}$ & $\mathrm{Si}$ & $\mathrm{Al}$ & $\mathrm{Cu}$ & $\mathrm{Ti}$ \\
\hline Super 304H & 18 & 9 & & 68 & & & 0.4 & 0.23 & & 3 & \\
\hline 347 HFG & 18.5 & 11 & & 67 & & & 0.8 & 0.5 & & & \\
\hline & & & & & & & & & & & \\
\hline 800HT & 21 & 31 & & 45 & & & & 0.4 & 0.3 & & 0.6 \\
\hline NF709 & 22 & 25 & & 48 & 1.5 & & 0.25 & & & & $<0.2$ \\
\hline Sanicro 25 & 22 & 25 & 1.5 & 42 & & 3.5 & 0.5 & 0.2 & & 3.0 & \\
\hline CCA 617 & 22 & 52 & 12.5 & $<3$ & 9.0 & & & $<1.0$ & 1.2 & $<0.5$ & 0.6 \\
\hline 230 & 22 & 48 & $<5$ & $<3$ & 2.0 & 14 & & 0.5 & 0.35 & & \\
\hline SAVE 25 & 22.5 & 18.5 & & 50 & & 1.8 & 0.45 & $<1.5$ & & & \\
\hline HR6W & 23 & 40 & & 25 & & 6 & $<0.2$ & $<1.0$ & & & $<0.2$ \\
\hline HR3C & 25 & 20 & & 51 & & & 0.4 & $<0.75$ & & & \\
\hline 740 & 25 & 48 & 20 & 0.7 & 0.5 & & 2 & 0.5 & 0.9 & & 1.8 \\
\hline HR120 & 25 & 37 & 3 & 35 & 2.5 & & 0.7 & 0.6 & 0.1 & & 0.1 \\
\hline & & & & & & & & & & & \\
\hline 45TM & 27 & 46 & & 23 & & & & 2.8 & & & \\
\hline Sanicro 28 & 27 & 31 & & 35 & 3.5 & & & 0.2 & & 1.0 & \\
\hline AC66 & 27 & 32 & & 39 & & & 0.8 & 0.2 & & & \\
\hline 690 & 29 & 62 & & 9 & & & & & & & \\
\hline 33 & 33 & 31 & & 32 & 1.4 & & & 0.3 & & 0.6 & \\
\hline
\end{tabular}

\section{Task 4C Steam Loop Design, Construction, and Testing}

\section{Objectives}

The objectives of this sub-task are to design, build, and test two experimental USC steam loops that will operate in a commercial boiler at metal temperatures up to $1400^{\circ} \mathrm{F}$. The elements of this subtask include the following:

- Design and construct two test loops using commercially-available, high-temperature corrosion-resistant alloys selected for the USC Plant.

- Install and operate the test loops at the Reliant Electric power plant, located in Niles, $\mathrm{OH}$ and burning high sulfur Ohio coal, and at another utility. 
- Test and monitor the relative performance of the USC tube alloys, coatings, claddings, and weld overlays, which comprise the test loops for a period of 18 to 24 months.

\section{Experimental Progress}

With regard to the test loop at the Reliant Plant:

- The two steam loops were installed in the unit - materials in the loop include 230, 740, CCA617, HR6W, Super 304H, RA333, Save12, and weld overlays 52, 72, and 622.

- The unit was restarted December 21, 2003. Steam loop has operated for the first five months at metal temperatures below the maximum target temperature of $1400^{\circ} \mathrm{F}$. Modifications of the thermocouples on the outlet tubes was required to bring metal temperatures up to the target range.

- In May, the thermocouples on Sections A and B were replaced and the unit restarted. The controls were tuned and released, and the maximum metal temperature of the sections was in the $1325^{\circ}-1350^{\circ} \mathrm{F}$ range. As a result of over-fire air (for ozone control) and the cooler gas temperature at the furnace exit, the maximum target temperature of the sections may be difficult to obtain until September when the ozone restriction is lifted. (If there are no major problems with the loop after the18 month exposure period, consideration may be given to extend the exposure time to achieve an 18 month period at the maximum target temperature.)

With regard to the second host site:

- Negotiations with Dairyland Power were discontinued in the first quarter.

- A host site proposal was sent to Basin Electric in April and, as of the end of June, no reply has been received.

- No other potential host sites have been identified.

\section{Concerns}

- Due to the use of over-fired air for ozone control at the Niles Plant, the maximum target metal temperature may not be achieved until September.

- Securing another utility for the second steam loop 


\section{Plans for Next Quarter}

- Monitor operation and maintain data acquisition of the steam loop at the Niles Plant.

- Come to some resolution concerning the installation of a steam loop at a second utility. 


\section{Task 5 \\ Welding Development \\ (Alstom)}

\section{Objectives}

The major objectives for Task 5: Welding Development are:

- To define weld metal choices for candidate materials.

- To establish acceptable welding procedures and practices.

- To evaluate the effects of manufacturing heat treatments and preheat and post weld heat treatments on weldment integrity and properties.

- To produce samples needed to determine the properties of candidate ultrasupercritical alloy welds and weldments, including the dissimilar metal weld joints between the various types of material (the actual mechanical and property testing will be performed under Task 2).

These objectives will be accomplished through execution of five sub-tasks. Where activity on these sub-tasks occurred during the reporting period, it is described below.

\section{Task 5A: Selection of Weld Filler Material}

\section{Objectives}

The primary objective of this subtask is to select and procure appropriate filler materials for each of the welding processes to be studied. However, procurement of base materials and general planning of task activities are also included.

\section{Progress for the Quarter}

- In spite of earlier information to the contrary, Sumitomo stated that they have no special filler metal for gas metal arc welding of Super $304 \mathrm{H}$.

- Matching composition electrodes and flux core wire for welding the SAVE 12 material were received.

\section{Concerns}

The following concerns have been expressed before and are not new. 
- Base material sourcing difficulties and long delivery times have, in some cases, delayed the start of welding activities by 9 to 12 months.

- The unexpectedly high cost of the nickel base alloys will cause the material budgets to be exceeded and might result in program cost overruns and/or reductions in program scope.

\section{Plans for the Next Quarter}

None, the subtask is complete.

\section{Task 5B: Optimization of Weld Parameters}

\section{Objectives}

The primary objectives of this subtask are to establish the baseline welding parameter values for each material/process/product form combination being studied. Included is the development of preheat and post weld heat treatment requirements.

\section{Progress for the Quarter}

\section{SAVE 12:}

- $\quad$ The remainder of the tubes (2-inch OD X 0.4-inch MWT X 34-inch length) were machined from heavy wall pipe to produce a smaller tubular product form for welding trials.

- A weld qualification using Grade 92 filler, as recommended by Sumitomo, was attempted on 2-inch OD X 0.4-inch MWT tubes machined from pipe and the sample is currently being evaluated.

\section{HR6W:}

A weld qualification using the custom HR6W filler was attempted on 2-inch OD X 0.4inch MWT tubes and the sample is currently being evaluated.

\section{Super $304 \mathrm{H}$ :}

Sumitomo, in spite of earlier information to the contrary, stated that they do not have filler metal and procedures for gas metal arc welding of Super $304 \mathrm{H}$ and have no plans to develop either because they consider this process to have very limited use in pressure part welding. The use of Type 347 filler for this process is now being reevaluated. 


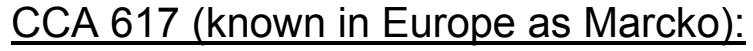

Attempts to weld plate using SMAW with matching filler were unsuccessful because of poor weldability (slag control) exhibited by the electrodes. However, a process was "qualified" using an out-of-position geometry with the matching electrodes. Conventional Inconel 617 electrodes had good weldability, compared with the matching filler metal, but plate weldments failed bend qualification tests and this issue is still being pursued with Special Metals.

\section{Inconel 740:}

Material was purchased for the weldability studies and additional weld process development work needed for this alloy.

\section{Concerns}

- Submerged arc welding, a high deposition rate process favored by boilermakers for thick sections, does not appear feasible for all nickel base materials. Tests on Haynes 230 and Inconel 740 have been unsuccessful because of cracking and the process is being abandoned on these two alloys.

- The unexpectedly high cost of the nickel base alloys will cause the material budgets to be exceeded and might result in program cost overruns and/or reductions in program scope.

- Funding issues have developed that must be resolved before any further welding development on the Haynes 230 and Inconel 740 alloys can continue.

\section{Plans for the Next Quarter}

- Resolve funding issues regarding Haynes 230 and Inconel 740 welding development.

- Begin welding efforts on tubes machined from SAVE 12 pipe.

- Continue qualification efforts on HR6W tube butt weld processes using matching filler metals.

- Determine efforts required to develop a gas metal arc welding process using Type 347 filler to make butt joints in Super $304 \mathrm{H}$ tubing.

- Continue to study problems with shielded metal arc welding of CCA 617 thick plates. 


\section{Task 5C Preparation of Laboratory Samples}

\section{Objectives}

The primary objective of this subtask is to produce multiple samples representing each of the material/process/product form combinations being studied. These samples will be evaluated by ORNL as part of the Task 2 activities.

\section{Progress for the Quarter}

Super $304 \mathrm{H}:$

Tube butt joint samples were prepared using the gas tungsten arc process that had been qualified and the samples were shipped to ORNL for testing.

\section{CCA 617 (known in Europe as Marcko):}

- Tube butt joint samples were prepared using the gas tungsten arc process that had been qualified and the samples were shipped to ORNL for testing.

- Plate butt joint samples were prepared using the submerged arc process that had been qualified and the samples were shipped to ORNL for testing.

- In spite of the welding difficulties, plate butt joint samples were prepared using an out-of-position geometry and the matching electrodes in order to provide study material and the samples were shipped to ORNL for testing.

\section{Concerns}

None.

\section{Plans for the Next Quarter}

None.

\section{Task 5D Weldability Testing}

\section{Objectives}

The primary objective of this subtask is to investigate any major weldability problems that arose during the weld procedure development efforts of Subtask 5C.

\section{Progress for the Quarter}

The advertised properties of Inconel 740 made it an attractive material for use in an ultrasupercritical boiler, however significant welding issues were encountered which 
necessitated fundamental weldability studies before procedure development could continue. Therefore, a contract has been signed with Edison Welding Institute to conduct these studies and a funding schedule has been established.

\section{Concerns}

None

\section{Plans for the Next Quarter}

Kickoff Inconel 740 weldability study program at Edison Welding Institute.

\section{Task 5E Examination of Dissimilar Metal Welds}

\section{Objectives}

The primary objectives of this subtask are to develop and study the dissimilar metal welds that would be required to make transitions between the various alloys included in this program and the conventional materials that would also be used in an ultrasupercritical boiler.

\section{Progress for the Quarter}

A process for making butt joint welds between Grade 91 and Super $304 \mathrm{H}$ tubing was developed and test samples are being prepared.

\section{Concerns}

None

\section{Plans for the Next Quarter}

- Complete Grade 91/Super 304H test samples.

- Continue development efforts for making butt joint welds between CCA 617 and Super $304 \mathrm{H}$ tubing 
Task 5: Welding Development - Milestone Chart

(DOE Fiscal Year Basis)

\section{(percentages indicate fraction of workscope completed as of 2004Q2)}

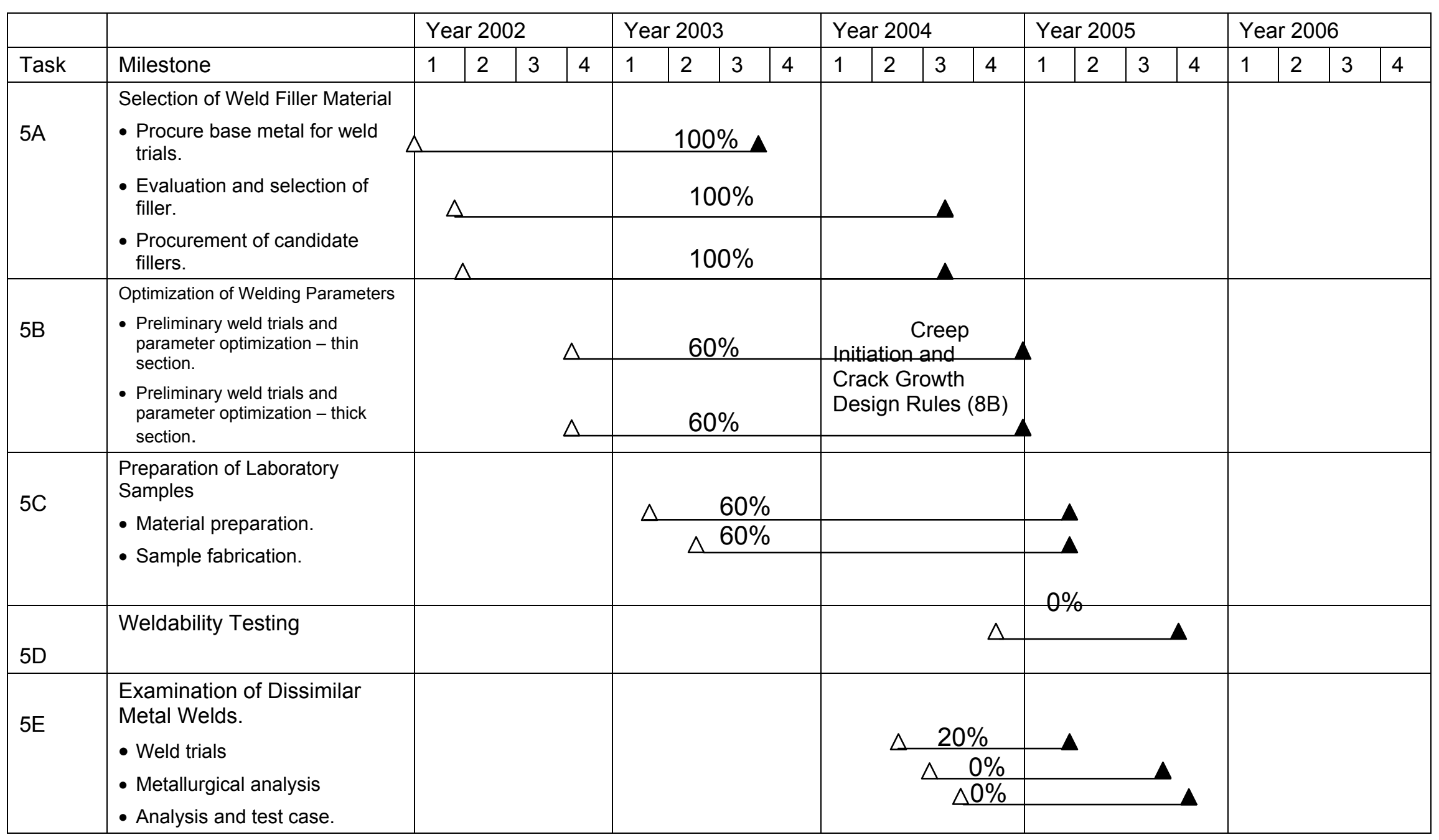




\section{Accomplishments Versus Expenditures}

(Alstom)

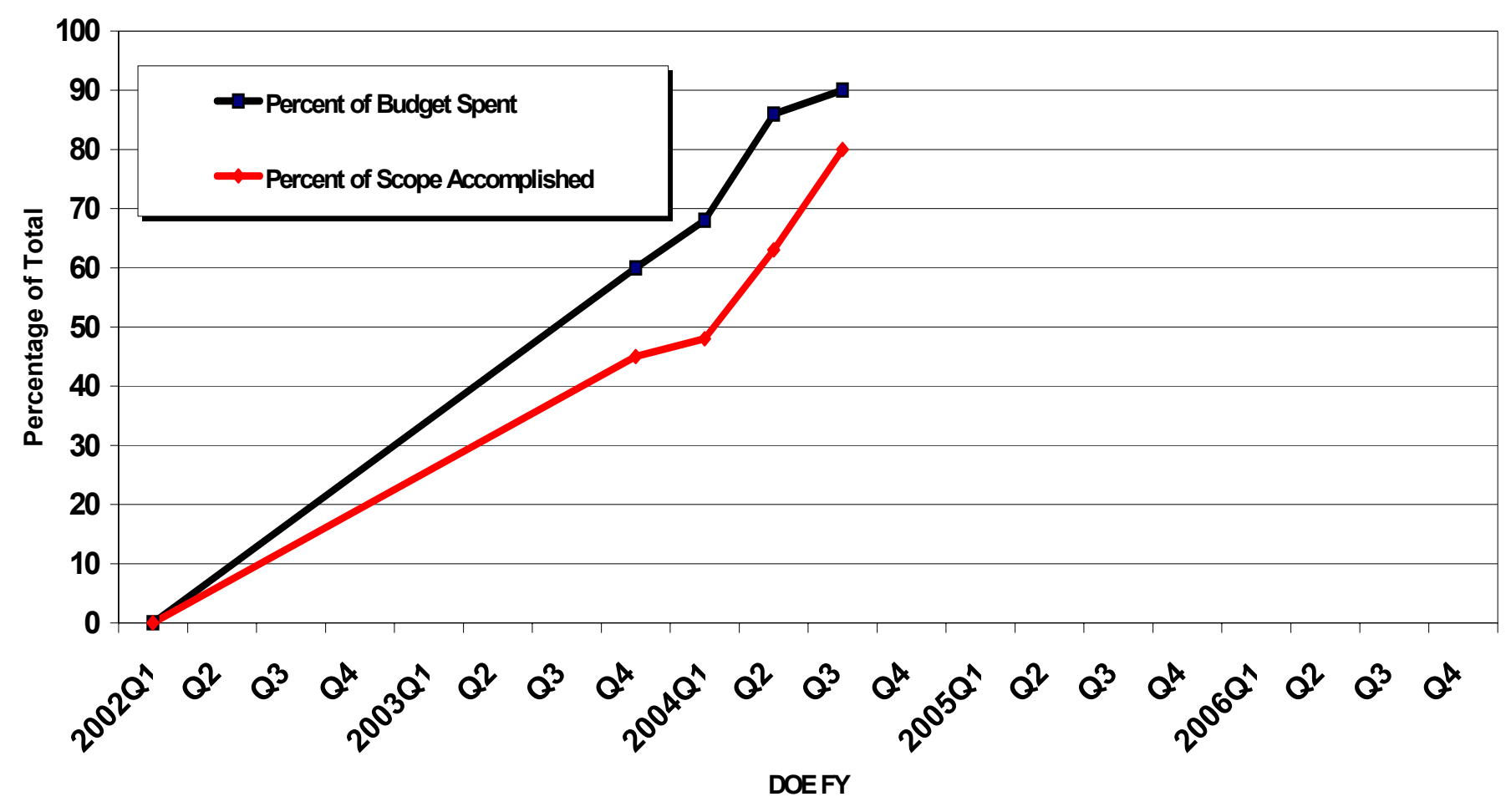




\section{Task 6 \\ Fabrication \\ $(B \& W)$}

\section{Objectives}

- The objective of Task 6 is to establish boiler fabrication guidelines for the high temperature, corrosion resistant alloys selected for the USC Project. The principal goals in this joint effort are:

- To establish fabrication guidelines for the high temperature, corrosion resistant alloys needed for boiler components in the USC power plant.

- To determine the thermomechanical treatments or other remedial actions necessary to restore material properties which might degrade due to fabrication operations.

- To investigate prototypical manufacturing operations for producing both thick wall and thin wall components from the USC alloys.

\section{Progress for the Quarter: Riley Power, Inc.}

- A plan established by Riley Power Inc. for the evaluation of the HR6W and SAVE12 materials has continued this quarter.

- Riley Power Inc. completed a series of U-bends of the SAVE12 tubing, as shown in the figures below. Bends from 2.0" OD x 0.400" MW SAVE12 tube materials have been made with strain levels of $15 \%, 20 \%$ and $35 \%$.

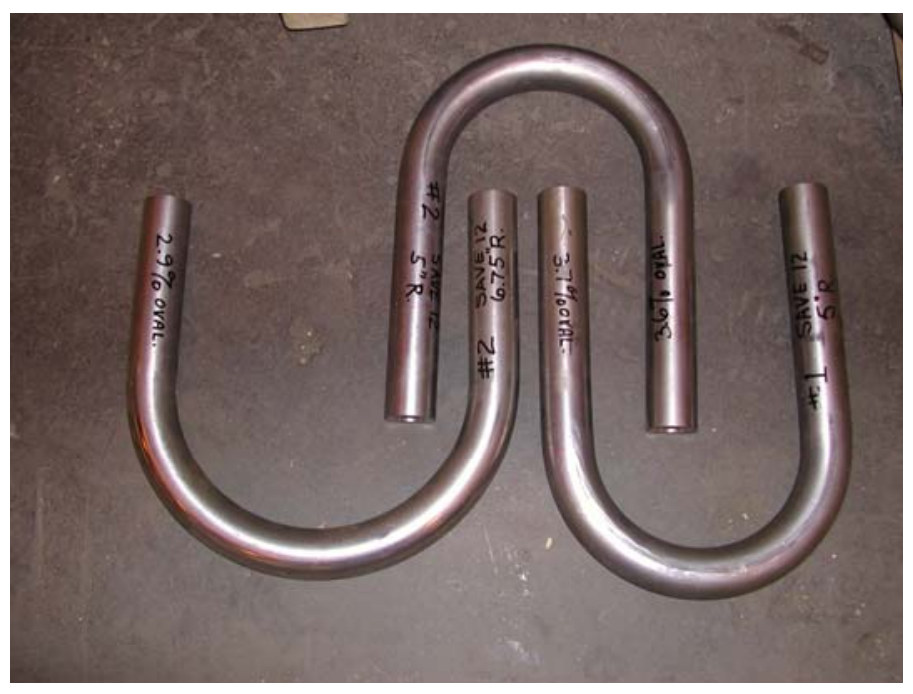

Digital image (view 1) showing tube U-bends produced by Riley Power from 2.00" OD X 0.400" MW Save 12 tube materials. 


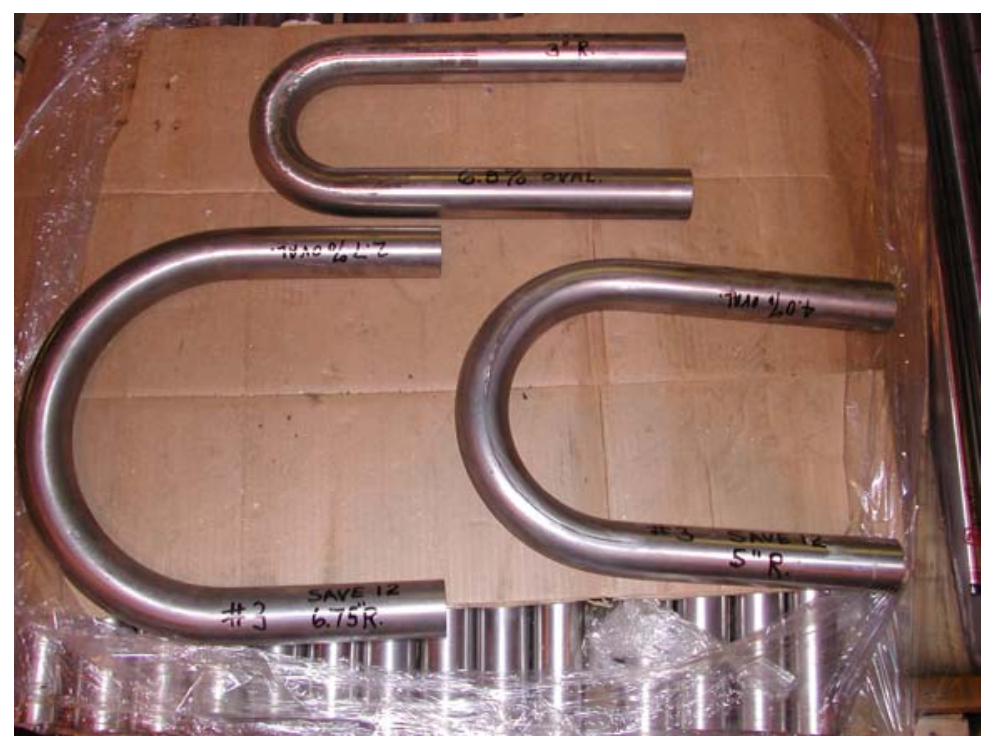

\section{Digital image (view 2) showing tube U-bends produced by Riley Power from 2.00" OD X 0.400" MW Save 12 tube materials}

- Prior to the bending and weld testing, the SAVE12 tubes were normalized and tempered in accordance with the procedures recommended by Sumitomo (see below). One set of three tubes was forwarded to ORNL for mechanical testing.

\begin{tabular}{|c|c|c|c|c|c|}
\hline \multirow{3}{*}{$\begin{array}{l}\text { RILEY POWER } \\
\text { A Babcock Power Inc. Company }\end{array}$} & \multicolumn{5}{|c|}{ NORMALIZING AND TEMPERING PROCESSES } \\
\hline & Project: & \multicolumn{4}{|c|}{$\begin{array}{l}\text { Boiler Materials for UltraSuperCritical Coal-Fired } \\
\text { Power Plants }\end{array}$} \\
\hline & & \multicolumn{4}{|c|}{$\begin{array}{l}\text { Worcester } \\
\text { / Erie }\end{array}$} \\
\hline $\begin{array}{l}\text { Subject / Notes } \\
\text { FOR SAVE12: as spec }\end{array}$ & $\mathrm{d}$ by Sum & itomo & $\begin{array}{l}\text { Summary By: } \\
\text { Holbrook }\end{array}$ & $\begin{array}{l}\text { Revision } \\
\text { 12-Apr-04 }\end{array}$ & $\begin{array}{l}\text { PROJECT NO. } \\
100192 \\
\text { Task } 6\end{array}$ \\
\hline
\end{tabular}

Normalizing

$\begin{array}{llll}\underline{\text { time }} & \frac{\mathrm{T}, \mathrm{F}}{\mathrm{0}} & \underline{\text { T rate, } \mathrm{F} / \mathrm{hr}} & \text { Hold, hrs } \\ 2: 00 & 70 & & \\ 3: 01 & 2100 & 1,000 & \\ 4: 52 & 70 & -1,100 & 1\end{array}$

\section{$\underline{\text { Tempering }}$}

$\begin{array}{llll}\underline{\text { time }} & \underline{\mathrm{T}, \mathrm{F}} & \underline{\text { Trate, F/hr }} & \underline{\underline{\text { Hold, }}} \\ 0: 00 & 70 & & \\ 4: 36 & 1450 & 300 & \\ 9: 36 & 1450 & & 5 \\ 18: 48 & 70 & -150 & \end{array}$



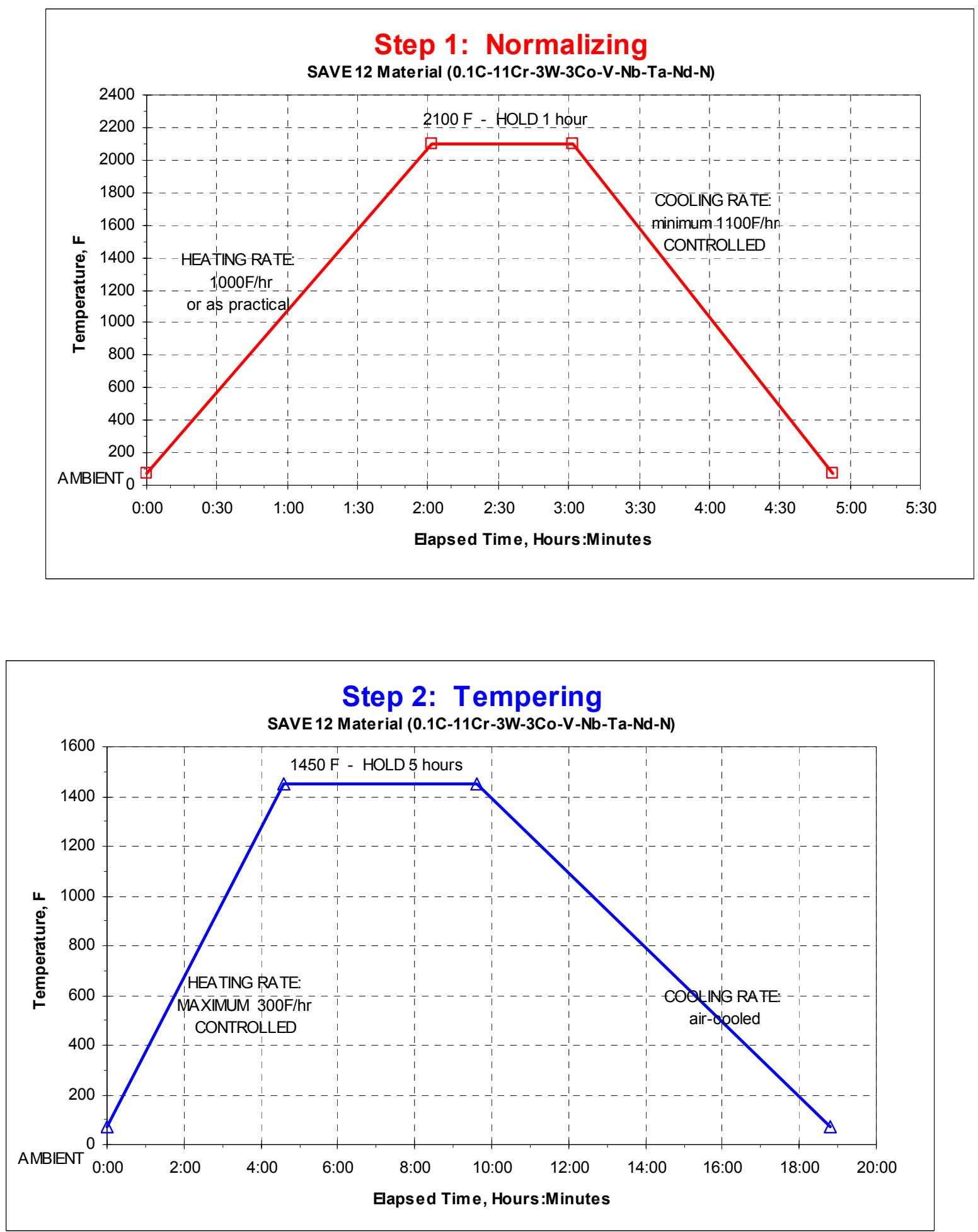

- Riley sent a heat treated sample of 2" OD x .400" MW tube SAVE12 tube to Foster Wheeler for use in conducting the recrystallization studies. This material 
was sent to replace the solid strip of SAVE12 pipe material that was originally sent to Foster Wheeler for these studies.

- Riley Power Inc. is currently awaiting the report[s] from Foster Wheeler regarding the with sample materials of the HR6W and SAVE12 materials in order to perform the recrystallization studies on these materials.

\section{Concerns}

None.

\section{Plans for the Next Quarter}

During the next quarter Riley plans on swaging the 2" OD HR^W and SAVE12 tubing after machining the ID of samples to establish a mean wall thickness of 0.200 ".

\section{Progress for the Quarter: Alstom Power, Inc.}

- Information was obtained from Sumitomo regarding the fabricability of Super 304H and will be used to plan the details of fabricability tests on this material.

- Eight sets of tapered tube samples were prepared for metallurgical examinations. These included four sets from each of the CCA 617 and Super 304H tubing and represented the as-formed conditions as well as 1,10, and 100-hour exposures at $1400^{\circ} \mathrm{F}$.

\section{Concerns}

None

\section{Plans for the Next Quarter}

- Make the series of Super 304H and CCA 617 U-bend specimens required for Task 2 testing.

- Complete the heat treating and examination of the tapered tubes used for the cold working studies.

- Determine the sensitivity of Super $304 \mathrm{H}$ to strain-induced embrittlement.

\section{Financials:}

- The efforts to date have been concentrated on planning, reporting, material procurement, and tapered specimen preparation and have resulted in a completion of $\sim 20 \%$ of the workscope. These efforts have consumed $\sim \$ 50,000$ or $\sim 25 \%$ of the $\$ 200 \mathrm{~K}$ budget. While the expenditures are slightly ahead of 
commensurate accomplishments, the deviation is not significant enough to warrant concern at this time.

\section{Progress for the Quarter: Foster Wheeler}

\section{Recrystallization Study:}

- Foster Wheeler (FW) received a machined Save 12 tube from Riley Power and prepared a tapered tube specimen. The specimen was strained at a slow rate in a similar fashion as the specimens of the other materials. The results achieved were 0.41 - $25.97 \% R A, 0.004-0.301$ TS, and 0.4 - 35.1 OFS (outer fiber strain).

- The microstructure and microhardness of the 740, 230, HR6W, and Save 12 material were characterized in the as-strained condition at the ten gage marks that represent the full range of strains. The range in microhardness values (from the lowstrain to high-strain regions) were:.

\begin{tabular}{lll} 
Material & \multicolumn{2}{c}{ Microhardness Range } \\
\cline { 3 - 3 } 740 & & \\
230 & $91 \mathrm{HRB}-39 \mathrm{HRC}$ & $(190-360 \mathrm{HB})$ \\
HR6W & $95 \mathrm{HRB}-40 \mathrm{HRC}$ & $(210-371 \mathrm{HB})$ \\
Save 12 & 88 HRB-32HRC & $(176-301 \mathrm{HB})$ \\
& $21 \mathrm{HRC}-31 \mathrm{HRC}$ & $(231-294 \mathrm{HB})$
\end{tabular}

- FW performed a $1500^{\circ} \mathrm{F} / 100$ hour thermal exposure on one full length of the 740 and 230 strained specimens. We are in the process of preparing metallurgical mounts of the specimens to determine if the hardness and microstructure at each gage length was altered by the thermal treatment.

\section{Fabrication of 740 :}

- FW sent a 15-foot length of the 740 tubing to Special Metals (SM) for re-solution annealing because of the higher-than-expected difference in hardness readings around the circumference. SM performed an anneal and reported that the hardness was uniform around the circumference, but higher than what they would like to supply in commercial tubing. The hardness in the re-solution tube was reported to be 100-102HRB; they would like it to be in the low-to-mid 90's HRB. They are in the process of a second re-solution anneal. Once they determine the heat treatment parameters, FW can send them the balance of the tubes for re-solution annealing. Once all tubes are re-solution annealed, bending trials can be conducted at the Riley Power shop in Erie, PA.

\section{Concerns}

None 


\section{Plans for the Next Quarter}

- Next quarter, FW plans to complete the characterization of the 740 and 230 strained material after the $1500^{\circ} \mathrm{F} / 100$ hour exposure. FW also plans to perform a first thermal exposure (temperature/time conditions not yet established) on the HR6W and SAVE 12 strained material and to characterize the resulting microhardness and microstructure. After assessing the data, a second thermal exposure of these materials will be planned and conducted.

- It is anticipated that Special Metals will successfully determine the re-solution annealing parameters for the 740 tubing material during next quarter. Providing that occurs, FW will ship the balance of the 740 tube material to them for re-solution annealing. When I get it back, I will then work with Riley Power to conduct U-bending and swaging trials at their Erie plant.

\section{Progress for the Quarter: B\&W}

- Plans for conducting swaging trials at a B\&W production facility using machined, thin-wall (0.2") alloy 230 tubing were established.

- Alloy 230 U-bends were selected for microstructural analysis and for comparison with microstructures developed in the strain-recrystallization-precipitation studies.

- Preliminary designs for Task 6 demonstration articles were developed.

\section{Concerns}

None

\section{Plans for the Next Quarter}

- Technical information concerning the deformation processing and thermal treatment of alloy 230 will continue to be reviewed.

- Microstructures of alloy 230 bends (extrados and intrados) will be examined, characterized, and compared to microstructures produced in the strainrecrystallization-precipitation studies.

- Alloy 230 tube samples will be machined to 2" OD X $0.200 \mathrm{MW}$ in preparation for swaging trials. 
TABLE 6

Schedule and Progress

\begin{tabular}{|c|c|c|c|c|c|c|c|c|c|c|c|}
\hline & & & & & 2000 & 2001 & 2002 & 2003 & 2004 & 2005 & 2006 \\
\hline ID & Task Name & Start & Finish & Status & \begin{tabular}{|l|l|l|l|}
$Q 1$ & $Q 2$ & $Q 3$ & $Q 4$ \\
\end{tabular} & \begin{tabular}{|l|l|l|l|} 
Q1 & $Q 2$ & Q3 & Q4 \\
\end{tabular} & \begin{tabular}{|l|l|l|l|} 
Q1 & $Q 2$ & Q3 & Q4 \\
\end{tabular} & \begin{tabular}{|l|l|l|l|} 
Q1 & Q2 & Q3 & Q4 \\
\end{tabular} & \begin{tabular}{l|l|l|l} 
Q1 & Q2 & Q3 & Q4 \\
\end{tabular} & \begin{tabular}{l|l|l|l|} 
Q1 & Q2 & Q3 & Q4 \\
\end{tabular} & \\
\hline 2 & 6A: Fab Trials for SH & Wed $1 / 2 / 02$ & Tue $11 / 30 / 04$ & In Progress & & & & & & & \\
\hline 3 & 6.1 SH Trial & Tue $1 / 1 / 02$ & Thu 9/9/04 & In Progress & & & & & & & \\
\hline 4 & Procure Materials & Wed $1 / 2 / 02$ & Fri $5 / 3003$ & Complete & & & & & & & \\
\hline 5 & Shop Sched \& Graphics & Tue 4/1,03 & Mon $6 / 2 / 03$ & Complete & & & & $=$ & & & \\
\hline 6 & Travel to Shop & Mon $6 / 2,03$ & Fri 6/4,04 & In Progress & & & & & (2) & & \\
\hline 7 & Cold Bending Trials & Mon $6 / 2,03$ & Fri 6/4/04 & In Progress & & & & & & & \\
\hline 8 & Cold Swaging Trials & Mon $6 / 2,03$ & Fri 6/4/04 & In Progress & & & & & & & \\
\hline 9 & Butt Welding Trials & Mon 6/203 & Fri 6/4/04 & In Progress & & & & & & & \\
\hline 10 & Attachment Welding Trials & Mon $6 / 2,03$ & Fri 8,6,04 & In Progress & & & & & & & \\
\hline 11 & 6A.2 Reporting & Fri $1 / 3,03$ & Fri $12 / 3 / 04$ & In Progress & & & & & & & \\
\hline 12 & 6A.3 SH: Met Test \& Eval & Fri $1 / 9,04$ & Fri 8,6:04 & In Progress & & & & & & & \\
\hline 13 & 6A.3.1 Mic Bends \&Welds & Fri $6 / 4,04$ & Wed 7/28,04 & Planned & & & & & 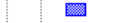 & & \\
\hline 14 & 6A.3.2 HT Studies\&Mic & Fri 6i4/04 & Thu 8/19/04 & Planned & & & & & 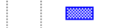 & & \\
\hline 15 & 6B: Fab Thk Wall Comp & Thu $1 / 2,03$ & Thu $3 / 3105$ & Planned & & & & & & & \\
\hline 16 & 68.1 Thick-Wall Fab Trial & Fri $1 / 9,04$ & Mon 6/21:04 & In Progress & & & & & $\equiv$ & & \\
\hline 17 & 68.2 Reporting & Fri $1 / 9,04$ & Thu $3 / 31,05$ & In Progress & & & & & & 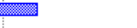 & \\
\hline 18 & 68. 3 Thick-Wall Comp & Fri $1 / 9,04$ & Fri 10/29/04 & In Progress & & & & & & & \\
\hline 19 & 6B.3.1 Met Analysis & Wed 9/29,04 & Mon $1 / 31,05$ & Planned & & & & & & & \\
\hline 20 & 6B.3.2 PMHT Studies\&Mic & Wed $9 / 29 / 04$ & Fri $12 / 31 / 04$ & Planned & & & & & & & \\
\hline
\end{tabular}




\section{Task 7 \\ Coatings \\ (Alstom)}

Objectives for Task 7 Coatings:

- Review state-of-the-art of coating technology and identify development needs.

- Develop coating manufacturing techniques, which can provide corrosion/erosion protection for components in USC boilers, cost effectively.

- Establish manufacturing techniques for application of internal coatings for oxidation protection, cost effectively.

- Provide coated samples for corrosion and oxidation testing in the laboratory and "in the field".

These objectives will be accomplished through execution of eight sub-tasks. Where activity on these sub-tasks occurred during the reporting period, it is described below.

\section{Task 7E: Process Scaleup}

\section{Objective}

Perform coating process trials at an intermediate scale between laboratory and commercial size.

\section{Progress for the Quarter}

Part 1: B\&W Effort

Activity reported under Task $7 \mathrm{H}$.

\section{Part 2: B\&W Effort}

Testing efforts completed this quarter. Quarterly activity is reported in detail in Appendix 1 to this report.

\section{Concerns}

None

\section{Activities Planned for Next Quarter}

B\&W contracted work at Praxair and ASB will be brought to completion, then, this task will remain on-hold until additional funding is released. 


\section{Task 7H: Specimens for Field Corrosion/Oxidation}

\section{Objective}

Provide externally and internally coated specimens for inclusion in corrosion/oxidation testing under Tasks 3 and 4 .

\section{Progress for the Quarter}

- Praxair has reported that they have completed laser deposition of $50 \mathrm{Cr} / 50 \mathrm{Ni}$ on Haynes 230 tube. This tube needs to be straightened and ground, and then it will be ready to be cut into tube samples for corrosion probe work by Foster Wheeler.

- ASB has completed their efforts to deposit $50 \mathrm{Cr} / 50 \mathrm{Ni}$ on Haynes 230 tube using the plasma transferred arc (PTA) process. This tube specimen is ready to be cut to length for inclusion in the corrosion probe work by Foster Wheeler.

- $\mathrm{Al}-\mathrm{Cr}$ and $\mathrm{Si}-\mathrm{Cr}$ diffusion coated specimens were prepared for inclusion in the Foster Wheeler field testing

\section{Concerns}

None

\section{Plans for the Next Quarter}

Samples with modified inside and outside surfaces will be provided to Foster Wheeler for inclusion in Task 4 corrosion probes. 
USC Materials -

\begin{tabular}{|c|c|c|c|c|c|c|c|}
\hline \multirow[t]{2}{*}{ Task Name } & \multirow[t]{2}{*}{ Status } & 2002 & 2003 & \multicolumn{2}{|l|}{2004} & 2005 & 2006 \\
\hline & & \begin{tabular}{|l|l|l|l|} 
Qtr 1 & Qtr 2 & Qtr 3 & Qtr 4 \\
\end{tabular} & \begin{tabular}{|l|l|l|l|} 
Gtr 1 & Qtr 2 & Qtr 3 & Qtr 4 \\
\end{tabular} & \begin{tabular}{|l|l|l|} 
Gtr 1 & Gtr 2 & Gtr 3 \\
\end{tabular} & Gotr 4 & \begin{tabular}{|l|l|l|l|} 
Gtr 1 & Gtr 2 & Gtr 3 & Gtr 4 \\
\end{tabular} & \begin{tabular}{|l|l|l|} 
Gtr 1 & Gtr 2 & Gtr 3 \\
\end{tabular} \\
\hline Task 7: Coatings & & & & & & & \\
\hline \multicolumn{8}{|l|}{ Task 7A: Detailed Study of Current State of the Art } \\
\hline Alstom Task 7A: Detailed Study of Current State of the Art & Complete & & & & & & \\
\hline \multicolumn{8}{|l|}{ Task 7B: Coating Feasibility (Internal Coating) } \\
\hline Alstom Task 7B: Coating Feasibility (Internal Coating) & Complete & & & & & & \\
\hline \multicolumn{8}{|l|}{ Task 7C: Coating Recommendations } \\
\hline Alstom Task 7C: Coating Recommendations & $20 \%$ & & & & & & \\
\hline \multicolumn{8}{|l|}{ Task 7D: Laboratory Testing } \\
\hline Alstom Task 7D: Laboratory Testing & $50 \%$ & & & & & & \\
\hline \multicolumn{8}{|l|}{ Task 7E: Process Scale Up - Preliminary Trials } \\
\hline Alstom Task 7E: Process Scale Up - Prelirninary Trials & $100 \%$ & & & & & & \\
\hline B\&W Task 7E: Process Scale Up - Preliminary Trials & $87 \%$ & & & dis & & & \\
\hline \multicolumn{8}{|l|}{ Task 7F: Process Optimization } \\
\hline \multicolumn{8}{|l|}{ Alstom Task 7F: Process Optimization } \\
\hline B\&W Task 7F: Process Optirnization & $87 \%$ & & $=0$ & & & & \\
\hline \multicolumn{8}{|l|}{ Task 7G: Manufacturing Recommendations } \\
\hline \multicolumn{8}{|l|}{ Alstom Task 7G: Manufacturing Recommendations } \\
\hline B\&W Task 7G: Manufacturing Recommendations & $30 \%$ & & & & 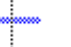 & & \\
\hline \multicolumn{8}{|l|}{ Task 7H: Specimens for Field Corrosion/Oxidation } \\
\hline Alstom Task $7 \mathrm{H}$ : Specimens for Field Corrosion/Oxidation & $70 \%$ & & 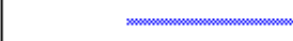 & & & & \\
\hline B\&W Task 7H: Specimens for Field Corrosion/Oxidation & $55 \%$ & & & & & & \\
\hline \multicolumn{8}{|l|}{ Task 7l: Project Management } \\
\hline Alstom Task 7l: Project Management & Ongoing & & & & & & \\
\hline B\&W Task 7l: Project Management & Ongoing & & & & & & \\
\hline
\end{tabular}


Scope Accomplished Versus Actual Expenditures Task 7 Coatings Alstom Scope

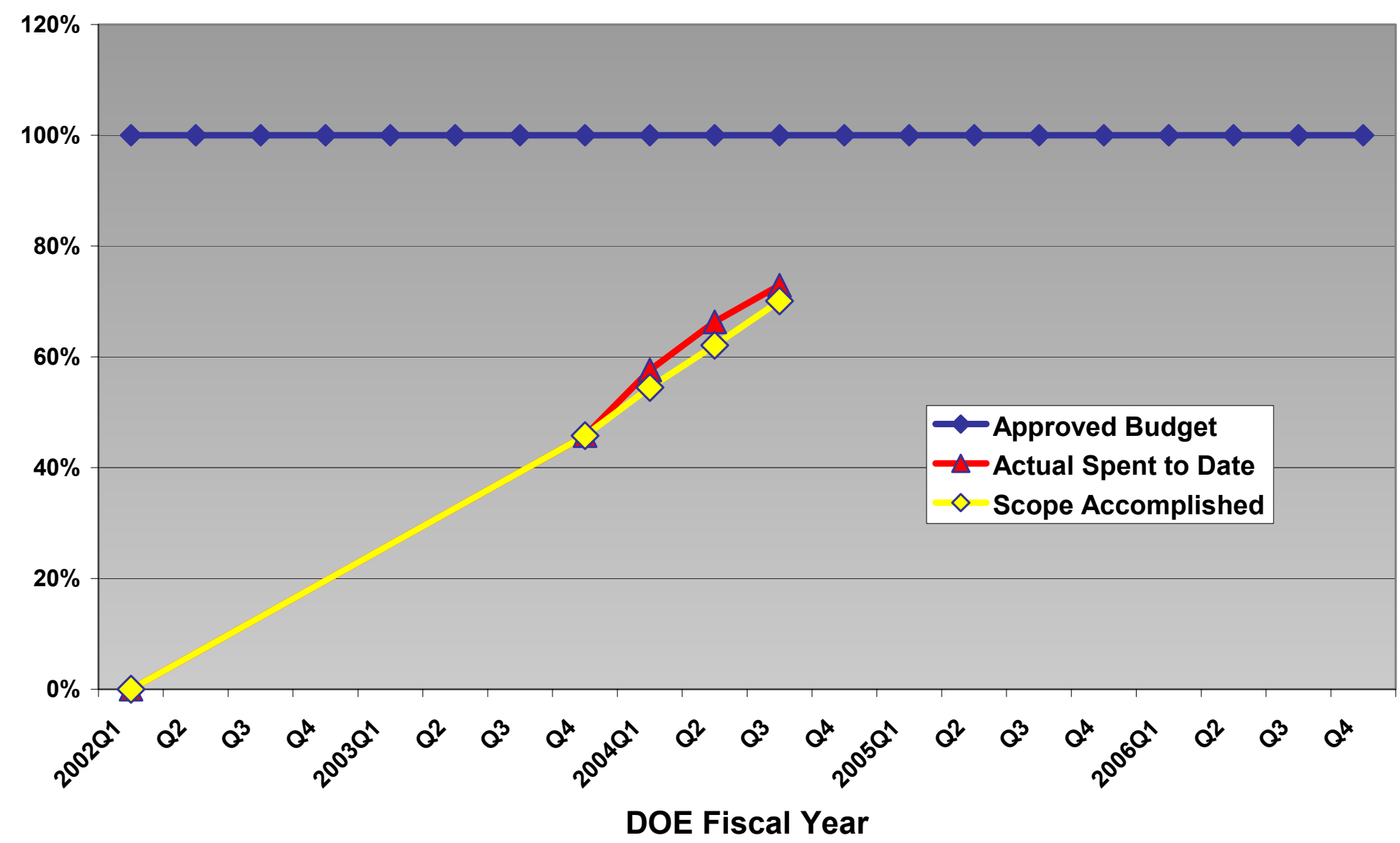




\section{Appendix 1 \\ Diffusion Coating Progress Report (Alstom Power Inc.)}

\section{Introduction}

The scale-up tests scheduled within ALSTOM Task 7E were completed in April 2004. A total of fourteen tests were conducted utilizing tubing samples of alloys $\mathrm{S} 304 \mathrm{H}$ and T92. Three diffusion-coating formulations were tested including chromizing, $\mathrm{Si}-\mathrm{Cr}$ coatings, and Al-Cr coatings. Table 1 lists the compositions for the pack powders used to coat the ID and OD of the tubing test-pieces. The ID formulations represent modifications of the OD powders with increases or changes in the amount of metal powders. These changes in composition were implemented to improve throw-power to account for the smaller ID in the T-92 alloy tubing. Preliminary laboratory work reported during task $7 \mathrm{~B}$ indicated that the ID of the tubing was related to throw-powder by limiting the amount of powder required to promote an ID diffusion layer of adequate composition and thickness.

TABLE 1

Pack-powder formulations used to generate ID diffusion layers

\begin{tabular}{|l|l|l|}
\hline Process & ID & OD \\
\hline Chromizing & $30 \% \mathrm{Cr}$ & $43 \% \mathrm{Fe}-\mathrm{Cr}$ \\
& $3 \% \mathrm{NH}_{4} \mathrm{Cl}, \mathrm{Bal} . \mathrm{Al}_{2} \mathrm{O}_{3}$ & $3 \% \mathrm{NH}_{4} \mathrm{Cl}, \mathrm{Bal} . \mathrm{Al}_{2} \mathrm{O}_{3}$ \\
\hline Si-Cr rich layer & $3 \% \mathrm{Si}, 30 \% \mathrm{Cr}$ & $2 \% \mathrm{Si}, 25 \% \mathrm{Cr}$ \\
& $1 \% \mathrm{NH}_{4} \mathrm{Cl}, 1 \% \mathrm{CaF}_{2}$ & $1 \% \mathrm{NH}_{4} \mathrm{Cl}, 1 \% \mathrm{CaF}_{2}$ \\
& $\mathrm{Bal} . \mathrm{Al}_{2} \mathrm{O}_{3}$ & $\mathrm{Bal} . \mathrm{Al}_{2} \mathrm{O}_{3}$ \\
\hline Al-Cr rich layer & $4 \% \mathrm{Al}_{2} 20 \mathrm{Cr}$ & $2 \% \mathrm{Al}_{1}, 18 \mathrm{Cr}$ \\
& $2 \% \mathrm{NH}_{4} \mathrm{Cl}, 2 \% \mathrm{MgCl}_{2}$ & $1 \% \mathrm{NH}_{4} \mathrm{Cl}, 2 \% \mathrm{MgCl}_{2}$ \\
& $\mathrm{Bal} \mathrm{Al}_{2} \mathrm{O}_{3}$ & $\mathrm{Bal} . \mathrm{Al}_{2} \mathrm{O}_{3}$ \\
\hline
\end{tabular}

The proprietary commercial formulation of ALSTOM Power was used for the chromizing tests. The Si-Cr pack cementation formulation was based on the patent \# 5,972,429 by Bayer \& Wynns. The formulation by M. Zheng and R. Rapp, of public domain was utilized to generate the Al-Cr diffusion layers. This report will summarized the different products in terms of composition and thickness as a function of time and temperature. Guidelines will be provided based on the experimental results to conduct the optimization tests. 


\section{Experimental}

The scale-up tests were conducted using tubular components made of $\mathrm{S} 304 \mathrm{H}$ and T92. The S304H tubing had a 2.5" OD with a 0.35 " wall while the T-92 tubing had a 1 "

OD with a $3 / 16$ " wall. Eight (8) tubing sections were coated in the loads using $5304 \mathrm{H}$ material and ten (10) tubing sections were coated during the test conducted with T-92 material. The tubing sections were five (5)-ft long and one thermocouple was attached to each section to monitor the heating characteristics of the pack. The tubular components and the pack powder were assembled in a steel retort that was sealed with a welded lid with a vent for the gases produced during the decomposition of the activator system. The exhaust pipe was continuously purged with Argon gas to prevent condensation and subsequent plugging. The joint of the Argon lance to the exhaust pipe was heated to $200 \mathrm{~F}$ using a heat mantel. A wall-fired gas furnace was utilized to conduct the tests. The temperature of the pack was recorded using an analog reader coupled with a digital converter to store the data in a lap top computer.

The OD formulation was used to coat the ID and OD of the S304H tubing but because of the smaller ID of the T-92, the ID formulations was slightly modified to increase the throw-power of the powder to generate coatings with similar characteristics to that of the OD. The ID of the component determines the amount of powder that can be used. As pre-determined from laboratory tests, an ID of 13/16" requires an increase in the metal constituents of the pack to be able to provide a coating composition similar to that of the OD. The hold time for these tests was 16 hours. All processes were conducted with a single temperature excursion. Hold time was initiated when the cooler thermocouple in the pack reached $2040 \mathrm{~F}$. The heating characteristics of the pack were controlled to avoid temperatures in excess of $2100 \mathrm{~F}$ for any significant length of time. Modifications to the test facilities and adjustments to processing parameters were implemented as needed. The objective of these tests was to define the optimum processing conditions to generate a consistent product. The tests began using the chromizing formulation followed by the Si-Cr and Al-Cr rich layers. The test matrix included a limited number of tests where the OD and ID were coated with different system formulations.

\section{Results}

The different diffusion coatings will be evaluated in terms of coating thickness and composition. Even though there is no sufficient experimental data to define coating requirements for steam-side applications, those currently imposed by fireside corrosion will be used as a baseline. For ferritic alloys the desirable thickness should be greater than 10 mils. There are no specific requirements for diffusion coated austenitic alloy, therefore the baseline for thickness will be arbitrarily set at a minimum of 6 mils. When considering effective coating thickness particular attention should be paid to coating chemistry. As it will be shown later, the composition of the diffusion coatings in the austenitic materials is different from that in ferritic alloys in that there are no steep concentration gradients. 
Coating thickness:

Alloy S304H: Table 2 lists the coating thickness ranges for alloy $\mathrm{S} 304 \mathrm{H}$ as a function of the coating process. The variance in thickness is related to exposure time and process temperature.

Table 2

Coating thickness for the diffusion layers generated in alloy S304H

\begin{tabular}{|l|l|l|}
\hline Process & OD (mil) & ID (mil) \\
\hline Chromizing & $6-10$ & $6-11$ \\
\hline Si-Cr & $11-17$ & $12-17$ \\
\hline Al-Cr & $30-35$ & $25-30$ \\
\hline
\end{tabular}

Alloy T-92: Table 3 depicts the variation in coating thickness per type of diffusion layer generated in alloy type T-92.

Table 3

Coating thickness for the diffusion layers generated in alloy type T-92

\begin{tabular}{|l|l|l|}
\hline Process & OD $(\mathrm{mil})$ & ID (mil) \\
\hline Chromizing & $15-27$ & $15-24$ \\
\hline Si-Cr & $26-35$ & $27-38$ \\
\hline Al-Cr & $42-48$ & $32-35$ \\
\hline
\end{tabular}

The data presented in tables 2 and 3 clearly indicates the easiness to coat ferritic alloys as compared to austenitic steels. This difference has been ascribed to differences in alloy structure, i.e. BCC vs. FCC, but it is also determined by the effect of alloying elements in the inter-diffusion coefficients. The dramatic increase in coating thickness observed during $\mathrm{Al}-\mathrm{Cr}$ processes is related to the affinity of $\mathrm{Al}$ and $\mathrm{Fe}$ to form intermetallic compounds. The latter is a chemical reaction. In the Al-Cr process, for a given temperature, there is a difference of about 5 to 10 mils between the coating thickness on the ID and OD of the tubing. This difference is most likely related to the limitations in pack availability imposed by the ID. The effect of the ID will also be reflected in the average coating composition, as will be discussed later.

Coating Composition:

Chromizing Process:

Alloy S304H: The average chromium concentration generated in alloys $\mathrm{S} 304 \mathrm{H}, 347 \mathrm{HFG}$ and $\mathrm{HR} 3 \mathrm{C}$ remained above $30 \mathrm{wt} \%$ through out the thickness of the ID chromized layers. Figure 1 depicts the variation of the average $\mathrm{Cr}$-concentration as a function of process temperature for alloy $\mathrm{S} 304 \mathrm{H}$. The major effect of temperature seems to relate to the overall coating thickness. A higher process temperature apparently resulted in a 
thicker coating. However, for the higher process temperature there is also a hidden contribution of longer processing times since the higher temperatures were recorded in the periphery of the retort box. The average coating hardness was about $68 \mathrm{Rc}$ comparable to that of $\mathrm{Cr}$-plating. A post-solution annealing at $2000 \mathrm{~F}$ for $30 \mathrm{~min}$ followed by a water quench lowers the average hardness of the diffused layer to about 36 Rc. Bending to $180^{\circ}$ had been successfully accomplished at room temperature after the solution annealing treatment. The post-solution annealing homogenized the coating composition resembling that of monolithic alloys, Figure 2.

Alloy type T-92: Figure 3 shows the trend of the process temperature effect on the composition of the chromized layer formed in the ID of T-92 tubing. To achieve a maximum $\mathrm{Cr}$-concentration of $25-w \mathrm{t} \%$ in the diffusion layer, it seems apparent that the process temperature needs to be controlled between 2060 and $2100 \mathrm{~F}$. The OD diffusion coatings temperature requirements to achieve this maximum $\mathrm{Cr}$-concentration seem to lie above $2030 \mathrm{~F}$. The average coating hardness varied from 92 and $80 \mathrm{Rb}$ as a function of coating thickness. Bend tests up to $180^{\circ}$ bends indicated no damaged to the ID coating layer in the as-coated and in the as post-tempered condition. Tempering was conducted at $1400 \mathrm{~F}$ for $1 \mathrm{~h}$. The hardness of the post-tempered samples varied from 88 to $72 \mathrm{Rb}$. The grain boundaries of the diffusion layer formed in T-92 were free of grain boundary precipitates.

\section{Si-Cr Process:}

Alloy S304H: The effect of the process temperature on the average composition profiles for $\mathrm{Si}$ and $\mathrm{Cr}$ in the diffused layers is depicted in figures 4 and 5 , respectively. The effect of $\mathrm{Ni}$ on the interdiffusion coefficient of $\mathrm{Si}$ and $\mathrm{Cr}$ generates uneven composition profiles. Regardless of the processing temperature, between 2050 and $2100 \mathrm{~F}$, the average Si content remained above $2 \mathrm{wt} \%$ through out the diffusion layer while that of chromium remained above $30 \mathrm{wt} \%$ similar to that of chromized layers. The implantation of Si apparently results in an increase in coating thickness of up to a $50 \mathrm{wt} \%$ straight chromizing. Similar results were observed during laboratory trials aimed at diffusing both $\mathrm{V}$ and $\mathrm{Cr}$. The combination of $\mathrm{Cr}$ and $\mathrm{Si}$ at these concentration levels makes this product a potential materials solution for coal-ash-corrosion. Si levels in excess of 1.8 $w t \%$ in austenitic alloys may prevent high-temperature-carburization.

The concentration profiles can be homogenized by a post-solution treatment at $2000 \mathrm{~F}$ for 30 minutes as indicated by Figure 6 . The hardness of the as-coated diffusion layer averages $58 \mathrm{Rc}$. Room temperature bending to $180^{\circ}$ resulted in cracking of both OD and ID layers. However, the post-solution annealing treatment allowed the bending of coated sections with no apparent detriment to the ID layer. One out of three bend tests showed incipient cracking of the OD. It is recommended to explore the benefits of hot bending for the OD layers.

Alloy type T-92: Regardless of the processing temperature in the range 2050 to $2100 \mathrm{~F}$, the maximum $\mathrm{Cr}$-content in the ID diffusion layers exceeds the minimum requirement of $25 \mathrm{wt} \%$, Figure 7. An effect of processing temperature is more obvious in the maximum 
Si-content, Figure 8. The Si-content remains above $1 \mathrm{wt} \%$ through the layer thickness for process temperatures in the range of 2050 to $2100 \mathrm{~F}$. The implantation of Si in the diffusion layer resulted in a 40 to $50 \%$ increase in coating thickness versus straight chromizing with no apparent requirement for stringent temperature control to achieve the maximum desirable $\mathrm{Cr}$-content of $25 \mathrm{wt} \%$. The coating generated in tubing sections of alloy types T-91 and T-23 was similar to that obtained with alloy type T-92.

The hardness of the Si-Cr diffusion layers in T-92 varied from $95 \mathrm{Rb}$ bellow the coating surface to $82 \mathrm{RB}$ approaching the base metal interface. After tempering at $1400 \mathrm{~F}$ for $1 \mathrm{~h}$, coated samples were bent to $180^{\circ}$ with no detriment to the ID layer. However, one out of three bend samples crack through the OD layer. The crack was of transgranular nature. Multiple cracking was observed in the OD and ID layers of tempered T-92 and T-23 samples. Cracks propagated in a transgranular mode. The grain boundaries of the coated T-23, T-91, and T-92 were free of carbide precipitates. Hot bending should be explored for these types of ferritic alloys coated with the Si-Cr formulation.

\section{Al-Cr Process:}

Alloy S304H: The coated layer was characterized by the dispersion of Al-Nitrides through the coating thickness. The nitride precipitates were fine bellow the coating surface and coarsened approaching the coating-base metal interface. The concentration profiles in both the ID and OD diffusion layers were very irregular and no apparent consistency could be established as a function of temperature, Figures 9 and 10. The coated samples had an average hardness of about 35 RC. In the as coated and annealed conditions the OD coating cracked and delaminated. The ID coating was not affected up to $180^{\circ}$ bends under either condition. Solution annealing homogenized the concentration profiles as illustrated by Figure 11 for the ID layer. The maximum Alcontent did not exceed $4 \mathrm{wt} \%$ and the Al-concentration in the diffusion layer was above $2 \mathrm{wt} \%$ through the coating thickness. The maximum $\mathrm{Cr}$-content was about $30 \mathrm{wt} \%$. After annealing the maximum Al-content in the OD layer was around $9 \mathrm{wt} \%$, close to the desired $10 \mathrm{wt} \%$ within the $\mathrm{Fe}_{3} \mathrm{Al}$ stability field. Al-contents in excess of $10 \mathrm{wt} \%$ can result in welding difficulties. No composition standards are available for optimum oxidation resistance in super-heated steam. The coating in the ID was about 5 mils thinner than the OD layers. The decrease in coating thickness and the reduced maximum Al-content suggest inadequate throw-power. Further modification of the ID formulation may have resulted in straight aluminizing as indicated by preliminary tests conducted within Task 7B.

Alloy T-92: The Al-concentration profiles were less irregular than for alloy $\mathrm{S} 304 \mathrm{H}$, however, there was no clear correlation with process temperature. The structure of the coating was very similar to that observed in the $\mathrm{S} 304 \mathrm{H}$ diffusion layers. A fine dispersion of aluminum nitride extended half way the coating thickness within an equiaxed grain structure. The rest of the coating showed a typical columnar grain structure virtually free of precipitates. The maximum Al-content in the OD layer was 
between 10 and $12 \mathrm{wt} \%$ while in the ID layer the maximum Al-content was between 3 and 4.5 wt\%, Figure 12.

The ID layers were about 10 mils thinner than the OD layers and, as reported for the $\mathrm{S} 304 \mathrm{H}$ alloy, this may be related to a low throw-power.

The hardness of the diffusion layer varied from 30Rc bellow the coating surface to 82 $\mathrm{Rb}$ approaching the coating/base metal interface. The base metal was hardened with an average hardness of $40 \mathrm{Rc}$. Little bending was required to fracture the samples in a brittle-transgranular mode. After tempering at $1400 \mathrm{~F}$ for $1 \mathrm{hr}$, the OD coating cracked in multiple places upon bending to $180^{\circ}$. The cracks did not propagated into the base metal. Crack propagation was of transgranular mode. The ID layer showed cracking at discrete places.

\section{Task 7F}

During task 7F, Process Optimization, the coating systems will be narrowed down to straight chromizing and Si-Cr coatings. To maximize heat up and cooling rates only the ID of the tubing pieces will be coated. During the first phase of the program to be completed in September 2004, the process will deal with ferritic alloys. Five (5) waterwall panels made with T-11 tubing $1 \frac{1 / 4}{4}$ OD will be coated per test. The panels will be supported by placing 1 " thick layers of alumina powder in between panels or $3 / 4$ OD dense alumina balls positioned along the membranes in between panels. The use of alumina powder would represent a $2 / 3$ reduction in the amount of powder used during Task 7E while the alumina balls would represent the maximum open space with less insulating material to sink heat during the heat-up step. Either the powder or the balls should be reusable. The objective is to attain a better temperature control within the 2060 to $2100 \mathrm{~F}$ range that seems to be critical to attain chromized layers of adequate composition. As discussed above, the Si-Cr process seems to be more forgiving in terms of achievable consistent compositions. As a final product the decision for commercializing either coating depends on the systematic evaluation of control samples under adequate steam oxidation test conditions. The Al-Cr coatings may be more valuable for fire-side applications. Al-containing alloys tend to absorb oxygen and are not protective for long-term application at temperatures below $850^{\circ} \mathrm{C}$.

\section{Conclusion}

1. The chromizing process generates diffusion layers of adequate thickness and composition in both alloys T-92 and S304H.

2. A process temperature between 2060 and $2100^{\circ} \mathrm{F}$ is required to generate ID layers with $\mathrm{Cr}$-contests $>25 \mathrm{wt} \%$ in small diameter T-92 tubing.

3. The Si-Cr process generates diffusion layers up to $50 \%$ thicker than those obtained during straight chromizing for similar process conditions.

4. The Si-Cr diffusion layers have a Cr-content $>25$ wt $\%$ in both alloys T-92 and S304H with Si-contents $\geq 2$ wt $\%$ for alloy S304H and $\geq 1$ wt\% for alloy T-92. 
5. Si-Cr diffusion layers of adequate thickness and composition are feasible with process temperatures between 2050 and $2100^{\circ} \mathrm{F}$.

6. The Al-Cr formulation results in significantly thicker ID coatings with a $\mathrm{Cr}$-content > $25 \mathrm{wt} \%$ and $\mathrm{Al}$-contents between 2 and $4 \mathrm{wt} \%$ in alloy $\mathrm{S} 304 \mathrm{H}$.

7. For alloy $\mathrm{T}-92$ the maximum $\mathrm{Cr}$-content in ID Al-Cr layers is 16 wt\% with $\mathrm{Al}$ concentration not exceeding $5 \mathrm{wt} \%$, resembling the KANTHAL Alloy composition.

8. Task 7F will deal with the process optimization for ID chromizing and Si-Cr.

9. Room temperature bending of chromized T-92 and $\mathrm{S} 304 \mathrm{H}$ tubing is feasible.

10. Hot bending should be evaluated for the Si-Cr and Al-Cr coated alloys.

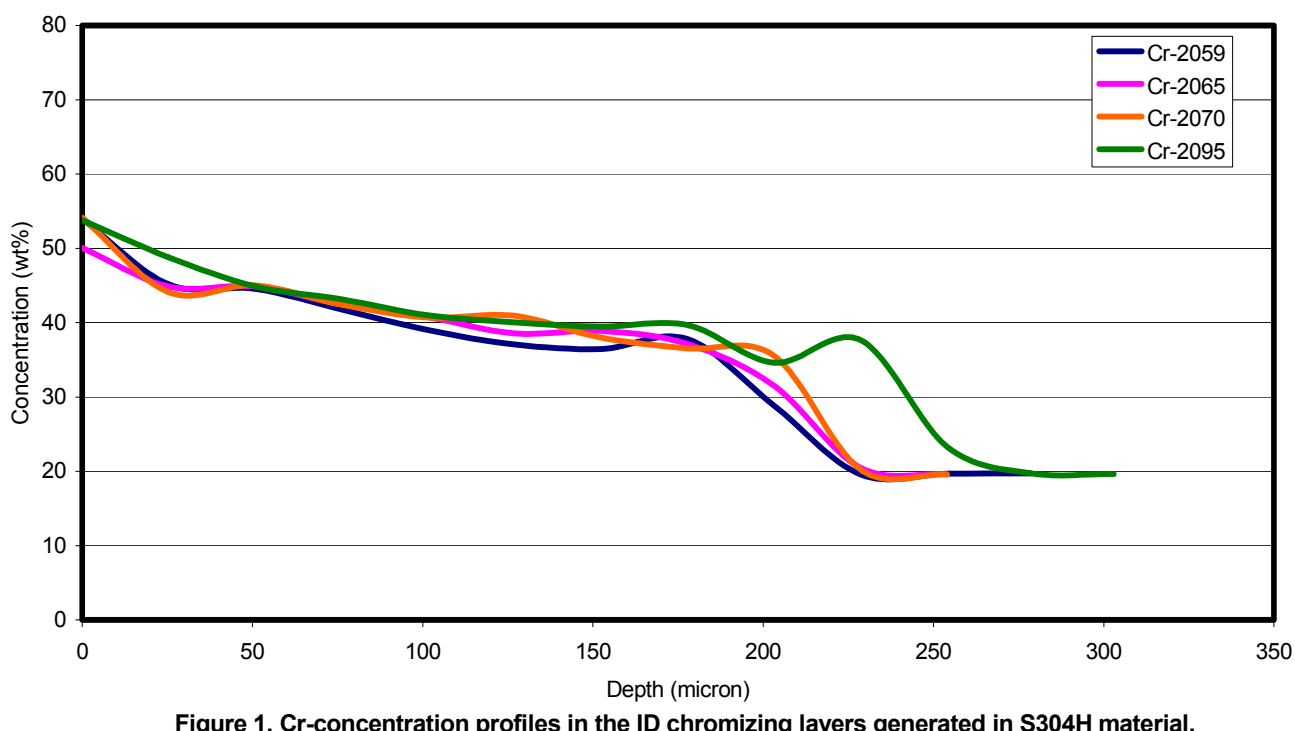

Figure 1. Cr-concentration profiles in the ID chromizing layers generated in S304H material. 


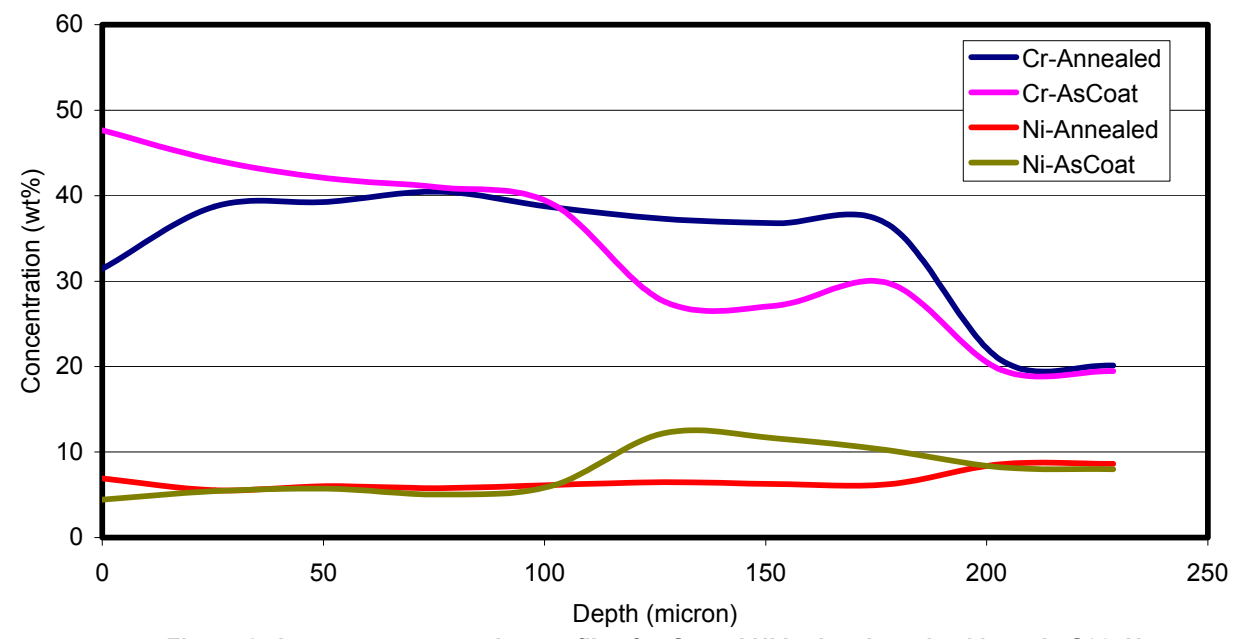

Figure 2. Average concentration profiles for $\mathrm{Cr}$ and $\mathrm{Ni}$ in the chromized layer in $\mathrm{S} 304 \mathrm{H}$.

As-coated vs Annealed.

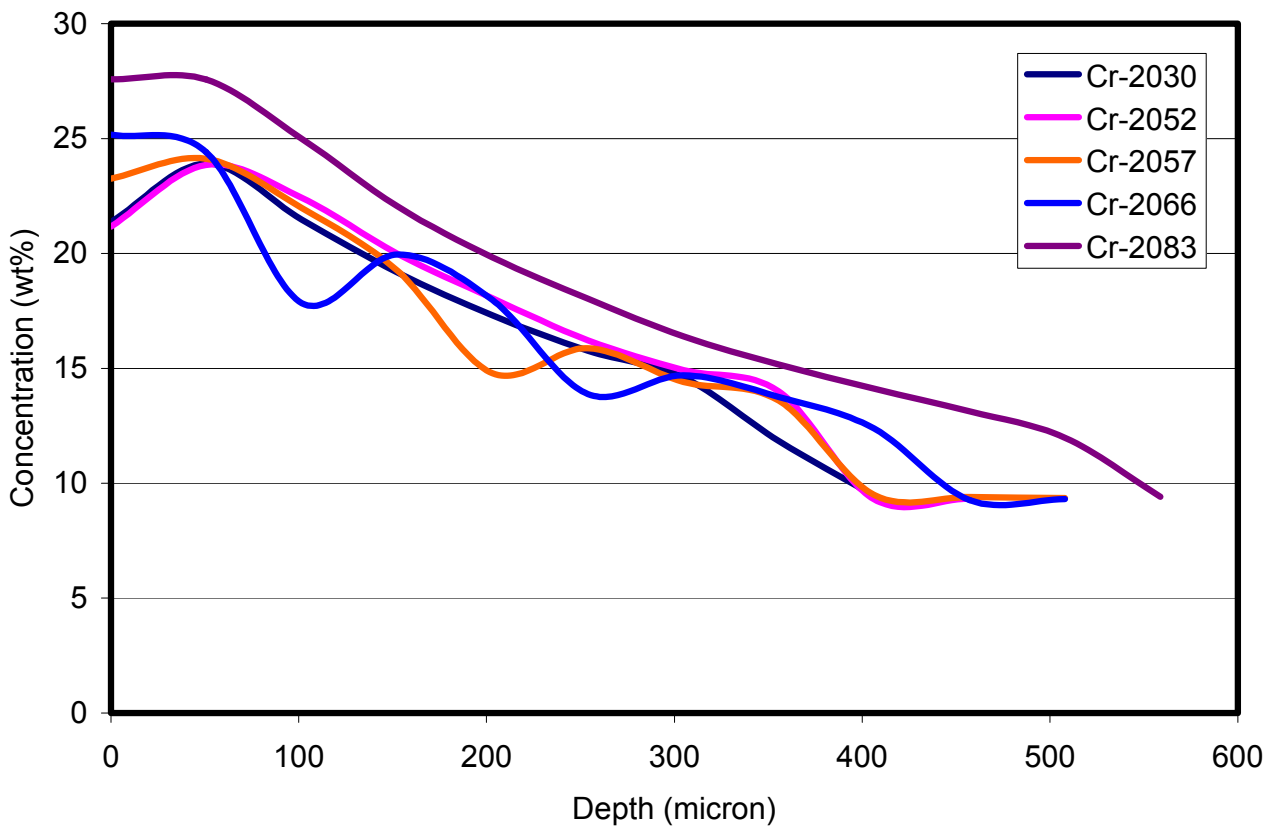

Figure 3. Average $\mathrm{Cr}$-concentration as a function of temperature for the ID chromized layer formed in T-92 material. 

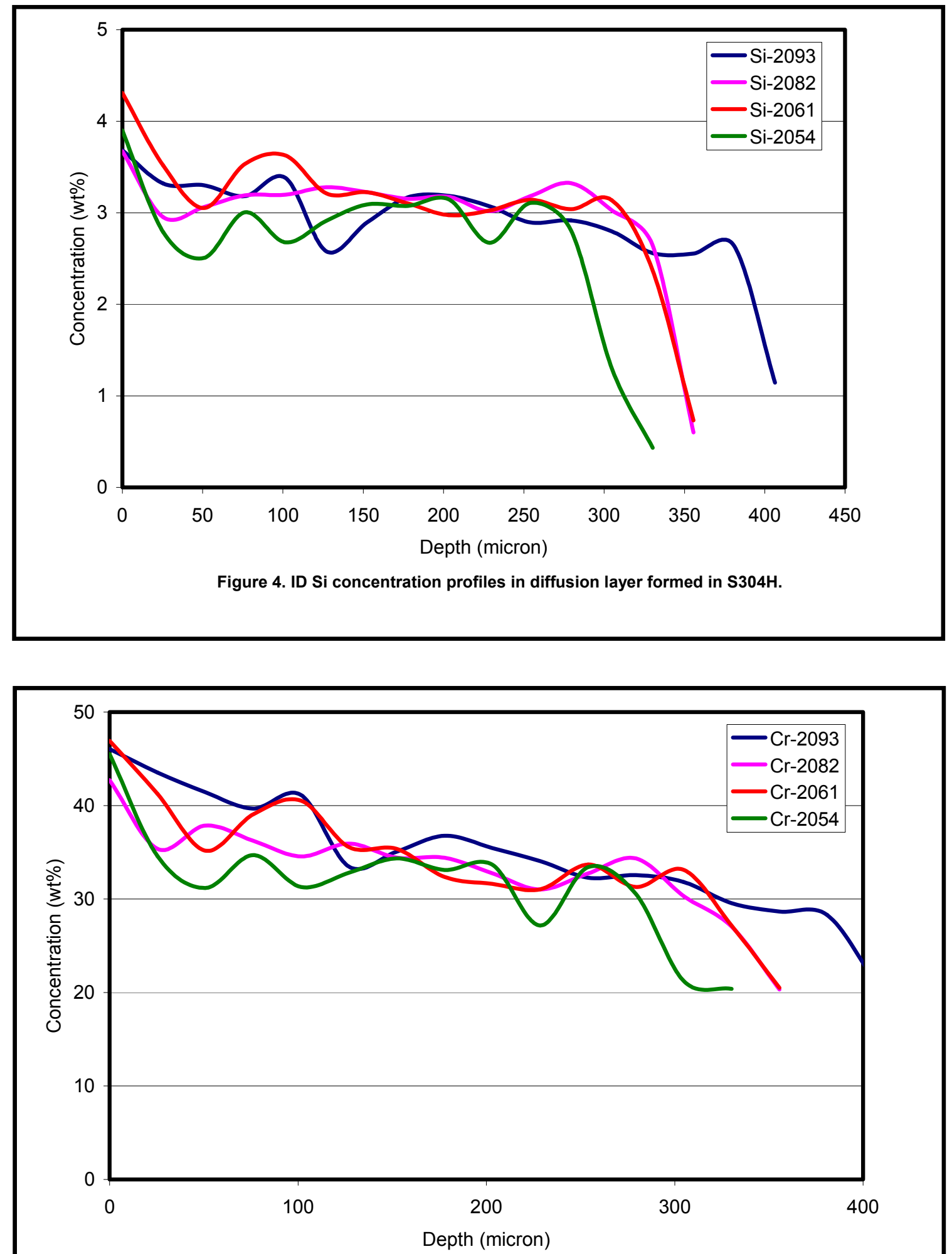

Figure 5. ID $\mathrm{Cr}$ concentration in diffusion layer formed in S304H. 

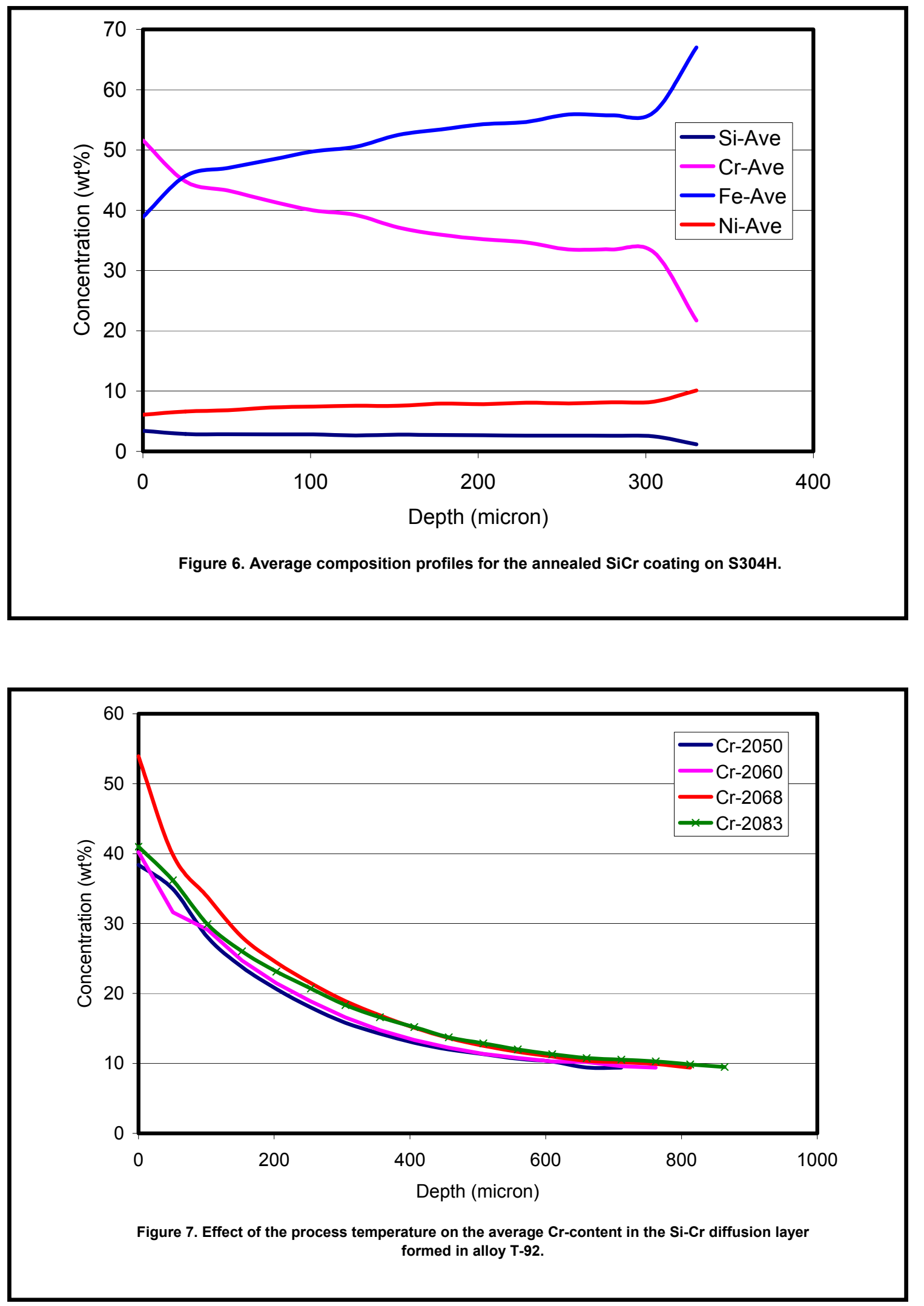


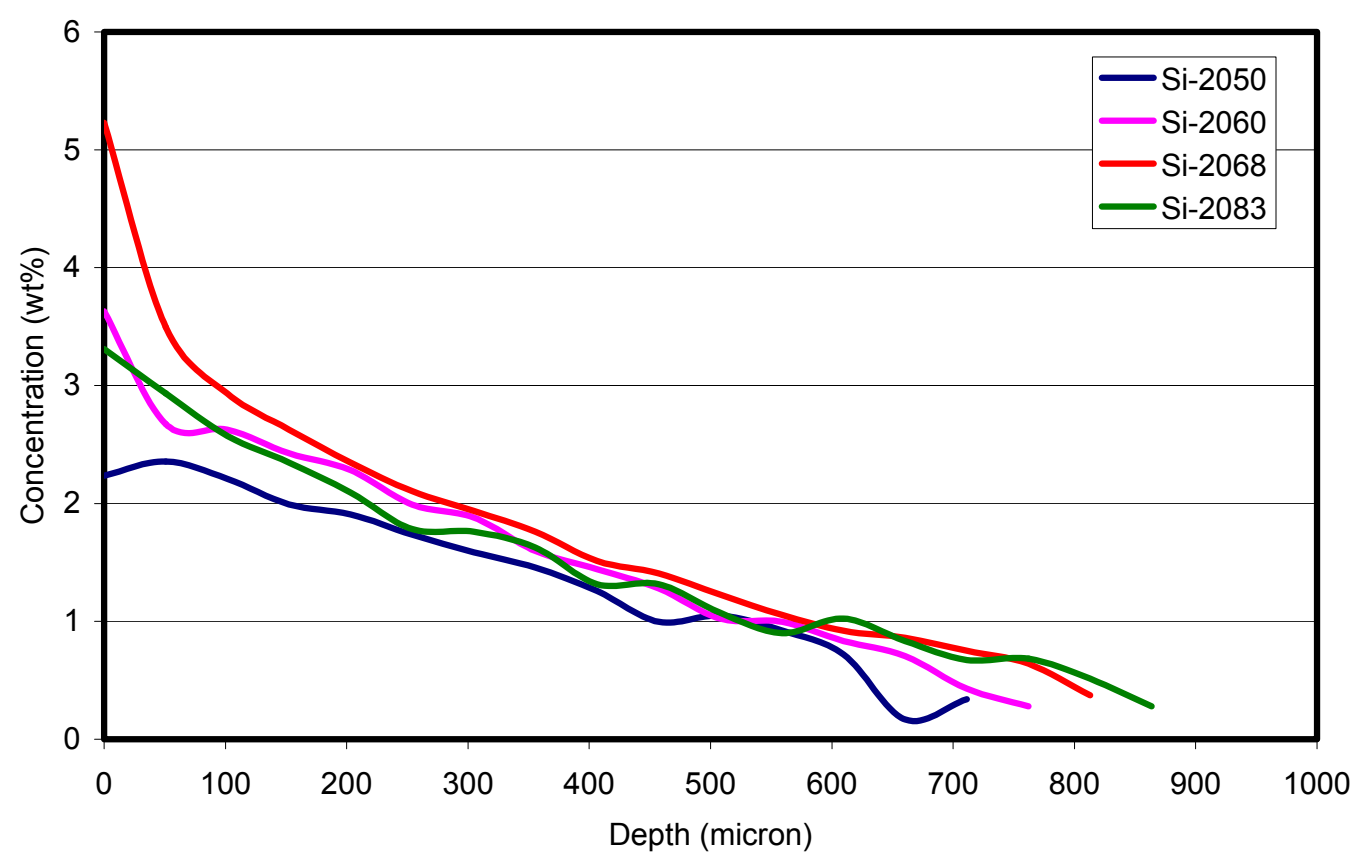

Figure 8. Effect of temperature on the average Si-content in the Si-Cr diffusion layer formed in alloy T-92.

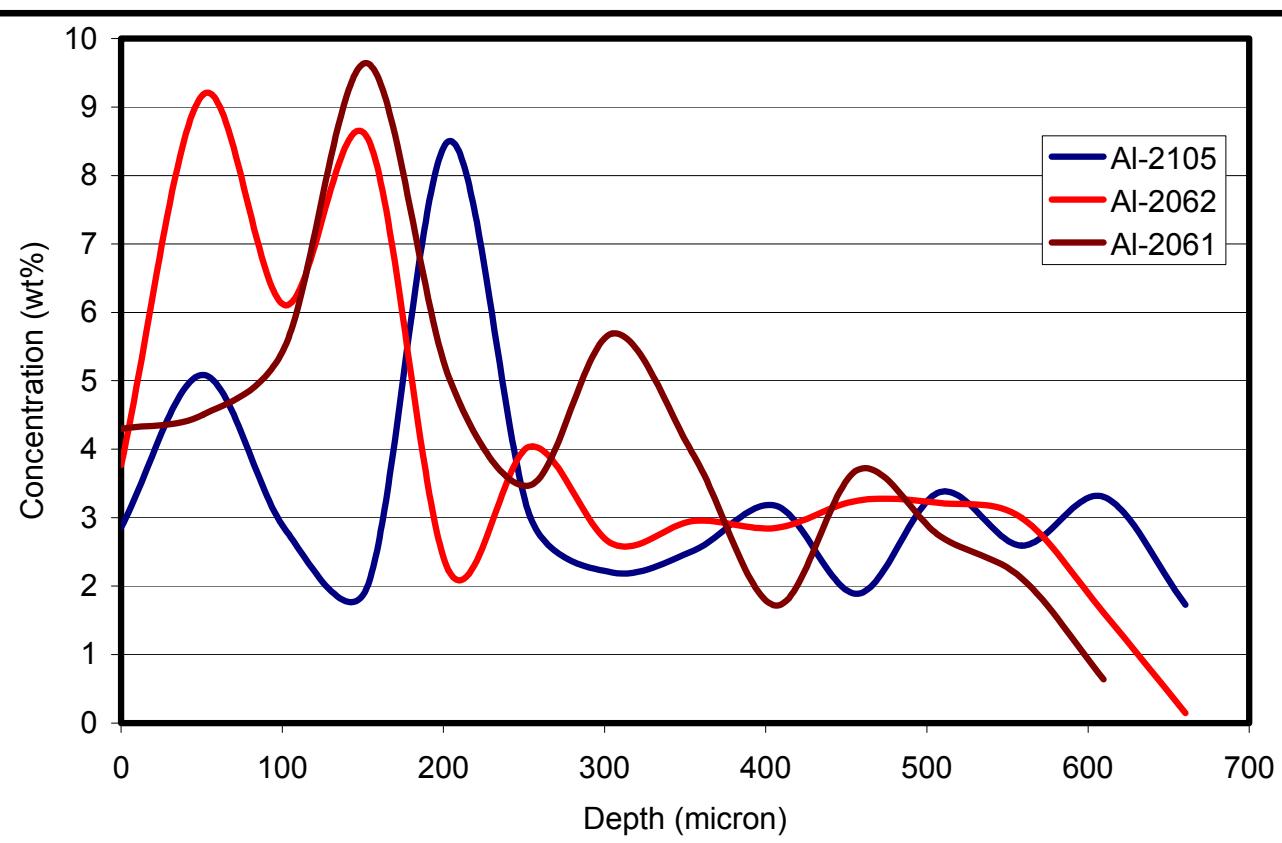

Figure 9. Average Al content in the diffusion layer formed on the ID of S304H tubing using the Al-Cr formulation. 


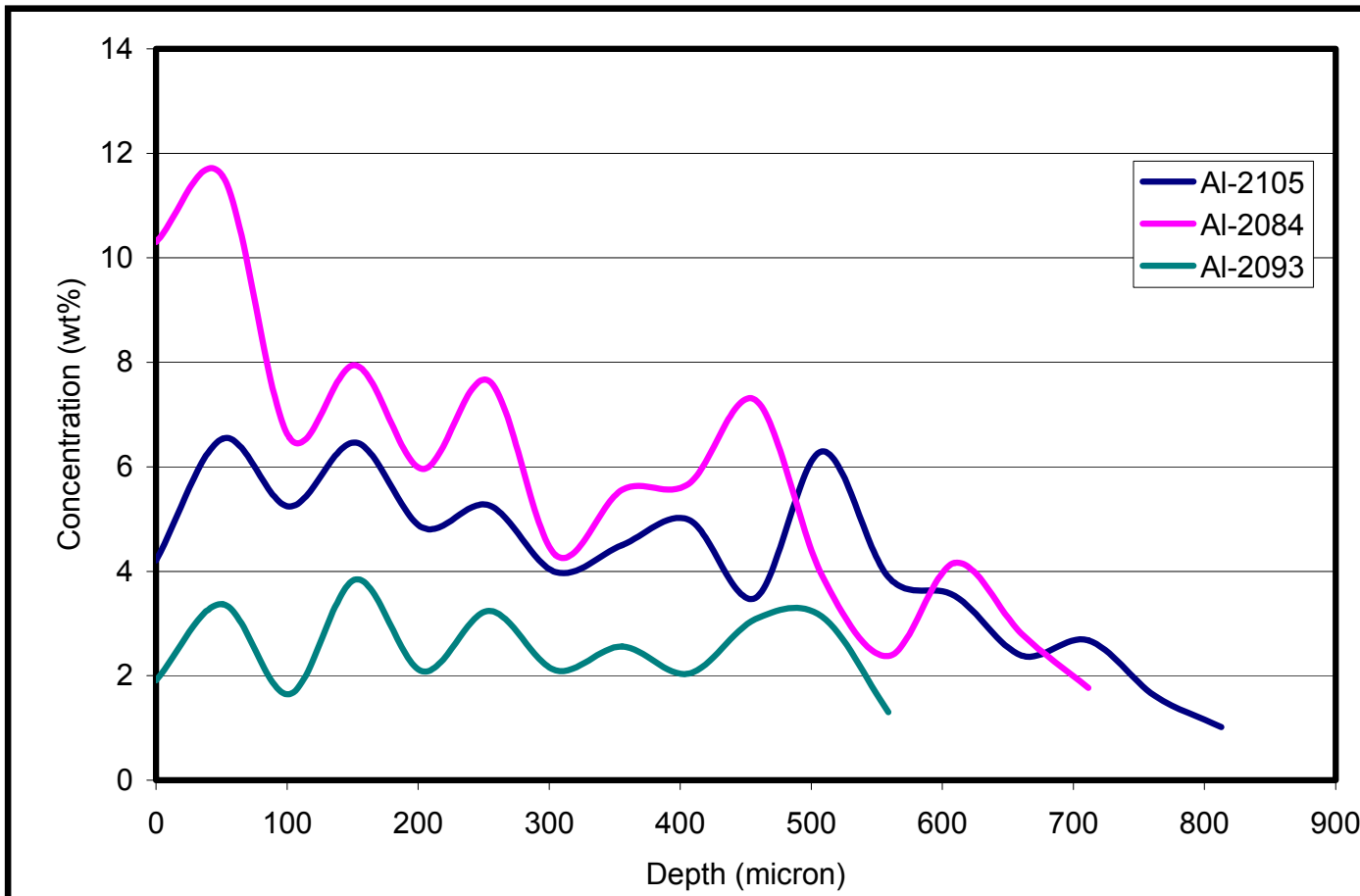

Figure 10. Average Al content of diffusion layers formed on the OD of alloy S304H using the Al-Cr formulation.

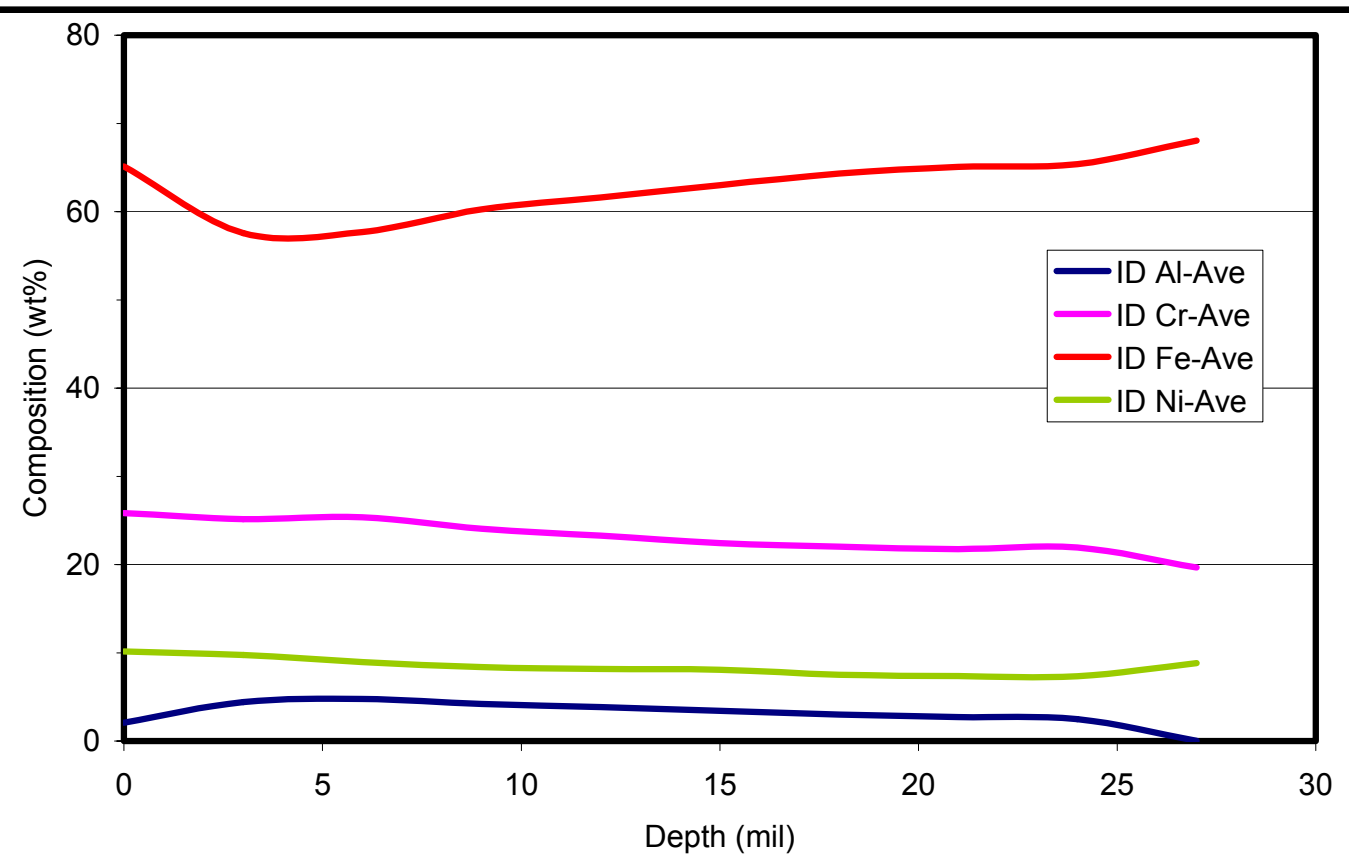

Figure 11. Average composition profile in the ID diffusion coating in alloy $\mathrm{S} 304 \mathrm{H}$ after solution annealing at $2000 \mathrm{~F}$ for $30 \mathrm{~min}$. 


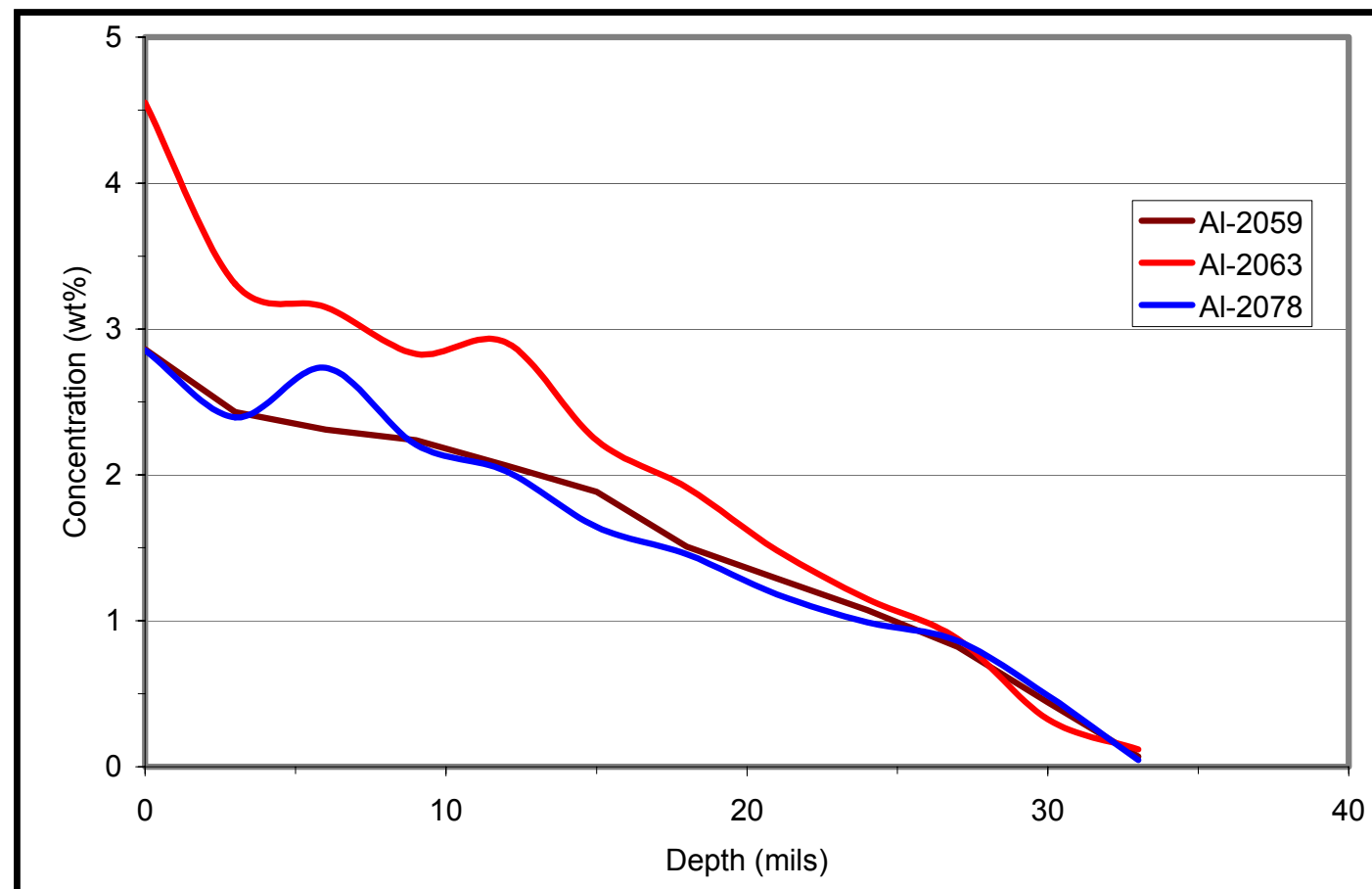

Figure 12. Al concentration profiles in the ID AI-Cr diffusion coatings on alloy T-92. 


\section{Task 8 \\ Design Methods and Data \\ (Alstom)}

Objectives for Task 8:

- Review the methods used by Section I of the ASME Boiler and Pressure Vessel Code to utilize materials properties and behavior models in the design of ultrasupercritical boilers.

- Develop and document methodologies whereby the results of the other tasks within this program may be most effectively applied within the ASME Section I design environment.

- Pursue the incorporation of such methodologies into Section I.

These objectives will be accomplished through execution of seven sub-tasks. Where activity on these sub-tasks occurred during the reporting period, it is described below.

\section{Task 8A: Task Management (ALSTOM)}

\section{Objective}

The primary objective of this subtask is the overall management of the task, coordinating meetings and preparing progress reports.

\section{Progress for the Quarter}

- Work continues to confirm commitments from each participant.

- The Gantt chart for Task 8, showing the overall plan and progress to date is included at the end of this report.

\section{Concerns}

Continued effort is ongoing to confirm commitments of each participant, update the project plan and develop curves to report scope completed as a function of spend.

\section{Plans for the Next Quarter}

Continue general task management activities. 


\section{Task 8B: Material Data Collation and Processing (FW)}

\section{Objective}

The creation of documentation to ensure that quality test data is transferred between tasks and that this data remains traceable. A second objective is the analysis of such data with the objective of improving the statistical correlation. Foster Wheeler is subtask leader, with Riley Power Inc. providing significant input to this subtask.

\section{Deliverables}

\begin{tabular}{|l|l|l|}
\hline \multicolumn{1}{|c|}{ Item } & Responsible & \multicolumn{1}{c|}{ Status } \\
\hline Material data transfer sheets & ALSTOM & $\begin{array}{l}\text { Transfer sheets provided for } \\
\text { creep and tensile tests. }\end{array}$ \\
\hline Electronic data repository & ORNL & Website complete. \\
\hline Recommendations for statistical analysis of data & & \\
\hline Data compendia and fits for key materials & & \\
\hline $\begin{array}{l}\text { Code case packages and submissions to code } \\
\text { committees }\end{array}$ & ALL & \\
\hline
\end{tabular}

\section{Progress for the Quarter}

Oak Ridge completed a first release of the website for material data. The on-line repository allows Task 8 members to obtain up to date information about specific tests. ALSTOM has downloaded data for CCA617 and plotted rupture life and creep rate against a large database for IN617. This demonstrates that at high stresses CCA617 has an apparent strength advantage over IN617 but as the stress level decreases the CCA617 data appear to merge with the IN617 data. Since only a few (4) rupture data points are available it is not possible to draw meaningful conclusions at this time.

Guidance was provided to Task 2 on testing to meet needs of Task 8. This included discussion of recommended test conditions for creep and fatigue tests of simple specimens, notched bars and structural feature tests, both with and without welds.

\section{Concerns}

None

\section{Plans for the Next Quarter}

Continue to view material data provided by ORNL and compare results with existing databases for comparable alloys. 


\section{Task 8E: Continuum Damage Mechanics (B\&W)}

\section{Objective}

The objective of this subtask is to analyze uniaxial and multiaxial creep test data from Task 2 for several (three) materials to:

- establish the continuum damage mechanics (CDM) parameters,

- evaluate multi-axial strength theories and failure criteria,

- assess the implications of cyclic creep for USC materials,

- evaluate and compare CDM, reference stress and Omega models of typical ASME geometries.

\section{Progress for the Quarter}

Full creep curves are now available through the ORNL material data web site, which will facilitate future activity. At present only a few tests are available so no meaningful analysis or interrogation of the data can be completed at this time. Progress on this task is likely to be hampered by funding issues at B\&W.

\section{Concerns}

Timely availability of creep data on ORNL web site and funding issues at B\&W.

\section{Plans for the Next Quarter}

Monitor material data web site to see if sufficient data is available to initiate a modeling activity.

\section{Task 8F: Weld Analysis and Assessment (ALSTOM) \\ Objective}

Create simplified analysis models of welds and heat affected zones (HAZ) utilizing material properties obtained from the open literature and from Task 2 to permit accurate creep life assessment of weldments. 


\section{Deliverables}

\begin{tabular}{|l|l|l|}
\hline \multicolumn{1}{|c|}{ Item } & Responsible & \multicolumn{1}{c|}{ Status } \\
\hline $\begin{array}{l}\text { Topical review of weld analysis and assessment } \\
\text { in creep range. }\end{array}$ & ALSTOM \& RPI & In progress. \\
\hline Collation of material data for weld metal and HAZ. & RPI & In progress. \\
\hline Creep models for weld metal and HAZ regions. & ALSTOM & In progress. \\
\hline $\begin{array}{l}\text { Report documenting the simulation of welded } \\
\text { specimens and common Code geometries. }\end{array}$ & ALSTOM & \\
\hline $\begin{array}{l}\text { Report documenting the development and use of } \\
\text { approximate weld assessment methods. }\end{array}$ & ALL & \\
\hline
\end{tabular}

\section{Progress for the Quarter}

ALSTOM and Riley continued work on the literature review. RPI developed a draft to summarize the material data and testing of welded components. Progress by ALSTOM was slower than planned due to resource issues.

\section{Concerns}

Resource problems continue hampered progress on this activity.

\section{Plans for the Next Quarter}

Continue work on literature review and develop an interim status report in support of the milestone associated with this task.

\section{Task 8G: Basic Design Rules for Cylinders (ALSTOM)}

\section{Objective}

Review the various equations used by the ASME Code, Section I for Power Boilers to define the minimum thickness of cylinders under internal pressure and develop a single methodology applicable to ultrasupercritical boilers.

\section{Deliverables}

\begin{tabular}{|l|l|l|}
\hline \multicolumn{1}{|c|}{ Item } & Responsible & \multicolumn{1}{c|}{ Status } \\
\hline $\begin{array}{l}\text { Report summarizing existing approaches and } \\
\text { comparing and contrasting their predictions }\end{array}$ & ALSTOM & Complete (Aug 2003) \\
\hline $\begin{array}{l}\text { Report recommending a single equation with } \\
\text { supporting theoretical data. }\end{array}$ & ALSTOM & Complete (Sept 2003) \\
\hline Code case submission & ALSTOM & Complete (October 2003) \\
\hline
\end{tabular}




\section{Progress for the Quarter}

Presentations made to ASME Section I and B31.1. Provided a statement of the benefits (likely material saving) associated with use of proposed formula. Specifically the new formula offers a $12.5 \%$ material savings on a standard supercritical boiler. The savings are fairly evenly distributed across all grades of material. This is a not inconsiderable amount - on a $600 \mathrm{MW} 1050^{\circ} \mathrm{F}$ boiler it would amount to over $\$ 600,000$ and, of course, with the material costs for advanced alloys used in the DOE USC boiler, the total savings would be much greater

\section{Concerns}

None

\section{Plans for the Next Quarter}

Continue to present proposed formula and address questions. A proposed rewrite of code language will be presented to both committees in September. 
Appendix A: Project Plan with Progress Identified

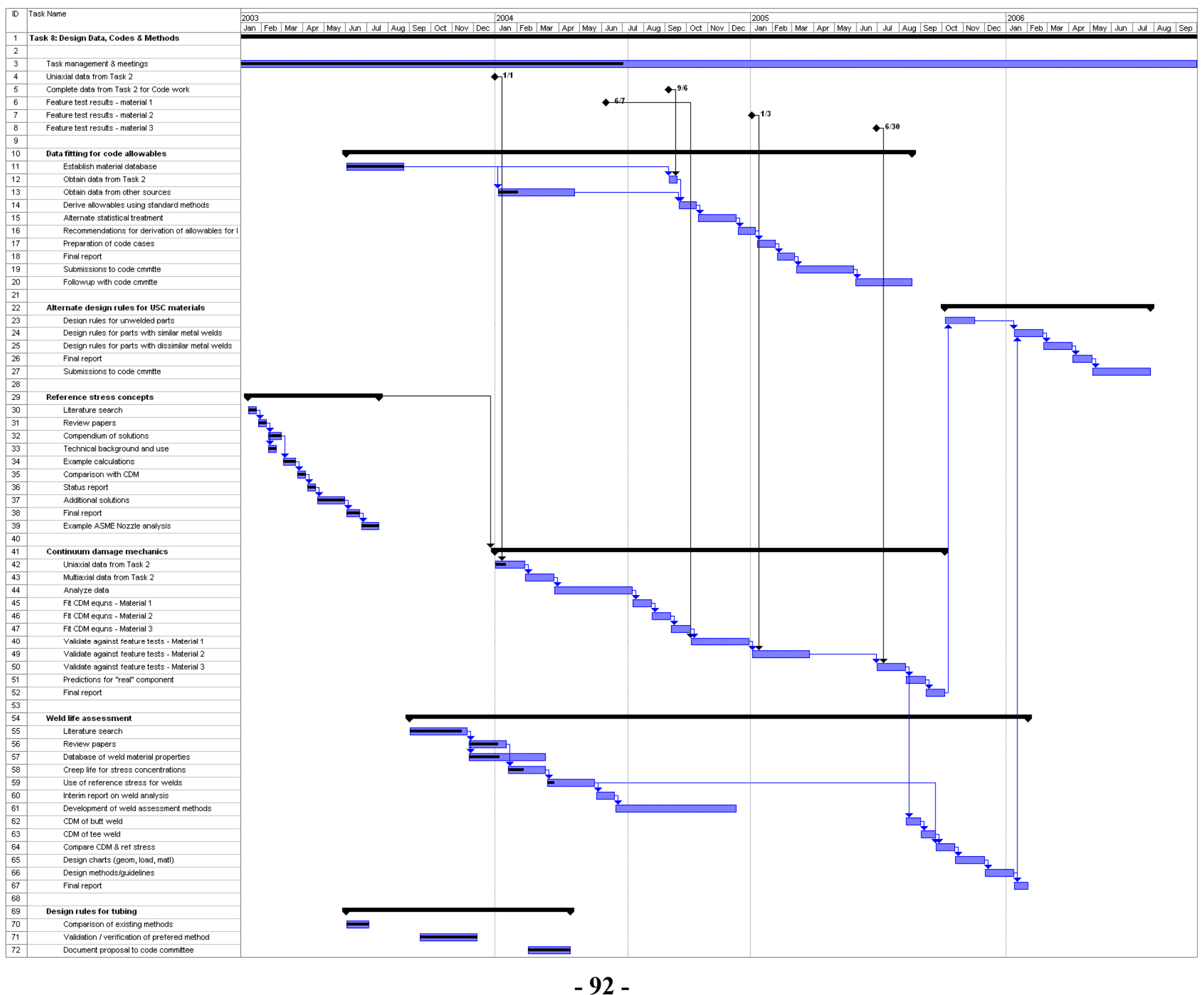




\section{Task 9 \\ Project Integration and Management (EPRI)}

The objective of Task 9 is to coordinate the project and provide reporting to DOE and Ohio Coal Development Office (OCDO).

\section{Progress for the Task}

- Completed Second Quarterly Report for 2004.

- Completed Monthly Reports for April and May, 2004.

- Monthly conference calls were held and the discussions were documented.

- Work is ongoing on the EPRI Fourth International Conference on Advances in Materials Technology for Fossil Power Plants. This conference is being cosponsored by DOE/OCDO and will include presentations on many of the developments from this project. The conference will be held at the Hilton Oceanfront Resort in Hilton Head Island, South Carolina on October 26-28, 2004.

- Papers have been accepted and a Conference Announcement should be ready soon.

- Presented a review of the project at the Air and Waste Management conference in Indianapolis on June $25^{\text {th }}$.

- Several papers were presented supporting the project at the Pittsburgh Coal Conference.

\section{Concerns}

None

\section{Plans for the Next Quarter}

- Issue Conference Announcement for Hilton Head Conference.

- Present an overview of the project at the Pittsburgh Coal Conference in Osaka Japan.

- Conduct a Steering Committee Meeting on August 4-5 in Columbus, Ohio.

- Issue monthly reports and hold conference calls as required. 